\title{
Changing Minds: \\ The Work of Mediators and Empirical Studies of Persuasion
}

\author{
James H. Stark \& Douglas N. Frenkel*
}

\section{INTRODUCTION}

Take this case: Diana Halverson, age fifty-nine, worked for eleven years as an office manager in the Hartford, Connecticut office of TSG Corporation, an East Coast manufacturer of seamless gutters. Sixteen months ago, she was denied a promotion for which she applied-a mid-level managerial position at the company's corporate headquarters in Philadelphia. The job went to a more recently hired male employee in his late thirties, on the ground that his "potential was greater." Ms. Halverson, feeling that she had an excellent work record, was hurt and offended. Needing her job, however, she bit her tongue. But when soon thereafter that job was eliminated in an administrative reorganization, she consulted a lawyer and, with his assistance, filed a charge of age and gender discrimination with the state human rights commission. The company responded to these allegations with a blanket denial of all charges, claiming that its decisions were lawful and justified by legitimate business considerations. When contacted by the agency several months later to see whether this matter might be mediated, both parties accepted the invitation.

You are a private mediator who handles approximately eight to ten employment discrimination cases per year on assignment by the human rights commission. You have been assigned to mediate this matter.

The pleadings, exchanged documents, and early summaries by counsel at the outset of the mediation revealed the following: (1) the claimant's

* James H. Stark is a Professor of Law and Director of the Mediation Clinic at the University of Connecticut School of Law. Douglas N. Frenkel is the Morris Shuster Practice Professor of Law at the University of Pennsylvania School of Law and heads its Mediation Clinic. We are grateful for helpful feedback we received on drafts of this paper in its various stages of development from participants at the 12th Annual ABA Dispute Resolution Conference, the Washington University School of Law ADR and Clinical Theory Workshop, the Quinnipiac-Yale Law School Dispute Resolution Workshop, the Mid-Atlantic Clinical Teachers' Workshop, the University of Connecticut Law School Faculty Workshop, and the New York Law School Clinical Theory Workshop. In addition, we want to express our thanks to Ian Ayres, Jon Bauer, Jennifer Brown, Peter Carnevale, Robert Condlin, Neil Feigenson, Rebecca Hollander-Blumoff, Jonathan Hyman, Daniel O'Keefe, Jennifer Robbennolt, and Karen Tokarz for their helpful insights and comments along the way. 
previous work evaluations were all positive to very positive, but the evaluations of the male employee who got the promotion were quite positive as well; (2) the two supervisors most directly responsible for the decisions adversely affecting the claimant had been overheard on a number of occasions in the past three years making overtly sexist remarks, though in informal rather than formal work settings and not directed at the claimant; and (3) cursory analysis of several documents pertaining to the administrative reorganization is somewhat suggestive of age and gender discrimination, though the reorganization itself seems legitimate, given tough economic conditions resulting from a plummeting housing market. Ms. Halverson's case, in other words, appears plausible on its face, but it is anything but a slam dunk.

During a pre-mediation phone call with claimant's counsel, you learned that in the twelve months since she was laid off, she was able to secure various odd jobs but has been unable to find comparable full-time employment. The strong sense you got between the lines from claimant's counsel is that Ms. Halverson has financial problems and (assuming that the company cannot or would not re-hire her) would like to resolve the dispute now if some quick money could be obtained. In a separate conversation with the other side, defense counsel revealed that the company is self-insured for this claim and took the same hard line position reflected by the pleadings, denying any liability and calling the complaint a "bunch of junk."

At the mediation, the following people are present: the claimant; her lawyer; Jason Hernandez, the claimant's former immediate supervisor; Sharon Stern, TSG's human resources director; and outside counsel for the company. On being invited by you to state her side of the case, the claimant's lawyer lays out a twenty-minute summary of the facts and the law that supports her liability and damages claims, demanding " $\$ 150,000$ to resolve this." When you ask the claimant if she has anything to add, she provides an emotional account of her employment history, weeping openly while recounting the early days of the job and how gratifying it had been. She also describes how degrading it was to be laid off after so many years of loyal service with nothing more than an impersonal email that explained the financial conditions prompting the reorganization and gave her just one week's notice.

At this point, the company's attorney apologetically interrupts, telling you that: "We, of course, could offer a different view of all of this. We could focus, for example, on the display Ms. Halverson put on at the office when she was passed over for the promotion she says was 'rightfully hers.' In front of several work colleagues, she made nasty and unprofessional personal comments about her supervisors. But perhaps we can make some progress if 
we try to deal with the legal and monetary issues instead of rehashing contested allegations." At this point, the lawyer reiterates at length the company's denial of any unlawful intention or action and summarizes the justifications for its decisions. At the end of her presentation, defense counsel makes a $\$ 15,000$ ("nuisance value") settlement offer. Claimant's counsel immediately rejects this offer as "insulting." You ask the human resources director and the claimant's supervisor if either has anything to add. Both shake their head no.

Now, almost an hour into the mediation, the claimant is fuming and the emotional climate in the room has deteriorated badly. You decide to hold a round of caucuses and to meet first with the company's representatives and their lawyer.

In thinking about how you might try to persuade the defendants to become more flexible in their view of the situation or negotiating position, you have identified the following possibilities:

(A) ask the company's representatives or counsel to try to articulate how the situation looks from the claimant's point of view;

(B) ask the claimant's supervisor in confidence whether there is anything about his or the company's conduct or the situation that he regrets, and if the answer is yes, encourage him to express that to the claimant when the process continues;

(C) instead of telling them your views, ask the defense representatives questions that suggest your views of the company's potential liability in the dispute in order to get them to assess the costs and benefits of not reaching a mediated settlement; or

(D) ask the supervisor, human resources director, or both how it would feel if a large trial verdict for Ms. Halverson were to necessitate laying off other employees.

These persuasion choices (and many others) present themselves to mediators every day in virtually every dispute. Which of these options strike you as likely to be effective? None? All? If all, and time is limited, in what order would you attempt these interventions? Why?

As Alan Tidwell has pointed out, merely by entering a conflict, neutrals inevitably bring some degree of influence to bear on it. ${ }^{1}$ Their presence in the mediation room, the questions they ask or don't ask, the statements they make, the agenda they help to create-all of these can and do affect how the parties communicate and the results they achieve. But while mediator influence may be unavoidable, it is the deliberate exercise of influence that is

1 Alan Tidwell, Not Effective Communication but Effective Persuasion, 12 MEDIATION. Q. 1, 6 (1994). 
the hallmark of persuasion, ${ }^{2}$ and it is on persuasion that we focus here.

In this article, we use the terms "persuade" and "persuasion" 3 to encompass a range of potential mediator interventions: from indirectly opening disputants to perspectives other than their own, to actively urging acceptance of specific proposals that might achieve their objective of ending a conflict. Although "persuasion"-as a word and an objective-is uncontroversial in the disciplines whose research forms the basis for this article, we recognize that the same cannot be said for the world of mediation, segmented as it is by practice area and philosophy. To be clear, we will not be discussing - and do not view as appropriate - coercive or manipulative persuasion practices by which a mediator tries to pressure reluctant parties to reach particular solutions, merely because he or she wants to "get a settlement."

Some mediators call themselves communication facilitators and take the position that mediators do not engage in persuasion at all. ${ }^{4}$ But in our experience, this claim ignores the reality of most mediation practice. First, persuasion is an everyday part of human discourse, used not only by timeshare and used car salesmen, but also by parents, teachers, mental health therapists and many others we consider in the "helping" professions. ${ }^{5}$ Second, persuasion in mediation is a two-way street. Long before a mediator might try to influence the parties to moderate their demands or consider the other side's point of view, chances are good that the parties will have tried to convince the mediator that they are "right" and the other side is "wrong." In the vast majority of disputes in which the assistance of a mediator is needed or requested, far more than mere "facilitation" is necessary to help the parties resolve deeply held or competitively bargained differences. Mediators in different practice settings and with differing ideological perspectives may well disagree about specific goals and methods of persuasion, but most mediators engage pervasively in persuasion activities.

If you question this statement, consider first some possible persuasion goals in mediation. A recent survey of thirty highly experienced mediators asked them to identify the "essential strengths and techniques" that most

${ }^{2}$ Id. at 6.

${ }^{3}$ According to one dictionary, "persuade" means: (1) "to prevail on (a person) to do something, as by advising or urging, etc.; (2) to induce to believe; convince." THE RANDOM House Dictionary OF THE ENGLish LANGUAGE 1076 (1979). Note that these definitions are consistent with both active forms of persuasion ("urging," "convincing") and more passive, indirect forms ("inducing"). In this article, we consider both.

${ }^{4}$ See generally Tidwell, supra note 1.

5 Douglas N. Frenkel \& James H. Stark, The Practice of Mediation: A VIDEO-INTEGRATED TEXT 228 (2d ed. 2012) [hereinafter, FRENKEL \& STARK]. 
contributed to their ability to settle disputes. More than seventy-five percent rated their ability to develop rapport with the parties- a relationship of understanding, empathy and trust-as the most important ingredient of their success. ${ }^{6}$ In our experience, most effective mediators engage in various forms of "rapport-building" persuasion, for example, by describing their credentials or previous successes as a mediator as a way of gaining the parties' confidence, or by listening "actively" to demonstrate understanding of the participants' feelings and concerns, thereby establishing a relationship of trust. Active listening by mediators is inherently desirable because it helps mediation participants feel heard. But it can also be used (and often is used) for instrumental purposes by mediators to inculcate trust and rapport so that their later, more overt persuasion efforts will be more effective.

Virtually all mediators, we would submit, also routinely engage in conduct we would term "process" persuasion. For example, they may try to convince reluctant participants to give mediation a good faith try; to agree to a set of ground rules that will assist in the process; to avoid retreating into private caucuses prematurely (in order to encourage direct party communications and hopefully foster empathy); or to share information, including damaging information and information about their actual bargaining authority, so that their true needs and priorities and a bargaining zone (if one exists) can be identified.

Next, mediation is often claimed to "add value" to unassisted negotiations by helping parties overcome cognitive, psychological, and strategic barriers to resolution that they cannot readily overcome themselves. ${ }^{7}$ We believe that most mediators-at least those who want to be effective-work hard at what might be called "attitudinal" persuasion, as for example when they try to persuade disputants to maintain their optimism in the face of apparent impasse, to avoid making extreme demands that might create an impasse, not to demonize the other side, presume it is acting out of bad motives, or react in a fit of pique to the other side's proposals and reject them out of hand. ${ }^{8}$

${ }^{6}$ Stephen B. Goldberg, The Secrets of Successful Mediators, 21 NEGOTIATIONs J. 365,366 (2005).

7 See generally Robert Baruch Bush, "What Do We Need a Mediator For?": Mediation's "Value-Added" for Negotiators, 12 OHIO ST. J. ON DISP. RESOL. 1 (1996).

8 Transformative mediators engage in attitudinal persuasion too. In what might be called "recognition" persuasion, they may try to persuade aggressive or self-confident parties to acknowledge their opponent's legitimate perspectives and constraints. The principles of transformative mediation are set out in ROBERT BARUCH BUSH \& JOSEPH P. Folger, The Promise of Mediation: Responding to Conflict Through EMPOWERMENT AND RECOGNITION (1st ed. 1994). 
Finally, although their approaches may differ, most mediators-both facilitative and evaluative-also engage in at least some form of "substantive" or "outcome-oriented" persuasion-for example by helping them to come to terms with the fact that their initial goals for the mediation may not be achievable; to consider the reality of how current proposals for resolution compare with their non-settlement options; or by asking questions, or making statements, designed to encourage them to think about the weaknesses of their case, or other ways that a disinterested person might look at contested events.

The methods mediators use to achieve these and other objectives are almost limitless in their variety. Mediators persuade by asking questions and by making statements. They persuade by trying to thaw damaged relationships and cool down heated emotions. They persuade by trying to engage the disputants in cooperative brainstorming activities. They persuade by "conditioning" the parties through flattery and humor or by using "just between us" type statements in private caucus. ${ }^{9}$

Mediators persuade by urging disputants to establish priorities or by obtaining commitments to a set of norms and standards that may guide the negotiations. ${ }^{10}$ They persuade by re-framing losses as gains. ${ }^{11}$ They may try to influence disputants' attitudes by presenting difficult messages in a way designed to make them "go down more easily." Sometimes, mediators persuade by instilling optimism and hope; at other times, by sowing doubt or anxiety. Mediators can regulate the degree of pressure that disputants experience by giving them frequent breaks to think things over, or alternatively, by establishing and sticking to short deadlines. Some of these modes of persuasion are benign and universally accepted; others might well be considered inappropriately manipulative or coercive. Because mediation is practiced in widely varying settings, what might be considered appropriate mediator persuasion in one context might be considered inappropriate in another. Our only point is that persuasion is endemic to mediation and the list of persuasion tools available to mediators - from which they may pick and choose - is very long.

The study of persuasion traces its roots back to Aristotle. ${ }^{12}$ In the past

${ }^{9}$ FRENKEL \& STARK, supra note 5, at 234-35.

10 Tidwell, supra note 1 , at 11 (describing how mediators persuade by helping the disputants make small, incremental commitments, first to the process, then to an agenda, then substantively, towards an agreement).

11 See, e.g., Daniel O'Keefe \& Jakob Jensen, The Relative Persuasiveness of Gain-Framed Loss-Framed Messages for Encouraging Disease Prevention Behaviors: $A$ Meta-Analytic Review, 12 J. HEALTH COMM. 623 (2007).

12 See ARISTOTLE, THE RHETORIC OF ARISTOTLE. 
fifty years or so, social psychologists and communication theorists have made substantial inroads in demonstrating empirically what kinds of persuasive interventions work, in contexts ranging from advertising to jury advocacy to politics. Today, well conducted meta-analyses ${ }^{13}$ of many individual empirical studies help social scientists generalize about empirical findings with greater statistical confidence. Given the prevalence of persuasion (as we have defined it) in all forms of mediation, it is surprising that more attention has not been paid by mediators to the many ways this body of empirical work might inform their practice. What might account for this?

One explanation may stem from the fact that, for some in the field, the word "persuasion" has a pejorative connotation (with images of slick or heavy-handed neutrals seeking to get a deal at almost any cost) that the more friendly "problem solving" does not. Writing more than fifteen years ago, Deborah Kolb and Kenneth Kressel observed that because mediators are frequently uncomfortable about the persuasive, potentially coercive, powers they exert, they are prone to engage in a "kind of denial about what they do. [This] denial stands in the way of learning and keeps the field from better understanding the uses and limits of pressure."14 We strongly concur with this view.

We suspect that most mediators who are comfortable acting in a persuasive mode have standard or default approaches for doing so. These may be based on some combination of (a) intuitions about what is effective, (b) normative views about what is "good" or "ethical" mediation, (c) personal style and comfort, and (d) a sense of mastery or lack of mastery of specific persuasive techniques. But if persuasion is an inevitable part of mediation, it behooves professionals in the field to acquaint themselves with what social science can teach about more and less effective persuasive practices, and the psychological and contextual factors that may make them so. If there are any potential tensions between "ethical" mediation and effective persuasion, mediators ought at least to be aware of these tensions, so that they can make better informed choices about how they wish to practice. Indeed, if research reveals new understandings about how

${ }^{13}$ For an analysis of meta-analytic methods, limitations and best practices from a leading persuasion researcher, see Daniel J. O'Keefe, Extracting Dependable Generalizations From the Persuasion Effects Literature: Some Issues in Meta-Analytic Reviews, 58 COMM. MONOGRAPHS 472 (1991).

14 Deborah M. Kolb \& Kenneth Kressel, The Realities of Making Talk Work, in WHEN TALK WORKS 459, 483 (1994). 
persuasion works, this might even affect what we view as "ethical."15

The social science literature on persuasion is vast and complex, and we make no attempt to canvass it all here. Many important topics are omitted. For example, we do not address the myriad of factors that may affect the credibility of the messenger or his or her message, as important as these source factors have been demonstrated to be. These include the likability, personal attractiveness, and authoritativeness of the person engaging in persuasion, as well as the success of his or her attempts to establish a sense of similarity, or personal connection, with the persuasion subject. ${ }^{16}$ Nor, with one important exception, ${ }^{17}$ do we focus on subject or receiver factors that may affect how persuasive messages are likely to be processed or how easily a person may be persuaded. For example, we largely exclude from our discussion the effect on persuasion of variables such as differences in a receiver's education and intelligence, ${ }^{18}$ self-esteem, ${ }^{19}$ egoism versus

15 The closest thing to a "universal" set of ethical standards for mediators are the Model Standards of Conduct for Mediators, first promulgated in 1994 and revised in 2004. A joint effort of the American Bar Association's Section on Dispute Resolution, the American Arbitration Association, and the Association for Conflict Resolution, the Model Standards are written at a high level of generality, speaking in conclusory terms (for which they have been criticized) about the importance of such values as party self-determination, mediator impartiality and confidentiality of the process. See, e.g., Michael L. Moffitt, The Wrong Model, Again: Why the Devil is Not in the Details of the New Model of Standards of Conduct for Mediators, 12 DISP. RESOL. MAG. 31 (Spring 2006). While the Model Standards make explicit that certain mediator goals are inappropriate-overriding party self-determination in pursuit of higher settlement rates, for example, see Model Standards of Conduct for Mediators, Standard IB-they are wholly silent on the ethical appropriateness or inappropriateness of specific mediator techniques and interventions.

16 On source factors affecting persuasion, see generally DANIEL O'KEEFE, Persuasion: Theory \& Research 181-213 (2d ed. 2002); Robert B. Cialdini, INFLUENCE: THE PSYCHOLOGY OF PERSUASION 167-229 (1993).

17 Because ego-investment and its corollary, position entrenchment, are such common barriers to resolution in negotiation and mediation, we do consider these in various sections of this article.

18 There is some research evidence that persons of lower intelligence are generally easier to persuade than persons of higher intelligence. See, e.g., HERBERT SiMONS, PERSUASION IN SOCIETY 37-38 (2001) (citing Nancy Rhodes \& Wendy Wood, Self-Esteem and Intelligence Affect Influenceability: The Mediating Role of Message Reception, 111 PSYCHOL. BULL. 156 (1992)). On the other hand, it has been difficult to test the impact of differing education levels on persuadability, because so many of the research studies use college and university graduates and undergraduates as their subjects. See Mike Allen, Comparing the Persuasive Effectiveness One- and Two-Sided Messages, in, Persuasion: AdVANCEs Through Meta-Analysis 93-94 (Mike Allen \& Raymond W. Preiss eds., 1998). In any event, mediators do not often get to pick and 
concern for others, ${ }^{20}$ and resistance to yielding, ${ }^{21}$ all of which have been subject to experimental study.

The principal emphasis of this article is on selected message and behavioral variables over which mediators may have most control. By "message" variables, we refer to variations in how the mediator's communications are conveyed-and the impact these variables may have on persuasion effectiveness. By "behavioral" variables, we are referring to the influence that a disputant's own behaviors-actions that are requested or induced by the mediator-may have on that disputant's attitudes, beliefs, or conduct. Put differently, the distinction we are drawing is between direct attempts at persuasion by the mediator, through various types of persuasive messages, as opposed to indirect attempts at persuasion by the mediator, by inducing the disputants to engage in conduct that may lead to self-persuasion. ${ }^{22}$

Four disclaimers are in order. First, we are lawyers, not social scientists. While we have made every effort to master this literature and have consulted with experts to answer some of our questions, all errors of omission, interpretation, and presentation are ours. ${ }^{23}$

Second, the studies we canvas are of persuasive interventions in fields as

choose the personal characteristics of the disputants whose cases they mediate. By contrast, they do get to choose the modes of persuasion they wish to use, and the order in which they will attempt them.

${ }^{19}$ See generally Rhodes \& Wood, supra note 18 . See also O'KEEFE, supra note 16 , at $243-44$.

${ }^{20}$ Carsten De Dreu, Laurie Weingart \& Seungwoo Kwon, Influence of Social Motives on Integrative Negotiation: A Meta-Analytic Review and Test of Two Theories, 78 J. PERSONALITY \& SOC. PSYCHOL. 889-905 (2000).

21 Id.

22 See, e.g., Elliot Aronson, The Power of Self-Persuasion, 54 AM. PsYCHOLOGIST 875-84 (1999).

23 In conducting the research for this article, we conducted word and author searches relevant to each topic, utilizing a wide variety of general and social science electronic databases, including: PsycINFO; Psychnet, EBSCO Communication and EBSCO Mass Media Complete; Psychology: A SAGE Full Text Collection; Google Scholar; and Dissertations and Theses Full Text. Often, social science experiments located in this fashion led to other studies and sources on that topic. While we cannot vouch for having read every relevant study, we followed the research where it led us - sometimes, as will be seen, in unanticipated directions. The individual studies and meta-analyses we canvassed are predominantly, although not exclusively, from Western and English language sources. While we acknowledge the importance of knowing how persuasion efficacy might vary across differing cultures and languages, a comprehensive comparative study was beyond the scope of this project. 
diverse as advertising, disease prevention, race relations, and politics; virtually none are of persuasion in mediation. Making reliable generalizations from any body of empirical work, no matter how broad or sound, is a dicey proposition. ${ }^{24}$ While we are obviously interested in speculating how the studies we canvas may apply to the world of mediation, we also want to avoid overly broad claims and generalizations.

Third, in making statements throughout this paper such as "[x-type] interventions have been shown to be more effective in persuasion than [y-type] interventions," we obviously do not mean to suggest that any particular persuasive intervention will or will not work in a specific situation. Social scientists deal in generalities, not particularities. Moreover, theorists agree that persuasion is usually an incremental process, in which people's minds are changed gradually, by means of multiple interventions over time. ${ }^{25}$

Fourth, as important as the topic is, detailed exploration of the ethical limitations of appropriate mediator persuasion is beyond the scope of this article. For our part and for what it's worth, we are comfortable with persuasive interventions that are primarily disputant-centered rather than mediator-driven: i.e., designed to help the parties- often under significant time constraints - to evaluate their needs, goals, and options more objectively and achieve quality resolutions to their problems that might otherwise elude them, rather than serving mediator goals such as "settlement for settlement's sake." 26 As for choosing proper means to achieve disputant-centered goals,

24 The basic problem is one of external validity, which concerns the extent to which social science research findings can be generalized beyond the particular study at hand to different people, different settings, and different times. See generally ROBERT LAWLESS, JENNIFER ROBBENNOLT \& THOMAS ULEN, EMPIRICAL METHODS IN LAW 39 (2010).

${ }^{25}$ SimONS, supra note 18 , at 30 . In addition, in some of the message areas we cover, "effect sizes"- the magnitude of the statistical relationship between the variables under study - even if statistically significant, may be small. See generally LAWLESS, ET AL., supra note 24 , at 409.

${ }^{26}$ See, e.g., Gary C. Woodward \& Robert E. Denton, Jr., Persuasion and INFLUENCE IN AMERICAN LIFE 17 (4th ed. 2000) (Persuasion may spring from selfish motivations or altruistic ones: we may gain money or prestige from our abilities to influence others or we may act out of genuine regard for the welfare of those we seek to influence). The difficulty with this formulation, of course, is that people often act for a complicated mix of both self-interested and other-directed reasons. In our view, ethical mediators conscientiously attempt to subordinate their own goals and interests at all times to those of the parties. But this requires a good deal of self-knowledge and reflection, and is clearly easier said than done. On the difficulty of avoiding unconscious mediator influence on outcomes in mediation and achieving mediator neutrality, see, e.g., David Greatbatch \& Robert Dingwall, Selective Facilitation: Some Preliminary Observations on a Strategy Used by Divorce Mediators, 23 LAW \& SoC'Y REV. 613 (1989); Alison 
we do not think that there are any simple litmus tests to determine when interventions cross the line from "proper" persuasion into inappropriate coercion or manipulation. Ultimately, these are difficult questions that mediators must decide for themselves, based on their mediation philosophy, the settings in which they practice, and the context of particular disputes in which they are engaged.

In this article, we present and analyze the existing research on a variety of persuasive interventions, in roughly the order at least some mediators might attempt them in a hotly contested mediation like the Halverson matter. In Parts II and III, we discuss orchestrating role reversals and apologies, two interventions that utilize an indirect or behavioral approach to persuasion. In Parts IV-VI, we turn to direct persuasion and to message variables that may affect the persuasive effect of such interventions, including the choice of rhetorical questions or statements (Part IV), the relative effectiveness of one-sided versus two-sided statements and the persuasive effects of message explicitness (Part V), and the use of "negative" emotions such as fear and guilt in efforts to persuade (Part VI).

In Parts VII and VIII, we turn to indirect and direct modes of persuasion that might be used in the later stages of the mediation process, once the actual bargaining begins. In Part VII, we consider group brainstorming as an indirect method of persuasion aimed at generating more ideas for resolution and/or inducing greater cooperation between the disputants. In Part VIII, we examine the use of a sequence of requests-as opposed to a single, straightforward one-to try to obtain bargaining concessions.

\section{II. "SAying is Believing": Persuasion Through COUNTER-ATTITUDINAL ADVOCACY}

One approach to seeking to change a person's mind is to have them actively engage and momentarily experience a competing perspective in some fashion. That engagement by the subject has been labeled counter-attitudinal advocacy. A classic example of this mode of persuasion - used by mediators, therapists, and others-is role reversal.

Role reversal is a technique that asks each party to "step into the shoes" of the other party and consider how a situation or an issue might look from that person's perspective. The goal is to have each person acknowledge,

Taylor, Concepts of Neutrality in Family Mediation: Context, Ethics, Influence and Transformative Process, 14 MEDIATION Q. 215 (1997). 
verbally if possible, that the situation might look differently when viewed from the other side. ${ }^{27}$

Interventions using role reversal generally ask parties to: (a) put aside their own perspective for the moment; (b) try to see the issue as the other side does (not as they would if they were the other side); and (c) articulate that other perspective. The theory is that once disputants have experienced saying, and hearing themselves say, such words, the other side's perspective may become more understandable (even if not totally convincing) and opposition to it may soften. On a deeper level, it is hoped that role reversals can trigger empathy for the other side, producing some thawing of strained relationships.

There are many variations of this basic concept, all of which involve the mediator's helping the party see a different perspective even if they cannot, or will not, at first. As examples, the mediator can help the parties to:

- Consider how their own statements and actions may have been understood (or misunderstood) by the other side, as in: "If you were Ms. Halverson, how would your conduct (proposal) look?" Or, "Put yourself in Ms. Halverson's shoes. What do you think she might have thought when she read her email notice of termination? ... I know you don't agree, but try to say in words what she might have been thinking."

- Consider how the other party's past actions might have a different and more innocent explanation, as in: "Looking at it from Ms. Halverson's perspective, why do you think she acted as she did when she learned that she had been passed over for the promotion? What are some possible reasons?"

- Better appreciate each other's arguments. A mediator can ask each party, including their counsel, "If you were the other side, what arguments would you make in support of your position?"' Or specifically here: "If you were Ms. Halverson's attorney, how might you use the overtly sexist comments attributed to Mr. Hernandez to buttress your case?"

Note how role reversal purports to work, as an indirect mode of persuasion: through a series of questions, in a type of role-playing process, the mediator attempts to engage each party actively in a process of self-persuasion. Each party is asked to consider a viewpoint that is different from his or her own and to improvise arguments in favor of that opposing point of view. Is role reversal effective in changing minds? Empirical studies of this type of persuasive intervention-called "counter-attitudinal advocacy"-date back more than fifty years, and the research evidence appears strongly to support its efficacy.

\section{A. Counter-Attitudinal Advocacy Studies}

${ }^{27}$ FRENKEL \& STARK, supra note 5, at 238. 
Two early experiments by a well-known Yale social psychologist and his research colleague were among the first to investigate empirically whether getting people to verbalize and advocate opinions that may not correspond with their inner convictions produces greater attitudinal change than merely exposing them to the same opinions passively (i.e., by their reading or hearing the material) ${ }^{28}$ In both studies, subjects were found more likely to change their opinions on the topic if induced to give a speech to others formulating and elaborating their own arguments in support of a position opposed to their own, as opposed to merely hearing another person's arguments (in the first study) or reading or repeating another person's arguments (in the second).

These findings have been replicated often in subsequent years. In several experiments, counter-attitudinal role-playing had a significant positive effect on opinion change, even on topics at odds with research subjects' deeply held beliefs. In one study, for example, students at a conservative Christian college were more likely to change their opinions on topics such as the sale of alcohol to raise money for the improvement of public schools if they were asked to prepare in writing their own best reasons for such an initiative, rather than being asked simply to reproduce the ideas of others. ${ }^{29}$ In another series of studies, Caucasian students were asked to write essays publicly endorsing a controversial proposal to double the number of academic scholarships available to African-American students at their college. The general attitudes of the student subjects became more favorable towards African-Americans as a result of writing these counter-attitudinal essays. ${ }^{30}$ Results from persuasion experiments involving other forms of role-playing are generally similar. ${ }^{31}$

28 Irving T. Janis \& Burt T. King, The Influence of Role-Playing on Opinion Change, 49 J. ABNORMAL \& Soc. PSYCHOL. 211 (1954) [hereinafter, "Janis \& King"]; Burt T. King \& Irving L. Janis, Comparison of the Effectiveness of Improvised Versus Non-Improvised Role-Playing in Producing Opinion Changes, 9 HUM. ReL. 177 (1956) [hereinafter, "King \& Janis"].

${ }^{29}$ O. J. Harvey \& George D. Beverly, Some Personality Correlates of Concept Change Through Role Playing, 63 J. ABNORMAL \& SoC. PSYCHOL. 125 (1961).

${ }^{30}$ Michael R. Leippe \& Donna Eisenstadt, Generalization of Dissonance Reduction, Decreasing Prejudice Through Induced Compliance, 67 J. PERSONALITY \& SOC. PSYCHOL. 395 (1994); Michael R. Leippe \& Donna Eisenstadt, A Self-Accountability Model of Dissonance Reduction: Multiple Modes on a Continuum of Elaboration, in Cognitive Dissonance THEORY: Revival with Revisions and CONTROVERSIES (E. Harmon Jones \& J. S. Mills eds., 1998).

31 See, e.g., Irving L. Janis \& Leon Mann, Effectiveness of Emotional Role-playing in Modifying Smoking Habits and Attitudes, 1 J. EXPERIMENTAL RES. IN PERSONALITY 84 
What are the psychological mechanisms underlying the effectiveness of counter-attitudinal advocacy? Janis and King theorized that this effect was not caused by deeper processing or increased comprehension, but rather by "a lowering of psychological resistance whenever a person regards the persuasive ideas emanating from others as his 'own' ideas." 32 According to the authors, the studies provide evidence that opinion change is substantially augmented by one's active participation. As they put it, "saying is believing." 33

Subsequent research has focused on two other factors that also may help explain the persuasive effectiveness of counter-attitudinal advocacy. One factor is "biased scanning": the process of focusing the attention of the subject on arguments that are different from his or her own views and thereby increasing the accessibility of those arguments to the subject." 34

This line of research links up with research on biased assimilation of information. Cognitive psychologists have demonstrated that people generally pursue and assimilate new information in accordance with their preexisting biases and beliefs. ${ }^{35}$ In a well-known experiment demonstrating

(1965) (female smokers induced to act in role-plays in which they learn from their doctor that they have severe lung cancer far more effective in inducing attitude change about smoking than listening to audiotapes of same session).

32 King \& Janis, supra note 28, at 183.

33 Janis \& King, supra note 28 , at 211 . This theory builds on earlier work by H.L. Hollingsworth, THE PSYCHOLOGY OF THE AUDIENCE (1943), positing that "resentment and negativistic reactions may interfere with acceptance of a direct suggestion from others, whereas the individual's belief that he is making a decision on his own initiative may increase the influence of an indirect suggestion." King \& Janis, supra note 28, at 183. The authors also note: "The notion that a direct approach tends to stimulate internal resistance seems to be a major assumption in theoretical discussions of the rationale for nondirective psychotherapy." Id. at 183 (citing CARL ROGERS, COUNSELING \& PSYCHOTHERAPY (1942)). Later studies confirm that active role playing generally produces greater attitude change than passive exposure to comparable information. See Alice H. Eagly \& Shelly Chaiken, The Psychology of Attitudes 502 (1993) (listing studies in support of this generalization).

34 EAGLY \& CHAIKEN, supra note 33, at 502-04.

35 See generally Daniel Kahneman \& Amos Tversky, Conflict Resolution: A Cognitive Perspective, in BARRIERS TO CONFLICT RESOLUTION (Kenneth Artow et al. eds., 1995); MAX H. BAZERMan, Judgment In MANagerial Decision MaKing (5th ed. 2001); Margaret A. Neale \& MaX H. Bazerman, Cognition and Rationality IN NEGOTIATION (1991); Leigh Thompson \& Janice Nadler, Judgmental Biases in Conflict Resolution and How to Overcome Them, in HANDBOOK OF CONFLICT RESOLUTION, 213 (Morton Deutsch \& Peter T. Coleman eds., 2000); Jane Goodman-Delahunty et al., Insightful or Wishful: Lawyers' Ability to Predict Case Outcomes, 16 PSYCHOL. PUB. POL'Y \& L. 133 (2010). 
how partisan perspectives affect how we assimilate new information, groups of proponents and opponents of capital punishment were each presented with two opposing studies, one supporting its effectiveness as a deterrent to crime, the other providing evidence showing no deterrent effect at all. After reading the two studies, each group thought that the study supporting their preexisting views was logically superior to the study opposing them. Not only that, but after reading the mixed evidence from a combination of the two studies, each side felt more committed to its original position than before. ${ }^{36}$

However, in a follow-up study, these researchers found that subjects told to "consider the opposite" were able to overcome their cognitive biases to a much greater extent than those told merely to "be fair and objective." 37 This suggests that counter-attitudinal advocacy may persuade by forcing subjects to personally engage with opposing viewpoints that they are psychologically predisposed against taking in.

According to another school of thought, counter-attitudinal advocacy works because of cognitive dissonance. According to cognitive dissonance theory:

[D]issonance (an unpleasant feeling) is aroused when an individual says or does something that runs counter to his or her own beliefs, especially if this action threatens the individual's self-concept of being a

${ }^{36}$ Charles G. Lord, Lee Ross \& Mark R. Lepper, Biased Assimilation and Attitude Polarization: The Effects of Prior Theories on Subsequently Considered Evidence, $37 \mathrm{~J}$. PERSONALITY \& SOC. PSYCHOL. 2098 (1979).

${ }^{37}$ Charles G. Lord, Mark R. Lepper \& Elizabeth Preston, Considering the Opposite: A Corrective Strategy for Social Judgment, 47 J. PERSONALITY \& Soc. PsYchol. 1231, 1239 (1984). The authors gave 120 Stanford undergraduates, who had earlier indicated support or opposition to capital punishment, two summaries of studies to read, one supporting and one not supporting the deterrent effect of the death penalty. Respondents were then divided into three groups, consisting of twenty opponents and twenty supporters each. As in the first study, the attitudes of respondents in the "replication" (of the 1979 study) group were more polarized rather than less in their thinking after reading the conflicting studies. Respondents in the second group were admonished (like a judge or jury) "to be as objective and unbiased as possible in evaluating the studies you read." $I d$. at 1233 . The attitudes of the respondents in this second group were just as polarized as that of those in the replication group after reading the studies. However, respondents in the third group--instructed (actively) to consider the opposite-specifically, to "[a]sk yourself at each step whether you would have made the same high or low evaluations had exactly the same study produced results on the other side of the issue"-experienced significantly less belief polarization than either of the other groups. Id. at 1233 . 
decent or rational person. To reduce dissonance, people will try to bring those disparate cognitions into greater harmony. ${ }^{38}$

Applied specifically to counter-attitudinal advocacy, tools like role reversal seem to work as a mode of persuasion because subjects ask themselves: "how can I come up with such plausible reasons if I don't believe they have merit?"39

Persuasion researchers working generally in the field of cognitive dissonance have also spent a good deal of time investigating how external incentives affect attitude change. In a famous early experiment, Festenger and Carlsmith demonstrated that smaller incentives produce greater self-persuasion than larger ones. ${ }^{40}$ Students paid $\$ 1$ to falsely tell other students that a boring task was fun later rated the task as more fun than those students paid $\$ 20$ to tell the same lie. According to one commentator, "the lower incentive facilitated more self-persuasion, presumably because these subjects had less external motivation to lie. As a result, they provided [their own] internal motivation or justification for their behavior." 41

Another fascinating pair of studies involved preschool children. In the first study, the children were divided into two groups and told not to play with an attractive toy. One group was given a severe threat for doing so; the other group a mild threat. When the threat condition was later lifted, children given the severe threat went right back to playing with the toy; children given the mild threat did so far less. Why? Because children given a severe threat knew why they were not playing with the toy: they would be severely punished by an adult if they did. Children given the mild threat had to "supply some additional justification on their own ... [they] subsequently convinced themselves that the forbidden toy was less attractive ...."42 The moral, according to one long-time researcher in the field: "Self-persuasion has staying power."43

38 Aronson, supra note 22, at 876. See generally LEON FESTINGER, A THEORY OF COGNITIVE DisSONANCE (1959).

39 Anthony G. Greenwald \& Rosita Daskal Albert, Acceptance and Recall of Improvised Arguments, 8 J. PERSONALITY \& SOC. PSYCHOL. 31, 33 (1968).

${ }^{40}$ Leon Festinger \& James M. Carlsmith, Cognitive Consequences of Forced Compliance, 58 J. ABNORMAL \& SOC. PSYCHOL. 203 (1959).

${ }^{41}$ E. Scott Geller, The Art of Self-Persuasion, SAFETYPERFORMANCE.COM 5 (2001), http://www.safetyperformance.com/pdf/Articles/2001/TheArtofSelf-Persuasion.pdf.

${ }^{42}$ Elliot Aronson \& J. Merrill Carlsmith, Effect of the Severity of Threat on the Devaluation of Forbidden Behavior, 66 J. ABNORMAL \& SOC. PSYCHOL. 584 (1963).

${ }^{43}$ Aronson, supra note 22 , at 877 . These toy studies have been replicated on a number of occasions. In one follow-up study, the second experiment was 
A general caution is in order, however. Many studies of counter-attitudinal advocacy tend to test subjects' persuadability on topics of relatively low interest or ego involvement to them.44 A 1976 study ${ }^{45}$ sheds some light on how counter-attitudinal advocacy may work differently with subjects who-like many parties in mediation-have strong feelings and opinions about a topic. In this study, researchers examined U.S.C. undergraduate students' attitudes about "required on-campus housing for all students." 46 Pre-testing sorted out students with strong negative feelings about this topic from those without strong views. Subjects were then asked to write essays advocating compulsory on-campus housing and were told that their essays would be used in subsequent efforts to convince others to adopt this policy. The study mostly found what the researchers predicted: Low-involvement subjects showed a significant change in their "most acceptable" positions as a result of writing these essays. Highly involved subjects reported no significant changes in their "most acceptable" positions: they maintained extreme, negative positions toward compulsory on-campus residence. Changes in viewpoints, if any, were only "at the margins."

\section{B. Mediation Applications and Questions}

Role reversal, "consider the opposite," and other forms of counter-attitudinal advocacy are persuasion tools that ought to be acceptable to most mediators, no matter what their role orientation or philosophy. They are tools by which the mediator attempts to lower tensions by inducing in each party greater appreciation of the other side's arguments and concerns. ${ }^{47}$

conducted-with similar effects-forty days after the first. Jonathan L. Freedman, Long-term Behavioral Effects of Cognitive Dissonance, 1 J. EXPERIMENTAL SOC. PSYCHOL. 145 (1965). In another replication, boys who were given severe or mild threats not to play with an attractive toy were later asked to falsify their scores on a separate test another researcher administered to them. Mark R. Lepper, Dissonance, Self-Perception, and Honesty in Children, 25 J. PERSONALITY \& SOC. PSYCHOL. 65 (1973). "Those boys who had earlier received the mild threat were significantly less likely to cheat than those who received the severe threat. Apparently, the boys who earlier complied with only a mild threat were more likely to develop the self-perception that 'I'm a good boy who resists temptation ..." Geller, supra note 41 , at 7 .

44 Greenwald \& Albert, supra note 39, at 31, 33.

45 Edward M. Bodaken \& Kenneth K. Sereno, Counterattitudinal Advocacy, Ego-Involvement, and Persuasive Effect, 39 W. SPEECH COMM. 236 (1976) (undergraduate students arbitrarily assigned to improvise arguments in favor of either general or specialized undergraduate education).

$46 \mathrm{Id}$. at 240.

${ }^{47}$ While they might not be equally comfortable or adept at trying to orchestrate a 
They appear to help overcome partisan assimilation of information-a pervasive cognitive bias. Lowering tensions and overcoming biases are considered important components of what effective mediators do, according to conventional theory. Moreover, these devices would appear to be widely applicable to all kinds of cases, including pure money disputes.

Even more important, some of this research suggests that self-persuasion devices like role reversal produce lasting changes in attitudes. This is a potentially highly significant finding for mediators. Disputants whose attitudes have really been changed are more likely to "own" their agreements, and are more likely to comply with them as well. ${ }^{48}$ As we will discuss, many other modes of persuasion can also be effective, but if they produce more ephemeral attitude changes, this can lead to post-negotiation regret and even repudiation of agreements.

Nonetheless, these persuasion techniques are obviously not a panacea. First, some research findings suggest what mediation experience demonstrates: when disputants are deeply entrenched (highly "ego-involved") in a position-for example, furious at their opponent for having acted disrespectfully or in bad faith, or supremely confident that their case is a "slam dunk" -inducing them to consider opposing viewpoints may produce slow, incremental change at best. Noted Harvard educational psychologist Howard Gardner observes that most "self-persuasion" is like this. It occurs gradually, as a result of small shifts in perceptions and viewpoints, rather than as the result of any single argument or sudden realization. ${ }^{49}$ To the extent that this is true, it may be the case that counter attitudinal advocacy interventions should be attempted early in the mediation process, well before the actual bargaining begins, perhaps buttressed by other, more direct persuasive devices. ${ }^{50}$

role reversal, mediators of all philosophies view the development of greater mutual empathy as both instrumentally and intrinsically valuable. Compare FRENKEL \& STARK, supra note 5, at 183-84, 238-39, and BUSH \& FOLGER, supra note 8, at 99-101 (emphasizing importance of perspective-taking in "help[ing] make each party more intelligible to each other"), with GARY FRIEDMAN \& JACK HIMMELSTEIN, CHALLENGING CONFLICT: MEDIATION THROUGH UNDERSTANDING (2008) (setting out a caucus-eschewing, "understanding-based" model of mediation that stresses the parties' ability "to take each other's views into account.").

48 See Craig A. McEwan \& Richard J. Maiman, Mediation in Small Claims Court: Achieving Compliance Through Consent, 18 LAW \& SOC'Y REV. 11 (1984).

${ }^{49}$ HOWARD GARDNER, CHANGING Minds 173 (2004).

${ }^{50}$ FRENKEL \& STARK, supra note 5, at 236-39 (proposing a "progressive" model of mediation persuasion, and recommending role reversal at an early stage of the persuasion process). 
Second, research experiments suggest that, although role reversal interventions may improve understanding of the other side's perspective, they do not necessarily lead to resolution when the parties' positions are directly incompatible. ${ }^{51}$ Some of the early literature on role playing comes from the field of therapy, in which the relationship between therapist and patient is fundamentally a cooperative one. By contrast, when directly opposing positions between two adversarial negotiators are clarified and better understood, competition may escalate rather than abate. It may therefore be the case that role reversal enhances cooperation in mediation only where the parties at some level wish to cooperate in the first place. ${ }^{52}$

Finally, none of the studies of counter-attitudinal advocacy we have read address the impact of role reversal on feelings, as contrasted with attitudes and beliefs (to the extent these can be separated). It is a common assumption among many mediators that role reversal works, in part, because of its capacity to induce empathy: the capacity to comprehend the other person's thoughts, experience and emotions. ${ }^{53}$ This might be a productive area for further research.

\section{PERSUASION BY ORCHESTRATING APOLOGIES}

Suppose that none of your efforts at role reversal have produced perceptible changes in the parties' conversation patterns or bargaining behaviors. In order to produce movement, might it be effective to try to induce some kind of apology, for example to see if the plaintiff's immediate supervisor, Jason Hernandez, would be willing to acknowledge and express regret to Ms. Halverson for the abrupt and impersonal way that he laid her off? Or for insensitive sexual comments on the job-albeit not directed at Ms. Halverson and (presumably, he and his counsel will contend) unrelated to the decision to lay her off? What are the components of an effective apology? Under what circumstances might such an intervention be productive or unproductive? Is there optimal timing for an apology?

The theoretical treatment of apology and forgiveness, from fields such as philosophy, religion, and psychotherapy, is voluminous. Here, as in the rest of this article, we focus only on empirical social science findings. To a greater extent than other topics in this article, this empirical literature has

51 David W. Johnson, Use of Role Reversal in Intergroup Competition, $7 \mathrm{~J}$. PERSONALITY \& SoC. PSYCHOL. 135, 140 (1967).

52 Id. at 140.

53 Indeed, in our own writings, we have referred to role reversal as "persuasion based on empathy." FRENKEL \& STARK, supra note 5, at 238. 
been surveyed and summarized by other dispute resolution scholars, ${ }^{54}$ although the topic has not been previously characterized as a mode of "persuasion" available to mediators. We include our own synthesis here because we view the successful orchestration of an apology as an important mode of indirect persuasion by means of induced behavior, whose empirical study should inform the field.

The impact of apologies on injured persons and third party observers has been a subject of sustained social science research for more than thirty years. A recent meta-analytic review of 175 studies involving 26,000 participants concludes that apologies are, in general, positively correlated with interpersonal forgiveness. ${ }^{55}$ As one article puts it, "[a]pologies are the world's most ... pervasive conflict resolution technique ... serving a crucial social lubrication role." 56

Studies involving apology have been conducted in the context of interpersonal disputes; 57 public confessions of wrongdoing by political and public figures; 58 disputes involving business, consumer or employment relationships; ${ }^{59}$ with children; ${ }^{60}$ and with mock criminal and civil juries, assessing the impact of public apologies and other expressions of remorse by

54 See sources cited infra note 62.

55 Ryan Fehr, Michele J. Gelfand \& Monisha Nag, The Road to Forgiveness: A Meta-Analytic Synthesis of Its Situational and Dispositional Correlates, 136 PSYCHOL. BULL. 894, 904 (2010) (reporting medium effects sizes).

56 Cynthia McPherson Frantz \& Courtney Bennigson, Better Late Than Early: The Influence of Timing on Apology Effectiveness, 41 J. EXPERIMENTAL SOC. PSYCHOL. 201 (2005).

57 See, e.g., Michael E. McCullough et al., Interpersonal Forgiving in Close Relationships: II. Theoretical Elaboration and Measurement, 75 J. PERSONALITY \& SOC. PSYCHOL. 1586 (1998); Shlomo Hareli \& Zvi Eiskovits, The Role of Communicating Social Emotions Accompanying Apologies in Forgiveness, 30 MOTIVATION EMOTION 189 (2006).

58 See Bernard Weiner et al., Public Confession and Forgiveness, 59 J. PERSONALITY 281 (1991).

${ }^{59}$ See, e.g., Edward Tomlinson et al., The Road to Reconciliation: Antecedents of Victim Willingness to Reconcile Following a Broken Promise, 30 J. MGMT. 165 (2004) (breach of contract involving small business owners); Cathy Goodwin \& Ivan Ross, Consumer Responses to Service Failures: Influence of Procedural and Interactional Fairness Perceptions, 1992 J. BUS. RES. 149 (consumer evaluation of complaint handling practices).

${ }^{60}$ See, e.g., Bruce W. Darby \& Barry R. Schlenker, Children's Reactions to Apologies, 43 J. PersonaltTY \& SOC. PSYCHOL. 742 (1982); Ken-Ichi Ohbuchi \& Kobun Sato, Children's Reactions to Mitigating Accounts: Apologies, Excuses, and Intentionality of Harm, 134 J. SOC. PSYCHOL. 5 (2001). 
offenders on sentencing and compensation decisions. ${ }^{61}$ Most recently, empirical legal scholars interested in negotiation and mediation have begun to examine how apologies affect the initiation and settlement of legal claims. ${ }^{62}$

Experiments involving apologies have taken a number of different forms. Quite common are what have been termed "scenario" studies. ${ }^{63}$ In these experiments, research subjects are asked to react to a written scenario in which they are told that they have been the victim of a hypothetical offense (for example, the loss of class notes by a classmate who borrowed them, or being hit by a car by a negligent driver while riding a bicycle), after which the "transgressor" did or did not apologize. Researchers then manipulate different types of offenses and injuries, as well as different types of apologies and apology components, to measure which are most effective in changing the injured person's (hypothetical) feeling states, perceptions of the transgressor, and inclination to forgive or punish. Such studies have the advantage of easy experimental control, but obviously lack a degree of realism. ${ }^{64}$ Occasionally, apologies are videotaped and shown to subjects, rather than being quoted (or characterized) on the printed page. ${ }^{65}$ This may increase their verisimilitude, by inducing emotional reactions on the part of research participants as well as cognitive ones. ${ }^{66}$

${ }^{61}$ See, e.g., Brian H. Bornstein et al., The Effects of Defendant Remorse on Mock Juror Decisions in a Malpractice Case, 20 BEHAV. SCI. \& L. 393 (2002); Dawn T. Robinson et al., Heinous Crime or Unfortunate Accident? The Effects of Remorse on Responses to Mock Criminal Confessions, 73 SOC. FORCES 175 (1994) (vehicular manslaughter case); Chris L. Kleinke et al., Evaluation of a Rapist as a Function of Expressed Intent and Remorse, 132 J. SOC. PSYCHOL. 525 (2001).

62 See Russell Korobkin \& Chris Guthrie, Psychological Barriers to Litigation Settlement: An Experimental Approach, 93 MiCH. L. REV. 107 (1994); Jennifer K. Robbennolt, Apologies and Legal Settlement: An Empirical Examination, $102 \mathrm{MiCH}$. L. REV. 460 (2003) [hereinafter, Robbennolt I]; Jennifer K. Robbennolt, Apologies and Settlement Levers, 3 J. EMPIRICAL LEGAL STUD. 333 (2006) [hereinafter Robbennolt II]; Jennifer Robbennolt, Attorneys, Apologies, and Settlement Negotiation, 13 HARV. NeGOT. L. REV. 349 (2008) [hereinafter Robbennolt III]; Kathleen M. Mazor et al., Health Plan Members' Views About Disclosure of Medical Errors, 140 ANNALS OF INTERNAL MED. 409 (2004) (in medical malpractice study, full disclosure of medical error and apology by professionals made respondents less likely to seek legal advice; results statistically significant only where medical error produced minor, not life-threatening, injury).

${ }^{63}$ Fehr et al., supra note 55, at 903.

64 Id.

65 See Kleinke, supra note 61 , at 527.

${ }^{66}$ Fehr et al., supra note 55, at 906 (reporting that scenario studies produce more 
Alternatively, research subjects can be asked to react to differing apologies for offenses they have actually suffered - either past harms they are asked to recall from their own everyday experience ("recall" studies), ${ }^{67}$ or transgressions engineered by researchers through the use of experiment confederates ("induced transgression" studies). In one recall study, for example, participants were asked a series of questions about "a recent conflict (within the last six months) you have had with another individual ... in which you felt you were wronged, and also in which the other gave you an apology of some kind." 68 Such studies have the advantage over scenario studies of greater realism, but may present problems of memory loss and distortion, as well as difficulty in controlling for widely differing types and degrees of offenses or harms suffered.

Perhaps more realistic are induced transgression studies. In one representative experiment, undergraduate marketing students were asked to prepare an advertising campaign for a new shampoo. Their work was then negatively evaluated by a person posing as a reviewer but who was actually an accomplice of the researcher. Following this, the researchers were able to measure the effectiveness of a number of different remedial interventions, including apology by the evaluator, in reducing the subjects' (presumably real) anger about their negative performance evaluations and their feelings that it was unfair. ${ }^{69}$

Least common of all, but perhaps most useful, are field studies, in which apologies are examined qualitatively, in actual, ongoing conflicts. In our literature review, we located only one such study, involving victim-offender mediation. ${ }^{70}$ In addition, almost all empirical studies to date focus on how apologies affect victim-recipients or third party observers; with only two

cognitions than recall methodologies, which stimulate more feelings).

67 Id. at 903 .

${ }^{68}$ Frantz \& Benigson, supra note 56, at 203 (study 1).

${ }^{69}$ Robert A. Baron, Countering the Effects of Destructive Criticism: The Relative Efficacy of Four Interventions, 75 J. APPLIED PSYCHOL. 235 (1990). In a similar vein, albeit in a more artificial context, the effects of apologies following one or more uncooperative acts have been studied in prisoner's dilemma and ultimatum ("take-it-or-leave-it") games. See, e.g., William Bottom et al., When Talk Is Not Cheap: Substantive Penance and Expressions of Intent in Rebuilding Cooperation, 13 ORG. SCI. 497 (2002) (prisoner dilemma game); Daniel P. Skarlicki, Robert Folger \& Julie Gee, When Social Accounts Backfire: The Exacerbating Effects of a Polite Message or an Apology On Reactions to an Unfair Outcome, 34 J. APPLIED SOC. PSYCHOL. 322 (2004) (ultimatum game).

70 Jung Jin Choi \& Margaret Severson, “What! What Kind of Apology is This?": The Nature of Apology in Victim Offender Mediation, 31 CHILD. \& YOUTH SERVICES REV. 813 (2009). 
exceptions, ${ }^{71}$ we found no experiments attempting to measure the possible effects of apologizing on the maker of the apology.

\section{A. Effects of Apologies on Apology Recipients' Perceptions, Feelings and Behaviors}

In general, it has been demonstrated that apologies tend to induce forgiveness in victims and observer third parties in two principal ways: by altering apology recipients' perceptions about the transgressor, or (as discussed below, the studies here are less robust) by altering apology recipients' feeling states, or affect. Importantly, it has been shown that these cognitive and affective changes can inhibit aggression - the desire to punish the transgressor or retaliate for his past acts - at a behavioral level. ${ }^{72}$

In his classic work, Relations in Public, sociologist Erving Goffman theorized that through the act of apologizing, a transgressor "splits himself into two parts, the part that is guilty of an offense and the part that disassociates itself from [the transgression]," thereby "affirm[ing his] belief in the offended rule."73 By signaling his recognition that he has broken a norm, and by stating that he regrets his actions, the theory goes, a transgressor enables victims and third persons to distinguish his acts from his moral character, and to conclude that such acts will likely not be repeated in the future. ${ }^{74}$ Seeing the transgressor in this better light can reduce the apology recipient's desire for vindication, punishment or revenge. ${ }^{75}$

Experimental studies generally confirm that those who apologize tend to generate more positive perceptions of themselves over a range of dimensions,

71 Charlotte Witvliet, Thomas Ludwig \& David Bauer, Please Forgive Me: Transgressors' Emotions and Physiology During Imagery of Seeking Forgiveness and Victim Responses, 21 J. PSYCHOL. \& CHRISTIANITY 219 (2002); Tyler Okimoto, Kyle Hedrick \& Michael Wenzel, I Make No Apology: The Psychological Benefits of Refusing to Apologize, IACM 23RD ANNUAL CONFERENCE PAPER (March 22, 2011), available at http://ssrn.com/abstract=1612866.

${ }^{72}$ Ken-Ichi Ohbuchi, Masuyo Kameda \& Nariyuki Agarie, Apology as Aggression Control: Its Role in Mediating Appraisal of and Response to Harm, 56 J. PERSONALITY \& SOC. PSYCHOL. 219, 226 (1989).

73 ERving Goffman, Relations In Public 113 (1971).

74 Weiner et al., supra note 58, at 284-85.

${ }^{75}$ As one article puts it, apologies are effective in resolving interpersonal conflicts because they convey the idea that the transgressor feels guilty and has already suffered, thereby lessening the need for any further "sentence." Seiji Takaku, The Effects of Apology and Perspective-Taking on Interpersonal Forgiveness, 14 J. SOC. PSYCHOL. 494, 494-95 (2001). 
including likeability, blameworthiness, and punishability, ${ }^{76}$ and that apologies often induce forgiveness by the victim or third party. ${ }^{77}$ These effects are not uniform, however, but appear to depend on the seriousness of the actor's transgressions, the resulting harm, or both. ${ }^{78}$ For example, in mock criminal jury studies, a confession coupled with a statement of remorse by the defendant is more likely to improve moral judgments about the defendant and influence juror sentencing decisions in a case of accidental vehicular manslaughter ${ }^{79}$ than a case of rape ${ }^{80}$ or murder. ${ }^{81}$ Similarly, apologies are more effective in cases involving a single transgression than a series of transgressions over time. ${ }^{82}$ They seem especially effective in influencing moral judgments about the wrongdoer and in inducing forgiveness in situations involving "attributional uncertainty" 83 - where the reasons for the transgressor's wrongdoing are unclear and susceptible to differing interpretations.

Because of the inherent limitations of hypothetical scenario studies, the empirical evidence they provide about the impact of apologies on recipients' feeling states about (as contrasted to perceptions of) the transgressor seems relatively weak; such experiments are unlikely to trigger strong, authentic

76 See Mark Bennett \& Christopher Dewberry, I've Said I'm Sorry, Haven't I? A Study of Identity Implications and Constraints That Apologies Create for Their Recipients, 13 CURRENT PSYCHOL. 10, 11 (1994).

77 Weiner et al., supra note 58, at 308.

78 See, e.g., Mark Bennett \& Deborah Earwaker, Victims' Responses to Apologies: The Effects of Offender Responsibility and Offense Severity, 134 J. Soc. PSYCH. 457 (2001). But see, Robbennolt I, supra note 62, at 492-95 (finding that neither the severity of the victim's injury nor strong evidence of transgressor responsibility affected effectiveness of apologies in ultimate settlement decisions).

79 Robinson et al., supra note 61 (displays of remorse by defendant strongly influence mock juror perceptions of past future behavior by defendant and resulting sentences); Michael G. Rumsey, Effects of Defendant Background and Remorse on Sentencing Judgments, 6 J. APPLIED SOC. PSYCHOL. 64 (1976) (drunk driving case, same results).

${ }^{80}$ Kleinke et al., supra note 61 (finding that expressions of remorse did not affect proposed jury sentences); R.L.Wiener \& N. Rinehart, Psychological Causality in the Attribution of Responsibility for Rape, 14 SEX RolEs 369, 378 (1986) (statements of remorse affect moral judgments but not sentencing).

81 Catherine A. Crosby, et al., The Juvenile Death Penalty and the Eighth Amendment, 19 L. \& HUM. BEHAV. 245, 259 (1995) (statements of remorse did not influence sentencing judgments).

82 Bottom et al., supra note 69 (apologies more effective in restoring cooperation in prisoner dilemma games following short, rather than long, period of competition.)

83 Weiner et al., supra note 58 , at 308. 
feelings. On the other hand, several induced transgression studies provide substantial support for the proposition that apologies reduce anger and induce forgiveness. Illustrative is an experiment in which Japanese undergraduate students, given a test of their intellectual abilities that they had been told was "easy," then "failed" the test because of (deliberate) mistakes made by an assistant in administering it. A public apology by the assistant to students, in the presence of the lead researcher, not only reduced their anger, but also decreased their desire to punish the assistant through a negative performance evaluation. ${ }^{84}$

\section{B. Types of Apologies and Their Effects}

Of course, not all apologies are created equal. ${ }^{85}$ Researchers studying the components of effective apologies have found (unsurprisingly) that: (1) more elaborate ("full") apologies are generally more effective than less elaborate ones; ${ }^{86}$ (2) the more serious the transgression or the greater the harm, the more elaborate the apology that may be expected by the victim or third party observer ${ }^{87}$ (3) partial apologies can be unproductive or even counterproductive in their effects on the recipient; 88 but (4) at least in some cases-- involving less serious injuries, less clear culpability, or both-- any apology, even if incomplete, may be better than none. ${ }^{89}$

The elements of a "full" or "complete" apology have been defined differently in different studies. One article suggests that full apologies ideally should include a statement of remorse by the wrongdoer ("I' $m$ really sorry

${ }^{84}$ Ohbuchi, Kameda \& Agarie, supra note 72, at 220 (study 1). For similar results in an employment context, see Baron, supra note 69 (study 1).

${ }^{85}$ Frantz \& Bennigson, supra note 56, at 201.

86 Steven Scher \& John Darley, How Effective Are the Things People Say to Apologize? Effects of the Realization of the Apology Speech Act, 26 J. PSYCHOLINGUISTIC RES. 127, 137 (1997); Darby \& Schlenker, supra note 60 (children).

${ }^{87}$ Bruce Darby \& Barry Schlenker, The Use of Apologies in Social Predicaments, 4 SOC. PSYCHOL. Q. 271, 275 (1981).

${ }^{88}$ See, e.g., Robbennolt I, supra note 62, at 483-91 (study 1) (partial apology, defined as an expression of sympathy without more, had no impact on perceptions of defendant motorist in bicycle accident case, but made plaintiff-recipients less likely to accept defendants' settlement offers). See also Goodwin \& Ross, supra note 59 (scenario study, in which apologies without at least some small token of restitution were not effective in restoring consumer trust and satisfaction); Skarlacki et al., supra note 69 (apologies increase participants' sense of unfairness and decrease their willingness to accept low offers in ultimatum games).

${ }^{89}$ Scher \& Darley, supra note 86, at 137. 
for what I did"), a statement accepting responsibility or admitting fault for the transgression ("I know that it was wrong"), a promise of forbearance ("I promise something like this will never happen again"), and an offer of recompense or reparation ("I want to set this right. If there is any way I can make it up to you, please let me know"). ${ }^{90}$ Another article adds a fifth element: explicitly acknowledging the victim's loss ("I know your bike, which I lost, means a lot to you"). ${ }^{91}$ Each added component appears to contribute to the overall effectiveness of the apology. ${ }^{92}$ When important components of an apology are missing, the recipient may tend to blame the transgressor more and want to sanction him or her more harshly than if a full apology were offered. ${ }^{93}$

It has often been hypothesized that the perceived sincerity of an apology influences its effectiveness. ${ }^{94}$ This is a difficult variable to measure in many scenario studies because most experiments are designed in such a way that apologies are presented in written form ${ }^{95}$ or only characterized. ${ }^{96}$ One

90 Id. at 132. See also Bornstein et al., supra note 60, at 394-95; Darby \& Schlenker, supra note 87 at 274 . Hareli \& Eisikovits, supra note 57 (similar effect, but also stresses the importance of demonstrated shame and guilt in reducing anger and inducing forgiveness).

${ }^{91}$ Manfred Schmitt et al., Effects of Objective and Subjective Account Components on Forgiving, 144 J. SOC. PSYCHOL. 465, 469 (2004).

92 Scher \& Darley, supra note 86, at 137.

${ }^{93}$ Id. at 137-38. On the other hand, one experiment found that the total gestalt of the apology may matter more to the victim than its objective elements, and that some apology elements may matter more than others. For example, acknowledging the victim's loss and offering recompense were the two most significant elements to victims, at least in cases where compensation could remedy the particular transgression (borrowing a friend's bicycle and then negligently allowing it to get stolen). In these circumstances, statements of remorse without an offer of compensation were counter-productive, because they were deemed insincere. Schmitt et al., supra note 91, at 478, 481-82. Offering compensation, the authors suggest, implies an admission of fault, acknowledgment of loss, remorse, or both; the victim receiving an offer of compensation will often fill these elements in, even if they are not stated.

94 See, e.g., Robinson et al., supra note 61, at 187 (citing Ronald Everett \& Barbara Nienstedt, Rationality and Remorse in Sentence Reduction: Competing Influences or is Saying You're Sorry Enough? (1992) (unpublished conference presentation) (reporting that probation officers react negatively to admissions of responsibility they perceive as insincere)).

95 See, e.g., Bornstein et al., supra note 61, at 398 (medical malpractice scenario study. In the physician "remorse" condition, participants read a description in which they were told that the defendant doctor "expressed remorse for the unfortunate death of Xavier. He said he was very sorry that Xavier had died, while neither admitting or denying that the death was his fault."). 
experiment, however, went a step further, providing subjects with written "transcripts" of videotaped confessions of a defendant in a vehicular manslaughter case that either included or omitted a written indication of remorse on the part of the offender (e.g., "Blood was splashed all over the windshield (rests arms on chair)" versus "Blood was splashed all over the windshield (starts crying)") Not surprisingly, displays of remorse accompanying a confession positively influenced mock juror perceptions of the defendant and lowered the sentences they administered. ${ }^{97}$

Delivering an effective, remorse-conveying apology in the context of a real, face-to-face exchange, however, is a more complex matter. In a qualitative case study of actual apologies made by eight juvenile offenders in a victim-offender mediation (VOM) program over the course of a year, researchers found substantial discrepancies between the offenders' views of the sincerity of their own statements and how those statements were perceived by victims, mediators, and others privy to the proceedings. ${ }^{98}$ The juveniles were required to write and then read letters of apology to the victims of their offenses. Although they were mandated by the court to participate in this program as a condition of having their cases diverted from prosecution, most were sincere about their apologies and put substantial effort into perfecting their written statements. Nonetheless, others' perceptions of their sincerity turned on such variables as the speed with which they read their statements, whether they established eye contact with their victim, and other aspects of their nonverbal behavior. The study concluded that "[t]hese VOM sessions make clear that composing and delivering an apology is a complex undertaking that requires attention to many factors, including recognition of the influences of the context in which the apology is delivered, as well as the actual form and presentation of the apology." 99

\section{Studies of Apologies in Legal Disputing and Negotiation}

96 See, e.g., Bennett \& Earwaker, supra note 78 , at 459 (scenario study varying responsibility of wrongdoer and severity of harm. In all conditions, participants informed only that "the offender offered a sincere apology and expressed remorse"); Tomlinson et al., supra note 59, at 176, 181 (scenario study of small business breach of contract dispute; perceived sincerity of apology characterized, with instructions given to subjects in the sincere apology condition that "it appeared that this apology was sincere." Study finds strong correlation between sincerity of apology and willingness to resume business relationship.).

97 See generally Robinson et al., supra note 61.

98 Choi \& Severson, supra note 70, at 813.

${ }^{99}$ Id. at 819 . 
Despite much theoretical interest in apologies and their potential effects in legal dispute settlement, until recently there was very little empirical work on this specific topic. Researchers have begun to remedy this deficit. In a 1995 study, 445 Stanford undergraduate students were asked to play the role of a tenant in a hypothetical landlord-tenant dispute. In the scenario, the tenant sued the landlord to recover a portion of $\$ 4,000$ in rent paid for a period of time in which the heater was broken and the apartment had no heat. Tenants were told by a student legal services lawyer that there was " $a$ good chance of recovering a portion of the rent," but no more. In the apology condition, they were told that at a meeting with the landlord prior to the small claims court trial, "the landlord apologized to you for his behavior. 'I know this is not an acceptable excuse... but I have been under a good deal of pressure lately." Asked whether they would accept $\$ 900$ to settle their claim, subjects were more likely to do so if the landlord offered this (characterized) apology than if he did not. 100

More recently, in a series of three studies using a simulated personal injury case, Jennifer Robbennolt has examined the effects of apologies on settlement decisions in greater detail. ${ }^{101}$ In each study, participants were asked to visit a website and to read a scenario describing an incident in which a bicyclist was injured by an allegedly negligent motorist. Respondents were then asked to take on the role of the injured person (in the third study, attorneys were asked to take on the role of the injured person's attorney) and to evaluate how likely they would be to accept a particular settlement offer from the other side. ${ }^{102}$ In the partial apology condition, participants were told that the motorist stated, shortly after the accident but prior to the filing of a lawsuit, "I am so sorry that you were hurt. I really hope that you feel better soon." In the full apology condition, the motorist said, "I am so sorry you were hurt. The accident was all my fault. I was going too fast and not watching where I was going until too late." 103 Professor Robbennolt examined the effects of these statements on the settlement attitudes and

100 Korobkin \& Guthrie, supra note 62 , at 147-50. Although the results approached statistical significance, they did not reach it. However, the authors state their belief that their result "understates the efficacy of apology for at least two reasons. First, the apology in the scenario, as written, was not particularly forceful . . . Second, it is likely that the force of an apology resonates more when it is expressed face-to-face than it is simply written down on a piece of paper. Given these limitations, it is surprising that our results are as strong as they are." Id. at 149.

101 See generally Robbennolt I, Robbennolt II, Robbennolt III, supra note 62.

102 Robbennolt I, supra note 62, at 483.

${ }^{103} \mathrm{Id}$. at $484, \mathrm{n} .112$. 
decisions of "litigants" and "lawyers" under various conditions, including more and less clear evidence of negligence, more and less severe injuries, and differing evidentiary rules governing the admission or exclusion of these types of statements.

Synthesizing the main findings from these studies, ${ }^{104}$ they can be summarized as follows: first, compared to defendants who made a partial apology or no apology, defendants who made a full, responsibility-accepting apology were far more likely to find the plaintiffs willing to accept their settlement offers. ${ }^{105}$ Consistent with earlier studies in non-legal contexts, full apologies not only positively influenced plaintiffs' perceptions of defendants (they were seen as more sympathetic and more moral, and were more likely to be forgiven), ${ }^{106}$ but also made plaintiffs more willing to settle. By contrast, partial apologies had little influence on plaintiffs' perceptions of the defendant or their amenability to defendants' settlement offers, except in cases of more serious injuries, clearer legal responsibility, or both-where they were shown to be counterproductive. ${ }^{107}$

Second, even where receiving a full apology caused plaintiffs to estimate their chances of success at trial more highly, they lowered their settlement targets and negotiating reservation ("bottom line") prices, and viewed defendants' settlement offers as more fair. ${ }^{108}$ This result is consistent with equity theory, which posits that perceptions of equity and fairness, not just objective fairness, play an important role in settlement. Quoting Russell Korobkin, "[a] settlement proposal that might be acceptable to a litigant who feels personally validated and fairly treated by her opponent, despite the legal dispute, may be unacceptable to a litigant who feels ignored, unheard, or invalidated by her opponent." 109 The flip side appears to be true as well: litigants may be willing to accept less than objective "settlement value" if they receive a full apology.

Third (and most provocatively), Professor Robbennolt found that full settlement apologies push plaintiffs' lawyers in a generally opposite direction

${ }^{104}$ Because of limitations of space, these findings are presented in a necessarily simplified form. Readers interested in the topic of apology would do well to read all three studies in their entirety, and in addition, Margereth Etienne \& Jennifer Robbennolt, Apologies and Plea Bargaining, 91 MARQ. L. REV. 295 (2007), containing a useful summary of the research.

105 Robbennolt I, supra note 62 , at $485-86,506$.

$106 \mathrm{Id}$. at $486-90$.

107 Id. at 494-99.

108 Robbennolt II, supra note 62, at 362-66.

109 Id. at 348 (quoting Russell Korobkin, Aspirations and Settlement, 88 CORNELL L. REV. 1, 17 (2002)). 
from their clients. Despite the fact that they viewed offenders making full apologies more sympathetically than those making partial (or no) apologies, "[a]ttorneys whose client received a full apology set somewhat higher aspirations and made somewhat higher estimates of a fair settlement value than attorneys whose client received no apology." 110 Attorneys, in other words, seem less influenced by equity concerns than their clients and less inclined to value apologies when made. 111 Professor Robbennolt hypothesizes that this may be because attorneys are trained to be more objective, less emotionally entangled, and more focused on legal rights and probable legal outcomes than their clients, among other reasons. ${ }^{-112}$

\section{Timing of Apologies and Other Matters}

Several additional apology findings seem potentially relevant to the work of mediators. First, Cynthia McPherson Frantz and Courtney Bennigson have examined the question of whether the timing of apologies influences their effectiveness. ${ }^{113}$ They hypothesized that, in general, later apologies would be more effective than earlier ones, because of ripeness issues influencing a victim's readiness to de-escalate a conflict. They further theorized that victims would in general want an opportunity fully to vent their feelings and express their point of view (be given "voice") before being open to receiving (much less accepting) an apology and forgiving their transgressor. These hypotheses were supported in both recall and scenario experiments they conducted.

${ }^{110}$ Robbennolt III, supra note 62, at 379-80.

111 Id. at $365-66$.

112 Id. at 365-69. A recent empirical study may provide additional indirect support for Robbennolt's findings regarding lawyers. Jean Poitras and his colleagues conducted a comparative analysis of workplace mediations with and without lawyers in Quebec Province, Canada. Contrary to expectations, they found that the presence of lawyers had no negative impact on settlement rates, mediation duration, or party satisfaction with the process or the outcome. However, they found that the presence of lawyers led to a statistically significant $(30 \%)$ reduction in the level of self-reported sense of reconciliation between the parties. They attributed this reduced level of reconciliation to (1) attorneys' tendency to focus on the legal, rather than the relationship-building, aspects of their cases; (2) their tendency to speak on behalf of their clients, rather than allowing them to speak for themselves; and (3) their reluctance to allow their clients to apologize. See Jean Poitras, Amaud Stimec \& Jean-Francois Roberge, The Negative Impact of Attorneys on Mediation Outcomes: A Myth or a Reality, 2010 NEGOTIATION J. 9 (2010).

113 Frantz \& Bennigson, supra note 56. 
Although it takes an offender to initiate an apology, it has been suggested that a victim must accept the apology for the exchange to be completed successfully and constructively. ${ }^{114}$ Researchers have begun to examine the conditions under which victims are most likely to accept an apology when offered. In two related studies, ${ }^{115}$ Seiji Takaku and his colleagues examined the efficacy of three perspective-taking strategies on victims' willingness to forgive their transgressors. ${ }^{116}$ They found that victims of a hypothetical interpersonal wrong (a classmate's three-hour delay in returning class notes before an important final exam) were significantly more likely to accept a (generous) apology from a transgressor if they were first asked to imagine themselves as a wrongdoer. Given an instruction that read, in part, "Please take a moment and visualize an event in which you broke a promise with, forgot to do something for, or intentionally/unintentionally hurt others in the past. Please try to remember how you thought, felt and behaved in that situation," victims had more positive perceptions of and feelings about the wrongdoer, and expressed a greater intent to forgive than in any of the other conditions.

On the other hand, some research suggests that, because of social norms (e.g., people may be viewed as churlish if they refuse to accept an offer of amends), victims will accept apologies (or at least not reject them publically) even when they think them inadequate or insincere. In one scenario study, even when subjects wanted to reject apologies they viewed as unconvincing, they indicated little intention to do so. ${ }^{117}$ And in the victim-offender field study previously discussed, actual victims reported feeling considerable pressure to accept apologies even when they perceived them to be insincere. ${ }^{118}$ From this perspective, apology exchanges may be somewhat effective in reducing interpersonal tensions even when they are ritualized and not entirely authentic.

\section{E. Effects of Apologies on the Apologizer}

114 Takaku, supra note 75, at 495 .

115 Id. See also Seiji Takaku, Bernard Weiner \& Ken-Ichi Ohbuchi, A Cross-Cultural Examination of the Effects of Apology and Perspective Taking on Forgiveness, 20 J. LANGUAGE \& SOC. PSYCHOL. 144, 149-50 (2001).

116 The three strategies were "recalling themselves as transgressor," "imagining how they would feel if they were the transgressor," and "imagining how the transgressor felt." In a fourth (control) condition, subjects were asked to "imagine the situation from your own perspective." Takaku, supra note 75, at 494.

117 See generally Bennett \& Dewberry, supra note 76.

118 Choi \& Severson, supra note 70 , at 818 (victim reported that telling the offender "No, I don't accept this" was never an option). 
Surprisingly, in contrast to all the empirical attention paid to the effects of apologies on recipients, comparatively little attention has been paid to the potential effects of making apologies on apologizers themselves. There are only two experimental studies of which we are aware, and their findings seem, at least at first blush, to diverge. In one experiment, researchers found that subjects asked to imagine themselves seeking forgiveness felt less sadness, anger, shame, and guilt - and correspondingly more hope-about themselves and their situation than those who simply thought about their transgressions. 119 Forgiveness-seeking imagery also produced positive physiological changes in subjects, including reduced muscle tension. ${ }^{120}$ In a second study, ${ }^{121}$ however, researchers found that at least in some settings, participant decisions ${ }^{122}$ to refuse to apologize increased their self-esteem and sense of power and control. Taken together, these studies underscore what is already well known to mediators: The psychology of apology is complicated. Clearly, more research into these effects is warranted.

\section{F. Mediation Questions and Applications}

While many of the foregoing findings may not seem surprising, for practicing mediators they raise as many questions as they answer. First, because of the complexity of apologies and party resistance to both making and receiving them, this form of persuasion often requires lengthy private caucusing sessions, in which apologies may have to have to be cajoled, rehearsed and then orchestrated in joint session by the mediator. Are apologies produced by such a process likely to be perceived as sincere? Are they apt to be effective?

Second, as to the impact of lawyers: The research seems to confirm what is often discussed half-jokingly ("There is no 1/3 contingent fee in an apology") among mediators: that the presence of lawyers may pose a

119 Witvliet, et al., supra note 71, at 224.

120 Id. at 227.

${ }^{121}$ See generally Okimoto et al., supra note 71.

122 In Study 1, university student participants were asked to imagine a scenario in which a campus food services cashier mistakenly gave them extra $\$ 10$ in change, which they kept. They were then discovered to have taken the extra money and required by the cashier to return it, and also asked to apologize. Study 2 utilized a recall methodology, in which participants were asked to recall their reactions to a personal situation in which "you did something that upset someone," whether or not it was your fault, and either apologized or did not. (emphasis added). In both studies, we would note, the participants' culpability was either shared with another person or unclear, increasing the likelihood that they might resist giving an apology. Id. 
significant impediment to harnessing the power of apology. But why? Is it a generalized reluctance to make an apology, for fear that if the mediation should fail, it will be viewed as an admission of liability (defense lawyers)? A concern that it will make one's clients less assertive than they would otherwise be in vindicating their rights, resulting in possible long-term regret about any settlement that is reached? (Both plaintiffs and defendants)? A concern about fees (both sides, but especially plaintiffs' personal injury lawyers)? A blind spot, based on the limitations of their training, to all things non-legal and non-monetary? A "total zeal" definition of their ethical responsibilities? Some of these concerns might be overcome by the mediator's working with counsel separately in advance of the mediation. But it would be useful to know more about why lawyers and apologies "don't mix."

It is noteworthy that, like much of the empirical work on this topic, Professor Robbennolt's study examined lawyers' reactions to unprompted, unilateral, "full legal admission" ("I want to let you know how sorry I am. The accident was my fault.") sorts of apologies which, experience suggests, are comparatively rare in mediation. What about apologies in more typical cases, where there is evidence of fault and responsibility on both sides? Might it be easier to persuade lawyers to accede to an apology in situations where an exchange of apologies is possible? Might their advice to a client change if instead of having to make a unilateral apology, both sides' willingness to admit some fault might prompt a mutual softening of positions and ease resolution? Mediators might be able to point out these advantages when working with lawyers.

What about apologies that address intangible harms and interests, but do not go directly to the legal merits? There are many potential gradations here, ranging from purely "social" sorts of apologies (e.g., lawyer to opposing party: "I'm really sorry that I kept you waiting almost an hour for the deposition last week. I know you were busy and I'm sure it screwed up your day.") to apologies for acts that do not directly establish legal liability, but nonetheless might hold sway if testified to in court (e.g., "I want to acknowledge the impersonal way you were laid off, after so many years of service to the company. We handled it very badly and we truly regret it.") We would hypothesize that the less an apology goes to the merits of a claim or defense, the more open most lawyers would be to allowing it to be made. Further investigation of these and other variables that arise in "lawyered" disputes would be useful.

Frantz \& Bennigson's findings ${ }^{123}$ on the optimal timing for apologies

123 See supra text accompanying note 112. 
(not too early, and after the injured person has had an opportunity fully to vent his feelings and tell his story) are consistent with the procedural justice literature on the importance of "voice" in fairness judgments and disputing, ${ }^{124}$ as well as with everyday experience in interpersonal conflicts (e.g., "Your apology is all well and good. But I'm not ready to forgive you yet."). The research has not examined the circumstances under which an apology might be offered too late to be helpful in resolving mediated disputes. Is there a point after which apologies begin to lose their persuasive power? For example, once serious bargaining begins over money or resources, do attempted apologies begin to look like tactical ploys and thus seem insincere to the recipient?

The scant research on the effects on apologizers of making amends leaves open many important questions for mediators-perhaps especially those who might see the active orchestration of an apology from a reluctant party as excessive mediator intervention. We would hypothesize that an apology — even or perhaps especially from a reluctant apologizer - would in many cases have a significant persuasive effect on him or her, and could induce a softening in negotiation stance. There are a number of reasons why this might be so. Like role reversal, the act of apologizing can be seen as an exercise in counter-attitudinal advocacy, with the resistant disputant led to consider (and articulate) his own contribution to a dispute and its impact on another person-thoughts and feelings that are unlikely to be paramount in his mind because of anxiety about legal exposure, denial, shame or other inhibitions. Goffman's theoretical work suggests that helping a disputant separate his past (regrettable) acts from his essential (positive) selfhood may be a highly effective form of self-persuasion. Cognitive dissonance scholars have found that dissonance effects are strongest (and self-persuasion greatest) when a person's actions are inconsistent with his or her self-concept of being a good person. ${ }^{125}$ Given the lasting attitude changes that other

124 See, e.g., E. Allan Lind \& Tom R. Tyler, The Social Psychology of ProCedURAL JUSTICE (1988); Robert Folger, Distributive and Procedural Justice: Combined Impact of Voice and Improvement on Perceived Inequity, $35 \mathrm{~J}$. PERSONALITY \& Soc. Psychol. 108 (1977); E. Allan Lind, Ruth Kanfer \& P. Christopher Earley, Voice, Control, and Procedural Justice: Instrumental and Noninstrumental Concerns in Fairness Judgments, 59 J. Personality \& Soc. Psychol. 952 (1990). See also, generally, Nancy A. Welsh, Disputants' Decision Control in Court-Connected Mediation: A Hollow Promise Without Procedural Justice, 2002 J. DISP. RESOL. 179 (2002).

125 Quoting Aronson, supra note 22, at 876: "The theory most associated with the phenomenon of self-persuasion is Leon Festenger's theory of cognitive dissonance . . [which] states that dissonance (an unpleasant feeling) is aroused when an individual says or does something that runs counter to his or her own beliefs, especially if this action 
role-playing experiments have demonstrated, ${ }^{126}$ this topic seems ripe for further study.

Research into why people resist apologizing and how apologizers respond to their own acts of contrition might even shed light on the question of "orchestrated" apologies. If a disputant's resistance is based on guilt or shame associated with behavioral lapses that have harmed others, might the ritual act of apologizing-especially if greeted by acceptance-lead such inhibiting feelings to abate, and actual (if previously denied) remorse to surface and be felt? Viewed this way, a skilled mediator's intervention in appropriate situations might convert an apparently "fake" apology by a reluctant disputant into a genuine one.

Finally, while empirical research suggests that apologies hold the promise of inducing significant attitude changes, helping parties express and receive apologies effectively requires a rather sophisticated diagnostic, intuitive and interpersonal skill set. This suggests that, to a greater extent than other modes of persuasion surveyed in this article, working effectively with apologies may require specialized training or cross-disciplinary collaboration for most mediators.

\section{PeRsuasion By RHETORICAL Questioning}

Suppose you have been unable to persuade the participants in the Halverson matter to engage in a meaningful apology exchange. The defendants reluctantly agreed to improve their offer to $\$ 20,000$ to settle the case, an amount that the plaintiff immediately and emphatically rejected. You sense that pointing out the company's liability risks and its costs of proceeding to litigation-interventions you have sought to avoid up to now-are the best (and perhaps only) hope of obtaining further movement towards a settlement.

In considering how to try to accomplish this, two possible approaches have occurred to you:

(A) Tell the defendants the legal and factual weaknesses and costs as you see them. ("From where I sit, this case will almost surely get to a jury. She makes a very good witness. And especially if those sexist remarks come into evidence you could be facing substantial exposure-including counsel fees." or "Merits aside, a hearing officer or jury may not like the way you laid her

threatens the individual's self-concept of being a decent or rational person (emphasis added). To reduce dissonance, people will try to bring those disparate cognitions into greater harmony."

${ }^{126}$ See supra text accompanying note 31 . 
off.")

(B) Ask them questions that suggest the legal risks you see ("Aren't you concerned with how a jury might react if the supervisors' sexist remarks come into evidence?"), the costs of going forward ("Is it really in your interest to have the commission's investigators coming to your offices, interviewing your staff, and combing through your files?"), or both.

If you prefer alternative (B), you have lots of company. "The widely accepted persuasive technique of asking, then answering the question posed, is deeply rooted in Western rhetorical tradition. Demetrius advised rhetors to build force by asking audiences questions without giving answers . . . . Consistent with this rhetorical legacy, modern persuaders receive advice to use rhetorical questions to affirm or deny a point by asking an emphatic question to which no overt answer is expected."127

A leading divorce text describes question-asking as "the core technique [of counselors and mediators]" and a "more widely acceptable mediational approach [than making statements]."128 Many mediation theorists echo this view. Professor Lela Love, in discussing the mediator's duty to assure that participants are making fully informed decisions, captured it this way: "asking questions [regarding possible legal outcomes] comports with the mediator's role, but giving or suggesting answers does not."129

Why do so many mediators prefer to ask questions rather than make statements when seeking to persuade? For some, this grammatical form is a matter of ideology: in general, questions seem less argumentative or pressuring-qualities that are anathema to widely-accepted norms of mediator neutrality and party self-determination. In addition, when statements pertain to probable legal outcomes, some mediators and theorists fear they may amount to providing legal advice, which they view as improper. ${ }^{130}$

${ }^{127}$ Barbara Mae Gayle, Raymond W. Preiss \& Mike Allen, Another Look at the Use of Rhetorical Questions, in PERSUASION: AdVANCES Through META-ANALYSIS 189 (Mike Allen \& Raymond W. Preiss eds. 1998).

128 JAy Folberg, ANn Milne \& Peter SAlem, DivorCe and Family MEdiation: MODELS, TECHNIQUES AND APPLICATIONS 86 (2004).

129 Symposium, Standards of Professional Conduct in Alternative Dispute Resolution, 1995 J. DiSP. RESOL. 95, 108 (1995) (comments of Lela Love).

130 As we have written elsewhere, attempts to distinguish providing parties appropriate legal "information" from (arguably inappropriate) legal "advice" are inherently problematic, and regulatory efforts to ensure that non-lawyer mediators providing evaluative mediation do not engage in the unauthorized practice of law are greatly complicated by the fact the "practice of law" is defined very differently in different jurisdictions. See James H. Stark, The Ethics of Mediation Evaluation: Some Troublesome Questions and Tentative Proposals, from an Evaluative Lawyer Mediator, 38 S. TEX. L. REV. 769, 784-88 (1997); FRENKEL \& STARK, supra note 5, at 333-35. 
For other neutrals, not ideologically opposed to evaluation per se, asking questions may provide a measure of comfort: doubt can be sown without having to make definitive predictions in an unpredictable legal world. Still others may view questions as being more likely than statements to engage a subject, or less likely to trigger resistance to the persuasive effort.

In considering the efficacy of rhetorical questioning as a mode of persuasion, we should make clear at the outset what we are and are not talking about. Research demonstrates that most effective persuasion is done with others, not $t o$ them. Competent adults generally cannot be persuaded to do something unless they want to do it. Effective persuasion is therefore an interactive process, in which the persuader must work closely with her subject to evaluate whether the advantages of taking a certain course of action outweigh the disadvantages. ${ }^{131}$ In general, questioning and dialogue are vital parts of that process. 132

Here, however, we are concerned with the efficacy of a more narrow, but nonetheless commonly employed, form of mediator questioning: the highly suggestive rhetorical question, i.e., one whose answer is implicit and understood by the receiver, and to which no overt response is expected. Such questions are sometimes planted by mediators acting as "agents of reality" in order to sow doubt, and hopefully, attitude change. ${ }^{133}$

What do we actually know about the relative effectiveness of such questions-as compared to statements--in changing attitudes? Research concerning the effectiveness of rhetorical questioning in persuasion is not as rigorous or uniform as one might like. Nonetheless, it tends to suggest that in settings like mediation, rhetorical questions may not be effective as a persuasion device, and under certain circumstances may even be counter-productive.

\section{A. Rhetorical Questions and Cognitive Elaboration}

A key determinant of the success of an attempt to persuade is the extent to which the message causes the subject to think about or "elaborate" on its

131 FRENKEL \& STARK, supra note 5, at 228.

132 See Kolb, supra note 14 , at 472-73 (quoting Lawrence Susskind for the proposition that "questioning is a way to teach without lecturing.")

133 Even within this definition, there are a range of question forms and tones that-viewed in their context-can serve this function. "How do you think a judge will rule?" or "Have you talked with a lawyer about your case?" are questions that may seem open-ended and free from suggestion. But, if, for example, they followed or preceded a discussion of case weaknesses, or were asked in a skeptical tone, they might be highly suggestive of the mediator's views. 
argument content. ${ }^{134}$ According to this view, greater cognitive elaboration should yield more positive and negative thoughts about a message, either increasing or decreasing its persuasive effect on attitudes depending on how strong or weak the message is. Where a message-especially a counter-attitudinal one that challenges a recipient's existing view-contains strong arguments, persuasion is enhanced by maximizing the recipient's thinking about those arguments. Early researchers hypothesized that questions are superior to statements in encouraging the subject to continue to think or be curious about the arguments that have preceded or will follow the question (or, where the question is a rhetorical one, that may be imbedded in the question itself). And indeed, some earlier research indicated that questions elicit more cognitions than statements. ${ }^{135}$

It was later found, however, that this elaboration effect may be limited to "low involvement" subjects. ${ }^{136}$ Where (as in mediation) the recipient is already "high involvement"-i.e., personally affected by and likely already to be engaged in deep thought about the subject matter of message-a rhetorical question may serve as a distraction that can interfere with message elaboration and reduce persuasion.

In one well-known study, ${ }^{137}$ undergraduates were presented with both stronger and weaker audio-taped arguments in favor of a proposed comprehensive pre-graduation examination, which culminated in either a statement summarizing the arguments or a rhetorical (leading) question suggesting a conclusion. The goal was to measure which grammatical format-statement or question-would yield the most elaboration of the persuasive message.

Where students had low involvement in the subject matter (the exam would be introduced at another school, not theirs) questions yielded more thoughts (positive thoughts when accompanied by strong arguments; negative thoughts when accompanied by weak ones) than statements. But

134 This is known as the elaboration likelihood model of persuasion. See Richard E. Petty \& Duane T. Wegener, The Elaboration Likelihood Model: Current Status and Controversies, in DuAL Process THEORIES IN SOCIAL PsyChology 41 (Shelly Chaiken \& Yaacov Trope eds., 1999).

135 Dolf Zillmann \& Joanne R. Cantor, Rhetorical Elicitation of Concession in Persuasion, 94 J. Soc. PSYCHOL. 223 (1974); Dolf Zillmann \& Joanne R. Cantor, Induction of Curiosity Via Rhetorical Questions and its Effect on the Learning of Factual Materials, 43 BRIT. J. EDUC. PSYCHOL. 172 (1973).

${ }^{136}$ Richard E. Petty, John T. Cacioppo \& Martin Heesacker, Effects of Rhetorical Questions on Persuasion: A Cognitive Response Analysis, 40 J. PERSONALITY \& SOC. PSYCHOL. 432, 439 (1981).

${ }^{137}$ Id. 
where students were high involvement-they had a stake in the result because the exam would be given to them - the rhetorical question distracted them from their argument processing and actually reduced the level of cognition about the persuasive message. ${ }^{138}$

\section{B. Rhetorical Questions, Source Assessment and Persuasion}

Rhetorical questions can also have the effect of focusing attention on the source of the persuasion in ways that may undermine persuasive efforts. One illustrative study —of reactions to advertisements for running shoes-sought to measure whether the grammatical form of the persuasive effort (statements vs. questions) affected perceptions of the message source and its tactics. ${ }^{139}$ To introduce the source emphasis, subjects were given information about the shoe company (one group was told the company was socially responsible, the other that it was not). One version of the ad made use of questions, the other only statements, to convey the same message content.

Subjects who had "persuasion knowledge"-were knowledgeable about or sensitive to persuasion tactics--found the use of questions (as compared to the more straightforward or direct approach of using statements) to be a deviation from their expectations. That reaction led them to try to understand that deviation in terms of the advertiser's motives, i.e., they focused more on the source and its tactics than the message content. And where their assessment of the message source was unfavorable, subjects exposed to questions were less persuaded and perceived the advertiser to be significantly more pressuring (and its tactics less appropriate) than those who read the same message in statement form. ${ }^{140}$

A pair of experimental studies by John Swasy and James Munch attempted to synthesize some of the early research by comparing the impact of rhetorical questions versus statements on cognitive elaboration, source

138 Id. at 438 .

139 Rohini Ahluwalia \& Robert E. Burnkrant, Answering Questions about Questions: A Persuasion Knowledge Perspective for Understanding the Effects of Rhetorical Questions, 31 J. CONSUMER RES. 26 (June 2004).

${ }^{140} I d$. at 32 . The authors add that the advertising message content can itself affect perceptions of its source, with comparative ads and fear appeals tending to produce negative source evaluations. Id. at 40 . Others have suggested that rhetorical questions might affect perception of the source of the message positively, by making the speaker either seem warmer or less assertive. See, e.g., Nora Newcombe \& Diane B. Arnkoff, Effects of Speech Style and Sex of Speaker on Person Perception, 37 J. PERSONALITY \& SOC. PSYCHOL. 1293 (1979). 
assessment and overall persuasiveness. ${ }^{141}$ Replicating and extending earlier studies testing high vs. low involvement students' attitudes about a required college comprehensive exam, ${ }^{142}$ they found, among other things, that: (a) fewer message arguments were recalled when rhetorical questions rather than statements were used in high involvement situations; (b) questioners were perceived as less expert-but no more polite-than statement makers in strong argument conditions; and (c) the use of a series of rhetorical questions (rather than only one) increased the perception of pressure, increased subjects' derogation of the source, and (most importantly) reduced message acceptance.

\section{Mediation Applications and Questions}

While some of this data may raise doubt about the conventional wisdom of using questions rather than statements to persuade, the overall picture is far from conclusive. Researchers have not agreed on any common definition or schema for rhetorical questions. For example, is there one only form of rhetorical question or are there many? ${ }^{143}$ Researchers have reached differing conclusions about the persuasive effect of rhetorical questions, but they have studied different grammatical question forms, different placement (e.g. as an introduction versus as a conclusion) of rhetorical questions in an argument and different frequency of rhetorical question usage in an argument, all of which may have affected their results. ${ }^{144}$

Most of the experimental settings discussed above also involved strictly rhetorical questions in the sense that no response was expected-or indeed even possible - within the research design. Few mediators (in contrast to mass advertisers or jury trial lawyers) would attempt such a non-interactive form of persuasion, given the intimate face-to-face setting in which they

141 John L. Swasy \& James M. Munch, Examining the Target of Receiver Elaborations: Rhetorical Question Effects on Source Processing and Persuasion, $11 \mathrm{~J}$. CONSUmer Res. 877 (1985); James M. Munch \& John L. Swasy, Rhetorical Question, Summarization Frequency, and Argument Strength Effects on Recall, 15 J. CONSUMER RES. 69 (1988).

142 Petty, Cacioppo \& Heesacker, supra note 136.

143 See, e.g., Gayle, Preiss \& Allen, supra note 127, at 190.

144 As one meta-analysis put it: "Aggregated effect sizes indicate that rhetorical questions are not potent persuasive tools. However, the host of related message feature [variables] preclude us from asserting that rhetorical questions disrupt the production of thoughts to distract the receiver, exert social pressure on the receiver to conform, direct the receiver's attention to opposing arguments, or do not create a minimal intent to persuade." Id. at 198. 
work. Moreover, when mediators use questions to persuade, the context--the stage of the proceedings (often late, with limited time remaining), earlier information or arguments (often including the opponents' arguments) from which the questions stem, previous efforts to persuade and the subject's reactions to them, how authoritative the neutral appears, how savvy about persuasion the recipient is-may all affect how a participant perceives even an innocuous or objectively open-ended question, much less a leading or suggestive one.

Many of these studies compared the effects of rhetorical questions to comparable statements when used in conjunction with persuasive arguments. But some mediators are reluctant to use "arguments" at all. What about the relative merits of just questions versus just statements without accompanying (before or after) arguments? 145

Assuming that the use of rhetorical questions poses at least some risk of undercutting persuasion, mediators who seek to use questions to sow doubt might be advised first to seek to lower a subject's ego involvementlessening how much he feels directly affected by or cares about a particular outcome-so as to open him up to thinking about the message. This might be done by attempting to foster empathy for the other side, developing attractive, alternative ideas for settlement, re-framing to highlight positives, lowering perceived stakes, and other similar interventions.

To reduce the potential for questions to appear as deviations from what is expected (with the attendant risk of turning the focus toward the source and his tactics), mediators might also do well to prepare participants for their use in advance. (For example, in a divorce mediation: "Ms. Avery, it's my job to make sure you've really considered all the ways that this situation might look to a judge. By asking you some questions, it's my hope that they will prompt you to put aside for a moment your views of the right outcome and consider other possibilities .... Now a few minutes ago, you said that Mr. Avery had worked two jobs to pay your nursing school tuition. Do you really think he'll only get $10 \%$ credit for his economic contributions when it comes time to divide up the equity in your home?") But might not such transparency also increase anticipation, and thus resistance and counter-arguing? ${ }^{146}$

145 Some older research, which is far from accepted, suggests that we are conditioned to associate rhetorical or leading questions with strong (embedded) arguments and thus such questions will be more persuasive than statements making the same arguments. See Dolf Zillmann, Rhetorical Elicitation of Agreement in Persuasion, 21 J. PERSONALITY \& SOC. PSYCHOL. 159 (1972).

146 See, e.g., William L. Benoit, Forewarning and Persuasion, in PERSUASION: AdVANCES Through Meta0ANalysis 146 (Mike Allen \& Raymond W. Preiss, eds., 1998) (Meta-analytic study concluding that "[f]orewarning an audience to expect a 
Despite some methodological limitations of this body of research, persuasion by narrow, suggestive questioning seems at the very least risky. The risk of a party's focusing on the persuader and his tactics rather than the message may raise particular challenges when used by (ostensibly-neutral) mediators. A mediator's rhetorical questions are often indirect evaluative efforts to overcome overconfidence by instilling doubt or even fear. Can such "negative" appeals, especially since they may also be seen as indirect endorsements of the opponent's stance, by themselves lead to lowered assessment of the source (the mediator) and, in turn, lowered odds of persuasion? ${ }^{147}$ If so, straightforward statements may be the best form of evaluation.

\section{PERSUASION BY DiRECT STATEMENTS}

Suppose that in the Halverson case, an evidentiary dispute has arisen between the lawyers about the significance and likely admissibility into evidence of the episode in which Ms. Halverson publicly "disrespected" her supervisors after initially being passed over for promotion. Ms. Halverson's attorney argues that while this episode was certainly unfortunate, it is inadmissible, inasmuch as the defendant has alleged in its pleadings that "purely economic considerations" prompted the company to lay Ms. Halverson off, not alleged poor relations with supervisors or a lack of on-the-job diplomacy. The company's attorney calls this argument "hyper-technical," adding that a host of job performance factors-including the plaintiff's mercurial temperament and growing job dissatisfaction after she was passed over for promotion - went into the decision to let her (and not someone else) go in a severe economic downturn.

At this point in the mediation, the plaintiff has lowered her demand to $\$ 80,000$ to settle the case. You believe that her position on the inadmissibility of this evidence is unrealistic and have offered to give her and her lawyer, in caucus, some feedback on that point. They have indicated receptivity to hearing your views. When you do so, what form of statement is likely to be most persuasive? Consider the following options:

(A) A one-sided statement of your views, with reasons briefly stated. ("The standard of relevance is, as you know, very broad. My opinion, unfortunately, is that this episode is relevant and admissible to show why the company chose your client in particular to lay off in an admittedly tough economic climate.")

persuasive message tends to make that message less persuasive.").

${ }^{147}$ See Ahluwalia \& Burnkrant, supra note 139 , at 39-40. 
(B) A two-sided message, which acknowledges arguments on both sides of the question, but does not take a position between them. ("There is no doubt that the inconsistency between the defendant's claim in their answer that they acted solely for business reasons and the position they are taking now raises questions, and you can argue their lack of credibility at a hearing. And it's possible that a hearing officer would go so far as to bar them from clarifying their position at trial. But it's also quite possible that the defendant's answer in the case would not preclude them from clarifying or even modifying their story at trial. As you know, the standard of relevance is very broad.")

(C) A two-sided message, which acknowledges arguments on both sides of the question, and explains briefly why one side is more likely to prevail than another. "There is no doubt that the inconsistency between the defendant's claim in their answer that they acted solely for business reasons and the position they are taking now raises questions, and you can argue their lack of credibility at a hearing. And it's possible that a hearing officer would go so far as to bar them from clarifying their position at trial. But unfortunately, I think that is extremely unlikely. After all, saying that they acted for reasons of business exigency does not logically preclude them from arguing that they also acted for performance-based reasons. When cuts need to be made for business reasons, employers usually consider performance in deciding which particular employees to lay off. And, and as you know, the standard of relevance is very broad.")

(D) A two-sided message, which gives detailed and explicit reasons why one side is more likely to prevail than another, and also provides explicit conclusions that flow therefrom. ("There is no doubt that the inconsistency between the defendant's claim in their answer that they acted solely for business reasons and the position they are taking now raises questions, and you can argue their lack of credibility at a hearing. And it's possible that a hearing officer would go so far as bar them from clarifying their position at trial. But unfortunately, I think that is extremely unlikely. After all, saying that they acted for reasons of business exigency does not logically preclude them from arguing that they also acted for performance-based reasons. When cuts need to be made for business reasons, employers usually consider performance in deciding which particular employees to lay off. And, even if their statements are viewed as inconsistent, the United States Supreme Court has recognized, in St. Mary's Honor Center v. Hicks, that when a defendant in an employment discrimination case takes a position in the pleadings that is inconsistent with the position it later takes at trial, this does not necessarily raise an inference of unlawful discrimination. A defendant in an employment discrimination case may conceal its true position in a pleading 
simply because it did not want to have to say anything personal or negative about the plaintiff. That could be what happened here. Unfortunately, I think the whole embarrassing episode will come in, and a hearing officer-or jury, if this case ends up in court-will hear all about it.")

Perhaps the answer is obvious, but if you chose option D, empirical studies tell us you are correct. "Two-sided refutational messages"-messages that present two (or more) sides to an issue or question, but then present reasons why one side is more persuasive than the other(s)-are more persuasive than either one-sided messages or two-sided, non-refutational messages. In addition, explicit arguments-arguments that state explicit reasons for a conclusion and describe those conclusions in detail-are more persuasive than arguments with implicit reasons and/or implicit (or no) conclusions.

\section{A. Message "Sidedness"}

Is it effective for persuaders to go beyond their own points of view and both acknowledge and refute opposing arguments? Empirical research on message sidedness is substantial, dating back more than sixty years. A 1999 meta-analytic review summarizes and analyzes persuasion effects from 107 investigations of the topic, involving more than 20,000 respondents. ${ }^{148}$

This review analyzes a wide variety of variables, including the effect of message sidedness on perception of messenger credibility vs. effect on actual persuasion outcome; differential effects of message sidedness for consumer advertising vs. non-advertising messages (messages typically involving political or social questions, as to which respondents-as in mediation-may have strong opinions); whether the two-sided message is refutational (e.g., one that "attacks the plausibility of opposing arguments") or non-refutational (one that "acknowledges the opposing considerations, but does not attempt to refute them directly"); and the ordering of the message (supporting arguments, then opposing ones? Opposing arguments, then supporting ones? Interwoven discussion of supporting and opposing arguments?)

The principal findings of this study are as follows: First, there is, overall, "no dependable difference in persuasive effectiveness between one-sided and two-sided messages."149 However, refutational two-sided messages enjoy "a

148 See Daniel O'Keefe, How to Handle Opposing Arguments in Persuasive Messages: A Meta-Analytic Review of the Effects of One-Sided and Two-Sided Messages, 22 COMM. Y.B. 209-49 (1999), (listing studies). Another useful meta-analytic review is Allen, supra note 18 at $87-98$.

${ }^{149} \mathrm{O}$ 'Keefe, supra note 148, at 218. 
dependable persuasive advantage over one-sided messages."150 This effect is especially strong for non-advertising messages. 151 By contrast, non-refutational two-sided messages are "significantly less persuasive than their one-sided counterparts," both for advertising and non-advertising messages. ${ }^{152}$ Finally, the ordering of a message does not appear significantly to affect its persuasiveness. ${ }^{153}$

The author discusses the fact that one might expect refutational two-sided arguments to be less persuasive than non-refutational arguments because they might appear to involve greater pressure to adopt the persuader's position, and thereby arouse reactance (a desire to fight back and thereby establish one's decisional autonomy) in the recipient. ${ }^{154}$ Why is this not borne out by the research? Do refutational arguments convey greater authoritativeness? Do non-refutational messages "[leave] open the possibility that an opposing view may have some merit"? ${ }^{155}$ Or that the speaker lacks confidence? These questions and others warrant further research, but the review concludes: "in non-advertising contexts, persuaders would generally be well-advised to employ refutational two-sided messages in preference to one-sided or non-refutational two-sided messages. In such contexts, refutational messages enjoy ... . significantly greater persuasiveness than do one-sided messages, and non-refutational messages are dependably less persuasive than one-sided messages." 156

Researchers have also extensively investigated both argument justification explicitness and conclusion explicitness and their persuasive effects. Two articles provide very useful meta-analytic summaries of each of these lines of research. ${ }^{157}$

${ }^{150}$ Id. See also Allen, supra note 18 (1998 meta-analysis reaching generally similar conclusions).

151 O'Keefe, supra note 148 , at 231.

152 Id. at $218-19$.

$153 \mathrm{Id}$. at 219 . In the discussion section of his article, the author also notes with interest the "absence of a general parallelism between effects on persuasiveness and effects on credibility." It might be thought, for example, that two-sided messages are more persuasive than one-sided messages because, by presenting two or more sides of a question, a persuader appears balanced and fair, thereby enhancing her credibility with her subject. But messenger credibility is not the only factor influencing overall message persuasiveness. Id. at 233-34.

154 Id. at 235, citing BREHM \& BREHM, PSYCHOLOGICAL REACTANCE: A THEORY OF FREEDOM AND CONTROL (1981).

${ }^{155} \mathrm{Id}$.

$156 \mathrm{Id}$. at $238-39$.

157 Daniel J. O'Keefe, Justification Explicitness and Persuasive Effect: A 


\section{B. Argument Explicitness}

Most communication theorists believe that argumentative explicitness (rather than evasion and concealment) is desirable as a normative matter in argument. ${ }^{158}$ But a person interested in persuasion might nonetheless legitimately fear that, rather enhancing persuasive effect, more explicit arguments impair persuasive effect, by making more obvious what claims are being advanced and thereby "enlarg[ing] the apparent 'disagreement space."'159 Are explicit messages more credibility-enhancing or persuasive than those that are not? One meta-analytic review concludes that in general, "advocates have little to fear from making their argumentative support explicit."160

The author focuses on three aspects of argumentative explicitness: the explicitness with which the advocate identifies the source of information and opinion relied on; the completeness of the arguments themselves (explicit articulation of premises, supporting information, etc.); and "quantitative specificity" (e.g., "seventy-five percent of the cases I have volunteered to mediate have settled" versus "Most of the cases I have volunteered to mediate have settled.") The data analysis suggests that arguments that (a) explicitly reveal their sources or (b) provide more explicit argumentative support "are significantly more credible and significantly more persuasive than their less explicit counterparts."161 Surprisingly, quantitatively explicit

Meta-Analytic Review of the Effects of Varying Support Articulation in Persuasive Messages, 35 ARGUMENTATION \& ADVOCACY 61 (1998) [hereinafter Justification Explicitness] (23 investigations, 5,358 participants); Daniel J. O'Keefe, Standpoint Explicitness and Persuasive Effect: A Meta-Analytic Review of the Effects of Varying Conclusion Articulation in Persuasive Messages, 34 ARGUMENTATION \& ADVOCACY 1, 6 (1997) (32 investigations, 13,754 participants) [hereinafter Standpoint Explicitness]. On the difficulties of accurately measuring explicitness in argumentation, see generally, Stefanie Alexa Stadler, Coding Speech Acts for their Degree of Explicitness, $43 \mathrm{~J}$. PRAGMATICS 36 (2011).

158 O'Keefe, Justification Explicitness, supra note 157, at 61. See, e.g., also, DEIDRE D. Johnston, The ART \& SCIENCE OF PERSuASION 53-54, 59 (1994) (arguing that ethical persuasion is characterized by honesty, directness and disclosure of relevant information, rather than false pretenses and evasion).

${ }^{159}$ O'Keefe, Justification Explicitness, supra note 157.

$160 \mathrm{Id}$. at 68.

${ }^{161}$ A caveat that O'Keefe notes is that these effects most probably depend on the character and quality of the articulated support. However, there is not much research on this point, as most of the research studies involve plainly relevant arguments advanced by likely high credibility sources. He calls for more research on this question. Id. at 68-69. 
arguments are not more credible or persuasive than qualitative arguments, at least not in a statistically significant way.

What is the most likely explanation for these effects? One hypothesis is that explicit arguments are more persuasive because they enhance the credibility of the speaker. That is, receivers might be thought to use a credibility heuristic to evaluate the persuasiveness of a message. However, the data does not appear to support this "explicitness-as-credibility heuristic" analysis. ${ }^{162}$ Alternatively, it may be the case that "explicit supporting argumentation directly enhances belief in the relevant supporting argument and thereby makes the message more persuasive."163 But here too the data is inconclusive. Overall, the research thus far has not isolated specific properties that make explicit arguments more or less persuasive. ${ }^{164}$

\section{Conclusion Explicitness}

A second meta-analytic review examines another aspect of argumentative explicitness: "the degree of articulation given to the advocate's overall conclusion."l65 Examining the research in the field, the author of the study notes that there are two bodies of research relating to this question and two ways that an argument's conclusion could be considered inexplicit: (a) by omitting any conclusion at all ("conclusion omission" studies) or (b) by stating a conclusion in a non-specific way ("conclusion specificity" studies). ${ }^{166}$

"It is an empirical question," the author writes, "whether argumentative explicitness inevitably sacrifices instrumental success." Those who seek to persuade might legitimately fear that more explicit conclusions are less persuasive because they could (a) increase "disagreement space" (as discussed in the previous study), or (b) cause "boomerang effects," either by insulting an audience with obvious messages, or by causing anger if the message is perceived as "aggressive, insistent or directive." This might in turn induce reactance in the recipient-a "motivational state of mind aimed at reestablishing freedom of action." 167 Conversely, an advocate might suppose that a less explicit message is more persuasive because it stimulates the

\footnotetext{
$162 \mathrm{Id}$. at $70-71$.

163 Id. at 71 , emphasis added.

${ }^{164} \mathrm{Id}$. at 71-72.

165 O'Keefe, Standpoint Explicitness, supra note 157, at 1.

166 Id. at 3-5.

167 Id. at 2 .
} 
audience's active participation, requiring them to "fill in the blanks."168

Analyzing eighteen studies involving conclusion specificity, with a total of 11,105 participants, and fourteen studies involving conclusion omission, with a total of 2649 participants, the review concludes first, that messages with explicit overall conclusions are significantly more persuasive than messages without conclusions; and second, that messages with more specific conclusions are significantly more persuasive than messages with generalized conclusions. Although sample sizes were small, these effects seem to hold true irrespective of a recipient's pre-existing (favorable or unfavorable) viewpoints-i.e., they apply even when message recipients are "dug in" against a persuasive message. ${ }^{169}$

Why are less explicit arguments less persuasive? The receiver may misperceive a less explicit message-assuming either that it is more similar to his own view than it actually is (and therefore less attitude change is necessary); or conversely that it is more discrepant from his own than it actually is (which might induce reactance and make the message less persuasive). ${ }^{170}$ Alternatively, specific conclusions-detailed descriptions of a suggested course of action-may be more persuasive because they better enable the message recipient to imagine future behavior that is different from previous behavior. This is in accord with a line of research suggesting that "imagining future behavior" makes that behavior more likely by increasing perceived behavioral control. ${ }^{171}$ The author of the study concludes: "When normatively-good argumentative practices interfere with persuasive success, advocates will face the unhappy choice of being good and being effective." But advocates face no such difficult choice because argumentative explicitness, considered a normative good, is also persuasive. ${ }^{172}$

168 Id.

${ }^{169} \mathrm{Id}$. at 7 . O'Keefe editorializes that these outcomes demonstrate the value of meta-analytic analyses: Whereas individual studies sometimes don't demonstrate these effects, when the effects of individual studies are combined, the statistical significance of the cumulative findings is very strong. Id. at 7-8.

${ }^{170}$ Id. at 8-9. See also Michael G. Cruz, Explicit and Implicit Conclusions in Persuasive Messages, in ALLEN \& PREIss, supra note 18 at 217-30 (Meta-analytic review, concluding that explicit messages were slightly more persuasive than implicit ones, even with highly involved subjects, and arguing that explicit messages seem to be better understood by recipients and therefore more likely to persuade. Furthermore, contrary to conjecture by many previous authors, explicit conclusion drawing does not negatively affect perceived source credibility.).

171 O'Keefe, Standpoint Explicitness, supra note 157, at 9.

$172 \mathrm{Id}$. at 10 . 


\section{Mediation Applications and Questions}

What applicability might these findings have to the work of mediators? It might be argued that disputants in mediation will generally be more resistant than "typical" persuasion subjects to explicit refutational statements because of the expectation of strict impartiality and neutrality by their mediator. While there may be specific mediation cultures in which this is true (and a mediator who promises the parties that she will not make legal statements or predictions may face party resistance-and reactance-if she attempts to do so thereafter), we doubt that it is true as a general proposition. Studies tend to show that many disputants want and expect feedback and evaluation from their mediators. ${ }^{173}$

The general findings about the persuasiveness of explicit messaging should have considerable potential significance for mediators, who, for a variety of reasons, may tend to "pull their punches" in delivering messages or making suggestions that aim to challenge a disputant's current attitude. An intriguing question is whether the level of outcome-directiveness of an explicit evaluative statement affects its persuasiveness. There are many gradations of feedback and evaluation. ${ }^{174} \mathrm{~A}$ mediator who explains in detail to a corporate executive why litigating a contested matter may not be the best use of his staff's time from a business standpoint is providing a common but mild form of feedback. In the example at the beginning of this section, the mediator provides a legal opinion about an evidentiary question-a more directive intervention, but one that is considerably less so than, say, providing a legal opinion about the predicted substantive outcome of a case ("My sense is that if the case goes to trial, the plaintiff will almost certainly get to the jury, and will likely win a verdict in the vicinity of $\$ 40,000$ to $\$ 65,000 \ldots$. .) or a specific settlement suggestion based on an evaluation of the law and facts of the case ("If you want my opinion, I think their $\$ 50,000$ settlement offer is right in the ballpark, and you would not be making a mistake if you decided to accept it."). Are explicit statements as persuasive when they include outcome predictions or recommend particular solutions as when they provide less directive forms of feedback? Might we generally expect greater reactance from disputants as persuasive feedback becomes

173 See, e.g., AMERICAN BAR ASSOCIATION TASK FORCE ON IMPROVING MEDIATION QUALITY, FINAL REPORT (2008) (study showing, inter alia, that ninety-five percent of attomey consumers of mediation wanted their mediators to give an analysis of the case, including strengths and weaknesses).

174 See, e.g., FRENKEL \& STARK, supra note 5, at 246-47, giving examples and citing sources. 
more directive? Put slightly differently, does persuasion work in similar ways when the persuader makes "is" statements (e.g., "The state of the law is [x]") as opposed to "ought" statements ("For [y] reasons, you might consider lowering your demand.")? ${ }^{175}$ Further research on such questions would be useful.

Despite these questions, we believe that these findings shed potentially significant new light on two important debates in mediation. First, there is the much debated question regarding the relative importance of process expertise versus substantive expertise as a mediator qualification. ${ }^{176}$ In our example above, the most persuasive message form, according to the research, would be the one in which the mediator explicitly identified the source for his conclusion, including discussing the potential impact of a U.S. Supreme Court decision on the evidence question presented. It is doubtful whether a mediator without substantial legal background in employment discrimination law would be able to provide such feedback. If highly detailed and explicit arguments and conclusions are more effective in persuasion than less explicit or detailed ones, this suggests the importance of industry knowledge as a key criterion for mediator success-at least when the parties want feedback.

Second, these lines of research shed light on longstanding theoretical debates about facilitative versus evaluative mediation. In most professional advising contexts, informational explicitness and directness are considered positive and desirable. Most patients or clients, for example, want their doctors or lawyers to lay out the pros and cons of differing courses of action and their recommendations, with supporting reasons, why one course may be preferable to another. ${ }^{177}$ Similarly, we want the salespeople with whom we deal to be forthright about the characteristics, benefits, and weaknesses of the various products or services we are considering buying.

In mediation, by contrast, the longstanding debate over facilitation versus evaluation has led many neutrals who seek to persuade to avoid explicit or direct efforts at persuasion, often in the name of party self-determination. Even when feedback has been expressly requested by the parties, mediators

175 We are indebted to Ian Ayres for suggesting this distinction to us.

176 See, e.g., Margaret L. Shaw, Mediator Qualifications: A Report of a Symposium on Critical Issues in Alternative Dispute Resolution, 12 SETON HALl LeGIS. J. 125 (1988); Christopher Honeyman, On Evaluating Mediators, 6 NEGOTIATION J. 23 (1990).

177 See generally, e.g., RUTH R. FADDEN \& TOM L. BEAUCHAMP, A HISTORY AND THEORY OF INFORMED CONSENT (1986) (informed consent duty of physicians); Jacqueline Nolan-Haley, Agents and Informed Consent, in ANDREA KUPFER SCHNEIDER \& Christopher Honeyman, The NegotIATOR's Fieldbook: THE DESK RefERENCE FOR THE EXPERIENCED NEGOTIATOR 505 (2006) (on the importance of client informed consent in legal negotiation). 
may "hedge their bets" by giving half-baked evaluations or making statements in an indirect, roundabout fashion, even regarding questions that have clear answers - out of fear of being seen as favoring a side, appearing coercive, or otherwise acting "inappropriately." At a minimum, this body of research suggests that such behaviors are suboptimal.

\section{Persuasion based on "Negative" Emotions: Fear and Guilt}

Suppose that your evidentiary predictions have not had the desired effect in causing the plaintiff and her lawyer to be more realistic about their settlement goals. You sense that Ms. Halverson, for many reasons, may not be fully assessing the risks - and the impact on her-of a trial. If anything, she and her lawyer seem to be getting less reasonable as the mediation progresses. You think she has a substantial chance of losing the case altogether if it is tried but that there is a good chance of getting the case settled quickly if she is willing to drop her demand by, say, $\$ 25,000$.

You are mulling over alternative ways of presenting this information. One option is to try to incite fear, as in for example:

I think you have a substantial chance of losing at trial. Win or lose, the incident in which you 'dissed' your employers in front of your coworkers will almost certainly be rehashed in detail. They may try to portray you as a loose cannon, irrational, disloyal, not a team player. With so many people looking for work in this economy, your conduct-even if it was justified-may look bad to a jury. In a slow news cycle, this might even be the kind of story that a newspaper or local TV station would want to cover. And if that occurs, the negative publicity could really hurt your prospects of being re-employed-no matter what else happened at trial.

What about attempting to tap into her possible guilt, for example:

I know you've struggled to raise your teenage son as a single mom, first on your unemployment benefits and now with part-time work. How would you feel about how you fulfilled your obligations to him if you were to lose your case after a long wait for the trial, knowing that you had the chance to receive some decent money in mediation but turned it down?

Mediation theorists and practitioners have a complicated relationship with the role of strong emotions in mediation. On the one hand, there is 
nearly universal acceptance of attempting to identify and (in non-destructive ways) bring to the surface the emotions that drive the conflict. ${ }^{178}$ Mediation trainers of all stripes and dispute resolution theorists have also focused a good deal of attention on the ways in which positive emotions (hope, trust, empathy, etc.) can lower tensions and reduce barriers to resolution. ${ }^{179}$ And the notion of reality testing-i.e., encouraging parties to weigh how realistic or attractive their non-settlement alternatives are, and how they might feel in the future under different resolution scenarios-enjoys widespread support. ${ }^{180}$

On the other hand, many in the field might recoil at the suggestion that a neutral would actively seek to evoke fear, guilt, or other "negative" emotions in order to produce a shift in attitude. Apart from its normative implications, there are more basic questions: do such approaches to persuasion work? If so, how and under what circumstances?

\section{A. Fear appeals}

For more than a half-century, primarily in the areas of public health and advertising, social scientists have studied the effectiveness of fear appeals in seeking to influence behavior change. Early researchers saw such appeals in purely emotional terms: the fear such messages aroused created unpleasant effects, which drove subjects to seek relief by accepting the message's recommendation. ${ }^{181}$

But laboratory results did not bear this hypothesis out at very high levels of aroused fear. The prevailing model was thus revised, with theorists hypothesizing that increased fear would produce increased message acceptance, but that after a certain optimal (moderate) level of emotional

178 See, e.g., FRENKEL \& STARK, supra note 5, at 159-60; MARK D. BENNETT \& SCOtT Hughes, The ART OF Mediation 73-74 (2d. ed. 2005); William A. Donohue, Communicative Competence in Mediators, in MEDIATION RESEARCH: THE PROCESS AND EFFECTIVENESS OF THIRD-PARTY INTERVENTION 322, 327-31 (Kenneth Kressel et al., eds., 1989).

179 See, e.g., JenNifer E. BeER With EILEEN STIEF, The Mediator's HandboOK 71-72 (1997); BuSH \& FOLgER, supra note 8, at 124-26; Clark Freshman, Adele Hayes, and Greg Feldman, The Lawyer-Negotiator as Mood Scientist: What We Know and Don't Know About How Mood Relates to Successful Negotiation, 2002 J. DISPUTE RESOL. 1 (2002); Jennifer Gerarda Brown, The Role of Hope in Negotiation, 44 UCLA L. REV. 1661 (1997).

180 See, e.g., FrENKEL \& STARK, supra note 5, at 270-71; KIMBERLEE E. KovaCh, MEDIATION: PRINCIPLES \& PRACTICE 207 (3d. ed. 2004).

181 For a discussion of "drive" models depicting subjects as driven to reduce fear, see Paul A. Mongeau, Another Look at Fear-Arousing Persuasive Appeals, in ALLEN \& PREISS, supra note 18, at 53. 
arousal, fear-based messages would "go too far" in their intensity, the level of tension aroused would be too great to be eliminated by the action recommended to the subject, and they would backfire in terms of persuasion. ${ }^{182}$ However, this "curvilinear" effect, depicted graphically as an inverted $U$, was never verified empirically. ${ }^{183}$

More recent public health research has found that stronger or more intense fear messages do arouse more fear and overall are more persuasive in producing a declared intention on the part of subjects to change their health behavior. But, according to this research, fear does not necessarily operate as originally believed. According to these findings, fear appeals produce not only emotional responses but also cognitive (thinking/perceiving) ones, and their effectiveness may be highly tied to, if not determined by, the thinking they engender. ${ }^{184}$ As fear appeal research continued in this direction, meta-analyses have verified this emotion-reason interaction and have attempted to explain when fear appeals are likely to work or fail.

According to several models, ${ }^{185}$ fear appeals can be broken down into two parts: (a) the threat or danger facing the subject, and (b) the recommended action or solution that the subject can take to avoid the harm. Each of these, in turn, is comprised of two additional components, seen from the subject's perspective. A threat is judged by the subject on the basis of his perception of (1) its severity and (2) its relevance-his chances of suffering its effects. The recommended action is appraised in terms of two different kinds of efficacy: (1) the likelihood that it will succeed in eliminating the threat and (2) the subject's own ability to carry out that action.

A typical experiment might manipulate these four variables, placing each subject in as one of eight possible experimental conditions. A 1987 breast cancer-based study 186 is illustrative: college-age female subjects were first

182 See, e.g., Irving L. Janis, Effects of Fear Arousal on Attitude Change: Recent Developments in Theory and Experimental Research, 3 ADVANCES IN EXPERIMENTAL SOC. PSYCHOL. 166 (1967).

${ }^{183} \mathrm{Kim}$ Witte \& Mike Allen, A Meta-Analysis of Fear Appeals: Implications for Effective Public Health Campaigns, 27 HEALTH ED. \& BEHAv. 591,593 (2000).

184 These have been dubbed parallel response or process models. For an early example, see generally Howard Leventhal, Findings and Theory in the Study of Fear Communications, 5 ADVANCES IN EXP. SOC. PSYCHOL. 119 (1970).

185 For a discussion of several frameworks that link emotional and cognitive/rational factors to explain the operation of fear appeals, see Witte \& Allen, supra note 183, at 593-95.

186 Patricia Rippetoe \& Ronald W. Rogers, Effects of Components of Protection-Motivation Theory on Adaptive and Maladaptive Coping With a Health Threat, 52 J. PERSONALITY \& SOC. PSYCHOL. 596 (1987). 
given either a high threat essay (coupling dramatic written and photographic descriptions of cancer, as well as the side effects of radical chemotherapy or mastectomy, with a focus on student susceptibility to the disease due to stress and poor diets) or low threat essay (far less intense depictions of breast cancer and its effects, subjects told that students rarely contract the disease). ${ }^{187}$ In addition, the essay described either a high or low likelihood that the desired response (breast self-examination) would be effective in early cancer detection, and presented a high (breast exams are easy to do correctly) or low (breast exams are difficult to do correctly, lumps are hard to detect) self-efficacy message. ${ }^{188}$

After taking in this information, subjects were instructed to rate themselves on several mood descriptors (frightened, tense, nervous, etc.) in order to measure their fear arousal and to rate themselves on a continuum of ways of coping with the threat of breast cancer, ranging from a declared intention to conduct regular self-examinations, to an intention to learn more about the disease and exams, to avoidance ("I try not to think about it"), wishful thinking ("a miracle cure in the near future is the answer to my fears"), prayer, and hopelessness ("it's almost useless to try to stay healthy"). ${ }^{189}$

Meta-analyses of these sorts of studies suggest that how subjects process fear-inducing information tends to differ in cases of successful and unsuccessful appeals. When a subject assesses the threat as low (because it is not severe, she is not susceptible to it, or both), little fear is aroused and she has little motivation to process the message further or to do anything in response. Thus, low-threat fear appeals are not persuasive. ${ }^{190}$ But when the subject's perception of both components of the threat-vulnerability combination is strong, she becomes motivated to do something to protect herself. ${ }^{191}$

${ }^{187}$ Id. at 599.

188 Id.

$189 \mathrm{Id}$.

${ }^{190}$ Since not all appeals of this nature produce fear, it has been suggested that they be termed "threat appeals" in order to differentiate messages from their (potential) effects. James Price Dillard, et al., The Multiple Affective Outcomes of AIDS PSAs: Fear Appeals Do More Than Scare People, 23 COMM. RES. 44, 63 (1996).

${ }^{191}$ For an explication of protection motivation theory, see Witte \& Allen, supra note 183, at 594; Ronald W. Rogers, Cognitive and Physiological Processes in Fear Appeals and Attitude Change: A Revised Theory of Protection Motivation, in BASIC SoCIAL PSYCHOLOGICAL RESEARCH 157, 157-60 (Cacioppo \& Petty eds. 1983). For its origins, see Ronald W. Rogers, A Protection Motivation Theory of Fear Appeals, 91 J. PSYCHOL. 93 (1975). 
What that something is depends on what she thinks about the effectiveness of the recommended action. If she believes in the efficacy of the recommended coping action (both generally and in terms of her own ability to carry it out), the subject is likely to seek to avoid the threat (this is called "danger control") by carrying out the recommended action, i.e., she is persuaded. But if she does not see herself as able to carry out a response that will be effective, the subject is more likely to seek a means of coping with her fear ("fear control") through denial of the danger, avoidance of a decision, suspicion/rejection of the source or other resistance. 192

Fear appeals thus produce two reactions that can potentially conflict: danger control and fear control. The research shows that the strength of defensive fear control responses increases with increasing intensity of the fear appeal and that they may have slightly stronger effects on the outcomes of fear appeals than do subjects' perceptions of the danger itself. ${ }^{193}$ Overall, the literature tells us that appeals that generate the most fear can be the most effective, so long as they convey both serious problems and strong, feasible solutions.

It is important to point out certain limitations in this body of research. First, the basis for much of what we know about fear appeals, at least in the area of public health, comes from laboratory settings in which subjects are provided hypothetical scenarios involving health risks and disease conditions that may not directly affect them in their lifetimes and that they may not find frightening. ${ }^{194}$ In a good number of the public health experiments, the subjects are relatively young and likely to see mortality and serious health problems as quite remote. As a result, they are likely less susceptible than the general population to fear arousal from any health threat. ${ }^{195}$ From this

192 This response to fear appeals entailing two appraisals (of the threat and of the coping action) with three possible outcomes (ignoring the message, controlling the danger, controlling the fear) has been termed the extended parallel process model. Witte \& Allen, supra note 183, at 594; Kim Witte, Putting the Fear Back into Fear Appeals: The Extended Parallel Process Model, 59 COMM. MonOGRAPHS 329, 337 (1992).

193 See Rippetoe \& Rogers, supra note 186, at 601; Witte \& Allen, supra note 183 , at 601 (noting negative correlation between danger control and fear control responses).

194 Some health-based fear studies involve fictitious diseases. See, e.g., Melissa C. Brouwers \& Richard M. Sorrentino, Uncertainty Orientation and Protection Motivation Theory: the Role of Individual Differences in Health Compliance, 65 J. PERSONALITY \& SOC. PSYCHOL. 102 (1993).

195 Many studies are conducted with college students, but some employ even younger subjects. See, e.g., Donna J. Fruin et al., Protection Motivation Theory and Adolescents' Perceptions of Exercise, 22 J. APPLIED SOC. PSYCHOL. 55 (1991) (studying the response of Australian high school sophomores and juniors to engaging in exercise to avert cardiovascular disease). 
perspective, fear appeals in the "real world" may be more effective than those measured by public health researchers.

On the other hand, results from these experiments may reflect an artificially high level of attention and response paid to fear stimulus messages. Unlike potential audiences for ordinary media advertising, subjects in these experiments must ingest and respond to the fear appeal. They have no option to turn off the television, ignore the billboard public service announcement, or otherwise tune out (and, in the process, likely reject) the message. ${ }^{196}$ This may skew the results in the opposite direction, showing fear-inducing messages to be more effective in laboratory settings than they are in certain real world settings. ${ }^{197}$

Furthermore, subjects in these experiments are commonly asked, in a one-shot questionnaire, about their intention to adopt a recommended action after being informed about the threat and response efficacy-a very different measure than actual behavior change. Little is known about actual attitude or behavior change in response to threat appeals. There is some empirical evidence that respondents who report that they intend to change their behavior often do not carry this through to actual conduct. ${ }^{198}$ Such findings may raise some doubt about the lasting effects of fear appeals.

\section{B. Mediation Applications and Questions}

Much of the debate over persuasion in the mediation literature is based on notions of autonomy: neutrals who seek to influence attitudes by underscoring undesirable or even frightening alternative outcomes (usually through legal evaluations) are said to be interfering with the parties' exercise

196 See Dillard, et al., supra note 190, at 67-68.

197 There may also be culturally-based limitations on how far one can export such threat appeal data. Subjects' expectations and responses may be shaped in part by their countries' differing attitudes and practices regarding the use of threats (as opposed to more supportive or empathic messages) in public safety or health ad campaigns. See Gerard Hastings et al., Fear Appeals in Social Marketing: Strategic and Ethical Reasons for Concern, 21 PSYCHOL. \& MARKETING 961, 965 (2004).

198 William DeJong \& Lawrence Wallack, A Critical Perspective on the Drug Czar's Antidrug Media Campaign, 4 J. HEALTH CoMM. 155 (1999). On the other hand, some studies show at least some promise of long term behavior change. See, e.g., Ronald W. Rogers, et al., An Expectancy-Value Theory Approach to the Long-Term Modification of Smoking Behavior, 34 J. CLINICAL PSYCHOL. 562, 564 (1978) (concluding 19\% of smoker-subjects who reported intending to quit after receiving a persuasive high-threat fear appeal were cigarette-free one year after the experiment). 
of informed, self-determined choice. ${ }^{199}$ Put another way, resorting to powerful emotional appeals is seen as having the potential to overwhelm rational cognitive processes traditionally viewed as essential to autonomous decision-making.

What may be significant in this research for mediators is that in addition to evoking emotional reactions, successful fear appeals also appear to trigger thinking, both about the threat and the subject's ability to avert it. Indeed, cause and effect are not clear from the research. Instead of being the stimulus for a change in thinking, fear may be the product of the processing of information about the severity and relevance of a threat. ${ }^{200}$ If this empirical literature is to be credited, it would appear, first, that decisions (at least most) people make in response to such persuasive efforts are not likely to be overwhelmed by the fear aroused; and second, that however they operate, effective fear appeals can sometimes act to neutralize defensive tendencies such as anger, overconfidence, or denial that may be getting in the way of logical thought. Viewed in this way, well-executed fear appeals, at least in some cases, may actually work to enhance participant autonomy.

Applied to mediation, this research may point to the wisdom of directness, if not bluntness, in describing the likelihood and severity of the consequences of non-settlement options. Pulling punches or speaking in shorthand in delivering such an evaluation or reality check may produce insufficient belief in the seriousness of the threat to trigger real openness to change. ${ }^{201}$ Moreover, if the perceived efficacy of a recommended action is an essential determinant of whether a fear-arousing message is accepted, merely stressing dangers-e.g.., the risks and noxious consequences of a trial or other alternative to settling-without more, may not suffice. Embedded in message resistance or avoidance may be a party's belief that the opponent will never agree to settle. ${ }^{202}$ Or (like so many smokers), a party may doubt

199 Compare, e.g., Lela Love, The Top Ten Reasons a Mediator Should Not Evaluate, 24 FLA. ST. U. L. REV. 937, 944-45 (1997) with Jacqueline Nolan-Haley, Informed Consent in Mediation: A Guiding Principle for Truly Educated Decisionmaking, 74 NOTRE DAME L. REV. 775 (1999).

200 O'KeEFE, supra note 16 , at 228.

201 This may raise a question about the efficacy of appeals that are aimed at creating mere "doubt" or "uncertainty" in order to change the minds of mediation participants. Such strategies are frequently endorsed in the mediation literature as effective in producing movement from confidently-held positions. See, e.g., FrEnkEL \& STARK, supra note 5 , at 246 . To the extent that such interventions are motivated by a desire to instill fear, this research suggests that they may fall short of their potential if they are too indirect or ambiguous.

202 Experienced neutrals are familiar with parties who enter the process convinced 
his or her own ability to afford or sustain the commitments needed to resolve the dispute. A successful effort to persuade by sowing doubt or fear may therefore need to unpack the reasons for a party's message resistance, give the party reasonable assurance that the threat can be averted through conduct taken in mediation, and provide at least general guidance as to what action will produce a resolution.

It thus may follow that a negative evaluation may not be persuasive unless relatively late in a mediation and only after a fair bit of caucusing, at least in cases where the bargaining is adversarial and real settlement parameters have been concealed. ${ }^{203}$ Once a mediator knows that one side will likely accept a specific offer, it should be relatively easy to assure the (fearful) opposing party that, by making that offer, she can put the threat behind her.

Before drawing too many direct applications to the mediation setting, however, a few additional caveats are in order. First, by focusing attention on one emotion at a time, these sorts of studies may not replicate the more complex realities of mediation. As mediation practitioners and others who deal in conflict know (and as some studies illustrate ${ }^{204}$ ), strong messages can often arouse multiple feelings, whose interaction may affect any response. Thus, for example, if a fear appeal by a mediator were to trigger not only fear but also anger (at the opponent, the mediator, the situation, or all three), the efficacy of the persuasion effort might well be undermined by the party's desire to strike back in response to the anger aroused ${ }^{205}$ or by general

(through earlier dealings, projection, or both) that the opponent will "never" be willing to resolve the matter on any reasonable terms.

203 While the research is not clear on this point, some studies suggest that for a fear appeal to be effective, the threat information should be transmitted before the recommended action. See, e.g., James Price Dillard \& Jason W. Anderson, The Role of Fear in Persuasion, 21 Psychol. \& MARKeTING 909, 914 (2004); but see, Howard Leventhal \& Robert Paul Singer, Affect Arousal and Positioning of Recommendations in Persuasive Communications, 4 J. PERSONALITY \& SOC. PSYCHOL. 137 (1966). If this reasoning is correct, it might call into question the efficacy of some of the received wisdom about the optimal (i.e., last resort) timing of fear-inducing evaluations in mediation, at least to the extent that they come after other persuasive attempts to produce the same recommended action. See, e.g., Marjorie Corman Aaron, ADR Toolbox: The Highwire Act of Evaluation, 14 AlTERNATIVES TO HIGH COST LITIG. 62 (1996).

204 See Dillard et al., supra note 190, at 45.

205 The desire to fight or attack and reject seems to be the "action tendency" associated with anger. See, e.g., James Price Dillard \& Eugenia Peck, Persuasion and the Structure of Affect, 27 HUMAN COMM. RES. 38 (2001) (discussing differing action tendencies produced by different emotions); Dillard et al., supra note 190, at 50 . 
message reactance. 206 At a minimum, this complicates matters for practitioners, by forcing them to attempt to identify-and address constructively - the varied emotions that may be contributing to a disputant's response to a persuasive message.

In addition, if, as studies suggest, fear appeals do not reliably produce lasting change in attitudes and behaviors, what of settlements that require long-term commitments, for example, a mother's agreeing to increased and regular child access for a father she hates? If her agreement to the settlement was in any substantial measure a byproduct of fear, might the type of persuasion used (as compared to others that were available) reduce her willingness to abide by its terms over time? For many mediators concerned with the stability of agreements reached with their assistance, this important measure of the quality of message acceptance would be helpful to know.

\section{Guilt Appeals}

The use of guilt as a persuasive tool is commonly found in efforts to induce greater volunteerism or charitable giving and to influence consumer-purchasing decisions. By directly or indirectly confronting audiences with discrepancies between their personal standards and their actual conduct, guilt appeals seek to trigger unpleasant feelings that will motivate people to seek relief by making amends for their self-perceived shortcomings.

\section{Direct Guilt Appeals}

Efforts to persuade by capitalizing on guilt take several forms. The most direct involves the presentation of a message which draws a subject's attention to the inconsistency of her (past or ongoing) behavior with her own standards or ideals. Like fear appeals, guilt-based persuasive messages have a "problem-solution" structure: (a) the guilt-inducing suggestion that the recipient's conduct or inaction violates her personal norms or some social or

206 The specter of arousing anger, sadness or other feelings as part of a fear appeal raises another practice-oriented question for many mediators: What emotions are likely to be aroused by (as is common in some difficult mediations) repeated references to the non-settlement threats that a party faces? Might the fear component have a diminishing impact over time if other feelings that are triggered strengthen? And would it be problematic if those other feelings (e.g. sadness) led a subject to exhibit lethargy or withdrawal in accepting the fear message? See Dillard et al., supra note 190, at 50; Dillard \& Peck, supra note 205, at 42, 59-60 (noting such action tendencies for sadness but identifying this as an area of undeveloped understanding). 
moral principle, and (b) the recommended change in behavior that can make up for the lapse and thus reduce the guilty feeling.

The extent of research in this area is rather limited as compared to empirical work concerning fear appeals. The field's one meta-analysis, based on approximately thirty years of guilt studies, ${ }^{207}$ summarizes the research as follows: as with fear appeals, more intense guilt messages arouse a greater amount of emotional response. But unlike fear appeals, guilt appeals can go too far: as guilt appeals become more intense or explicit, they become dependably less persuasive. ${ }^{208}$

Illustrative of the experimental methodology in this area is a 1995 study of advertisements aimed at encouraging working mothers' purchase of dental floss. ${ }^{209}$ Subjects in the study were given information that included statements that attempted to stimulate varying degrees of guilt: low ("Keeping your child's teeth clean and fresh ... that is FLOSS-IT's job!"), medium ("You shape your child's dental health, so don't let your family down.") and high ("It's YOUR responsibility to make sure that your kids have healthy teeth and gums . . . don't make any mistakes . . DO IT $R I G H T$ !'). ${ }^{210}$ Subjects were then asked to describe their own response to the ad by reporting whether and how much they experienced fifteen emotions, ranging from "happy" to "guilty" to "angry" (and twelve others). ${ }^{211}$

The results of this study showed, first, that the amount of guilt felt was higher in response to moderate and high guilt appeals than to low intensity messages; second, that as guilt content rose from moderate to more blatant, such appeals generated anger and negative source attributions, (e.g., "The company is trying to manipulate my attitudes and feelings," "The company is primarily concerned about making money. "); and third, that purchase intent declined as guilt levels rose. ${ }^{212}$

Similar results have been reported in studies involving transgressions in close or intimate personal relationships. While research in this area shows that targets of their victims' guilt-heaping messages report having learned a

207 See generally Daniel J. O’Keefe, Guilt and Social Influence, 23 Сомм. Y.B. 67 (2000). Note the comparatively small size of this meta-analysis: it was based on nine studies of guilt arousal involving 630 subjects and only five studies of the impact of guilt message explicitness on persuasion, involving 323 participants.

208 Id. at 83.

209 Robin Higie Coulter \& Mary Beth Pinto, Guilt Appeals in Advertising: What Are Their Effects?, 80 J. APPLIED PSYCHOL. 697, 699 (1995). In this study, felt guilt was actually lower in the high guilt appeal than in the moderate version.

210 Id. at 700.

211 Id. at 701 .

212 Id. at 701-703. 
lesson from such incidents and that feelings of guilt had an impact on their subsequent behavior, such targets also report resenting this approach. ${ }^{213}$

Why do recipients resent guilt-based appeals and reject them as the arousal of guilty feelings intensifies? The best explanation is that such appeals (especially if they come from a third person) trigger psychological reactance: messages are perceived as attacks on the self and as efforts to limit one's freedom, coming from sources (such as advertisers) not entitled to criticize one's conduct. ${ }^{214}$ Resentment, anger, and a desire to lash out against the message and the messenger are often the result. 215

\section{Hypocrisy Induction and Anticipated Guilt}

Persuasion efforts seeking to trade on aroused guilt or on closely-linked emotional states are not limited to direct appeals. Recent research into a related area, hypocrisy induction, has revealed this device to be an effective form of active self-persuasion. In a typical hypocrisy induction experiment, subjects are asked to make a speech advocating a stance that embraces "prosocial" ideals that they support (e.g., regular condom use, water conservation, recycling) and then recall times in the past when they failed to act in keeping with those standards. When surveyed, these subjects state significantly greater intention to bring their future conduct in line with the espoused ideals than do others who merely made a speech or were reminded

213 See generally Roy F. Baumeister et al., Personal Narratives About Guilt: Role in Action Control and Interpersonal Relationships, 17 BASIC \& APPLIED SOCLAL PSYCH. 173 (1995) (studying first person autobiographical narratives of guilt experiences). In another study, subjects were shown a videotape depicting a person in need appealing to a reluctant friend for help in the form of a ride to school or help on a math test. Requests were either framed in terms of altruism ("Can we find a solution to this together?") or guilt ("If you don't help me, you're selfish."). On being asked to enact the part of the friend whose help was sought, subjects exposed to the guilt appeal reported, overall, a lower likelihood of compliance with the request and greater reactance (more overt or covert anger) and less liking of and respect for the friend than those in the altruism group. See generally Jeffrey Rubin \& Warren F. Shaffer, Some Interpersonal Effects of Imposing Guilt Versus Eliciting Altruism, 31 COUNSELING \& VALUES 190 (1987).

214 O'Keefe, supra note 207, at 84; Robin Higie Coulter, et al., Believe It or Not: Persuasion, Manipulation and Credibility of Guilt Appeals, 26 ADVANCES IN CONSUMER RES. 288, 292 (1999).

215 This may be especially true where subjects infer that the guilt-based message is manipulative in intent, a perception that may be found especially in subjects who are knowledgeable about persuasion tactics. See June Cotte, Robin A. Coulter \& Melissa Moore, Enhancing or Disrupting Guilt: The Role of Ad Credibility and Perceived Manipulative Intent, 58 J. BUS. RES. 361 (2003). 
of the importance of, e.g., wearing condoms. ${ }^{216}$

In addition, (and perhaps especially useful in mediation) researchers have begun to study the use of anticipated guilt as a persuasive device. In contrast to the direct and indirect efforts to persuade by arousing feelings of guilt in the moment, researchers have sought to measure the effects of causing people to forecast how they will feel in the future if their current action or inaction produces harmful effects, or causes them to fall short of their own standards.

In an illustrative recent study, undergraduate student subjects were asked to get tested to see if they could join the bone marrow donor registry during National Bone Marrow Awareness Month. ${ }^{217}$ While all students were given the same written description of the diseases for which bone marrow transplants might be life-saving and of the simple procedure for getting tested, the experiment varied the intensity of its anticipated guilt component. One group was given a "naturalistic" appeal which underscored the seriousness of the blood diseases that could be treated by donation and urged subjects to join the donor registry, concluding: "You may save a life!"218 The rest of the subjects were given a high anticipated guilt message which added brief stories about two children with leukemia-one who died for lack of a transplant, the other flourishing after getting one-and a closing exhortation to "think about how bad you might feel if you decided not to help when it is so easy."219

Compared to those who read the naturalistic appeal, students who read the more intensive message reported a higher estimate of the guilt they would feel if they failed to volunteer, and a higher level of intention to take the first step to becoming a donor. ${ }^{220}$ Regardless of their level of intensity, these

216 E. Aronson, C. Fried \& J. Stone, Overcoming Denial and Increasing the Intention to Use Condoms Through the Induction of Hypocrisy, 81 AM. J. PUB. HEALTH 1636,1637 (1991). The persuasiveness of this approach has been explained on the basis of dissonance aroused by revelation of one's hypocrisy: the discrepancy between the norms subjects espouse and their past behavior. In order to reduce dissonance, subjects state their intention-and, in some cases, follow through with behaviors designed- to bring their conduct in line with their beliefs. It has been asserted that these results can just as readily be explained on the basis of guilt arousal and reduction. O'Keefe, supra note 207 , at 87 . See supra text accompanying note 38 for a discussion of role reversal and its relationship to dissonance theory.

217 Lisa L. Massi Lindsey, Anticipated Guilt as Behavioral Motivation: An Examination of Appeals to Help Unknown Others Through Bone Marrow Donation, 31 HUM. COMM. RES. 453, 460 (2005).

218 Id.

219 Id. at 461.

${ }^{220}$ Id. at $463-64$. 
messages were not met with reactance: subjects generally found nothing objectionable about them. ${ }^{221}$ Such forecasted feelings may not withstand the test of time, however: when surveyed a week or so later, students who had taken no action toward becoming a donor reported feeling less actual guilt than they anticipated they would. ${ }^{222}$

\section{Mediation Questions and Applications}

Guilt-at least if employed in the form of a direct message from the neutral-would seem to be a potentially risky tool of persuasion in mediation. As this research suggests, direct guilt appeals are unlikely to be effective, and indeed may backfire, unless employed in small doses, with delicacy and tact. Finding a level of intensity that arouses motivating guilt but avoids psychological reactance may be difficult for mediators in most real life circumstances. If guilt messages typically trigger resentment and anger, even in personal relationships, the challenges for outsiders (like mediators) to leverage such bad feelings would seem even more daunting. And if that mediator has pledged to remain neutral and impartial, any obvious "guilt trip" seems particularly likely to fail. ${ }^{223}$

Adding to these challenges for mediators is the fact that, for direct guilt appeals to be effective, some discrepancy between a person's standards and conduct must be acknowledged. This would seem to rule out guilt appeals in contested situations in which a party denies that his conduct was wrongful or

\section{$221 \mathrm{Id}$. at 470 .}

$222 \mathrm{Id}$. at 471 . A final way of using guilt to change behavior-known as the transgression-compliance effect-has been tested in research in which experimenters trigger an actual wrongful act on the part of a subject and then compare the extent to which such subjects (as opposed to those who have not "transgressed") comply with subsequent requests for help. In a representative study, subjects ostensibly knocked down and upset the ordering of another student's stack of precisely organized computer cards and then were asked to make helpful phone calls for the experimenter. See Paula Konoske, et al., Compliant Reactions to Guilt: Self-Esteem or Self-Punishment, $108 \mathrm{~J}$. SOC. PSYCHOL. 207 (1979). In this and other such settings, those who transgress comply with subsequent requests for help in significantly and predictably greater numbers than those who are simply asked for help without having committed a "wrong." The desire to alleviate guilt that results from "real time" (even accidental) wrongdoing seems to be a strong motivator, uncomplicated by the reactance that tends to accompany having one's behavioral lapses pointed out by others. The success of the "door-in-the-face" strategy may be explained on this basis. See infra text accompanying notes 288-98.

223 In order to avoid reactance, mediators might attempt to arouse guilt through questioning, rather than direct statements. But, as we have seen, this form of persuasion has its own problems. See supra text accompanying notes 134-42. 
problematic to begin with. Moreover, in legal disputes, because of technical defenses, legal responsibility may not ultimately attach to conduct for which guilt might ordinarily be aroused. As a result, ordinary notions of wrongdoing may become attenuated, and normal guilt feelings diluted or eliminated.

Can other uses of guilt that hold more persuasive promise (at least in the laboratory) be harnessed successfully by mediators? For example, can hypocrisy be induced effectively by a mediator who anticipates a participant's extreme adversarial tactics? What of seeking early in the process to gain a party's explicit commitment-in the party's own words, if possible - to certain substantive or personal standards (e.g., "Can we agree that in general children should have generous access to both parents post-divorce?" "Am I correct that, as an owner with more than thirty years' experience doing business in the community, you generally try to make your customers' experience a quality one?") or process-oriented norms ("Can we agree that today's session will go better if everyone dispenses with extreme statements or other excessive hardball in bargaining?")-with an eye to having that party repeat their commitments if they behave inconsistently later in the mediation? Research supports the persuasive power of these kinds of interventions.

Anticipated guilt appeals may also have direct application to mediation. Urging disputants to consider how the consequences of failing to resolve a matter could make them feel ("How will you feel about how you performed your role as a dad if you turn down her offer, and continue to see your child only one afternoon a month for the next seven or eight months until the judge hears the case?" "Consider how it might feel if the company suffers a large adverse verdict at trial and, since you're uninsured, you have to lay off several employees.") would seem to hold the promise of considerable persuasive potential. In laboratory settings involving prosocial activities such as bone marrow donation, anticipated guilt appeals have not produced reactance. Coming from a mediator, would the kinds of anticipated guilt appeals we have described be as reactance-proof? This would be useful to test.

Finally, as seems to be the case with the use of fear, there is a question as to how long the persuasive effects of guilt appeals actually last. If this kind of persuasion largely results from experiencing unpleasant emotions, it is plausible that the effects of such influence may be ephemeral, weakening over time. The same would hold true for the effects of successfully-induced anticipated guilt, if, as the research suggests, people tend to overestimate 
their future levels of guilt.224 This might argue against the use of such persuasive tactics in mediations where compliance with long-term commitments is important.

\section{E. Some Concluding Thoughts on Persuasion and "Negative Emotions}

Taken as a whole, the empirical research suggests that both fear and guilt appeals, skillfully executed, have the capacity to be effective in changing minds. But as noted earlier, this begs the normative question: Are such "negative" emotional appeals an appropriate exercise in mediator persuasion?225

As political scientist Drew Westin recently observed, "'feelings' are millions of years older than the kind of conscious thought processes we call 'reason,' and they have been guiding behavior for far longer."226 Mediation is often a highly emotional process, in which the parties' feelings hold strong sway on their communication patterns and decision-making processes, sometimes in ways that disserve them. When this occurs (whether they admit it or not), mediators commonly invoke negative emotions in response. Those who engage in any form of evaluation or reality testing, sowing doubt about a disputant's position or negotiating stance, do so knowing at some level that this may produce anxiety, or even fear. Mediators who try to help parties honestly confront their own past bad behavior and contributions to a dispute understand that these interventions may bring feelings of regret, guilt and shame. Certain role reversal interventions, such as asking a party to consider how his or her actions may have affected or hurt the other side, can foreseeably produce the same guilt-evoking effect. All such interventions seem well within the mainstream of accepted mediator practice.

Why is this so? If one thinks closely about the so-called "negative" emotions of fear and guilt, they are not really negative at all. Fear, of course, is highly adaptive when it helps humans avoid risk or escape danger. And while guilt is often derided in our culture, the ability to empathize with those we hurt is at the root of conscience and is what enables us to act morally towards one another. In the specific context of mediation, a healthy dose of

224 Lindsey, supra note 217 , at 472.

225 While other sections of this article may also raise normative questions, we address this issue here out of a sense that, for many mediation theorists and practitioners, persuasion based on fear or guilt may be the most emblematic of the "ideological divide" in the field.

226 Drew Westin, The Political Brain 57 (2007). 
anxiety, induced by the mediator, may help disputants reconsider overly confident decisions not in their long-term interest. A dollop of induced guilt may help disputants come to terms more fully with the negative effects of their behaviors on others, thereby developing greater objectivity about their situation. So long as fear and guilt appeals are not exaggerated by the mediator, both kinds of interventions can help disputants surface and confront painful thoughts and feelings about which they may have been in denial, and produce more fully considered decisions. 227

Some mediators will resist this notion. Individuals might cite their own lack of competence or training as the reason, but such prudential concerns ought not be confused with normative claims about "proper" mediator conduct. Nor should personal discomfort at the prospect of inflicting unpleasant feelings on another person. ${ }^{228}$ Regardless of how neutrals ultimately resolve questions about the proper use of persuasion in the cases they mediate, the empirical research on fear and guilt appeals ought at the very least inform their decisions.

\section{GROUP BRAINSTORMING: PERSUASION BY EXPANDING OPTIONS? BY INDUCING COOPERATION?}

Despite your best efforts, the Halverson mediation has continued to be a completely zero-sum, tug-of-war affair. Both parties have privately given strong signals that they want to resolve the matter, but they have been unable to bridge the monetary divide between them. You decide to make another effort to broaden the discussion, by having the parties consider non-monetary ways of resolving their dispute. (The defendants previously refused to consider this; you have now persuaded them in caucus to give it a shot.) Having prepared both sides for what will ensue, you bring them together in joint session to try to identify together as many possible solutions to their dispute as they can generate (involving money and not), and then to evaluate them, based on their interests. Is this a good idea? Is it likely to work? In this situation?

Group brainstorming is a mode of problem-solving used in several forms of mediation today. Consistent with the trend in recent years by negotiation

${ }^{227}$ Indeed, to the extent that fear or guilt appeals tap into and bring to the surface preexisting emotions of the parties (as opposed to interposing the mediator's views), such interventions can be seen as exercises in self-persuasion and self-determination, rather than direct persuasion by the mediator.

228 This has been termed "meta-guilt." See Baumeister et al., supra note 213, at 176. 
scholars to advocate interest-based rather than positional bargaining, 229 some mediation texts and trainers endorse brainstorming as a preferred, or even sole, method of negotiation. ${ }^{230}$ In some respects, this is not surprising. Although not every dispute has integrative potential, 231 mediation practitioners and scholars often tout the "value creating" aspects of the process: its power to help disputants to think more broadly about their interests and generate more creative, satisfying and optimal solutions to their problems. Group brainstorming seems an ideal way to try to achieve such outcomes.

Other scholars have emphasized the potential affective advantages of face-to-face brainstorming: its capacity to reduce rigid thinking or build a sense of group cohesion that enables participants to set aside their individual interests and analyze a problem collectively. ${ }^{232}$ What do empirical studies actually tell us about the efficacy of group brainstorming as a vehicle for generating ideas, inducing cooperation and changing minds? Some of what researchers have learned is surprising.

\section{A. Direct Studies of Group Brainstorming}

It has been more than fifty years since Alex Osborn first set out his theory of group brainstorming as a creative way for organizations to solve their problems. ${ }^{233}$ Based on its widespread use today, most people are at least dimly aware of the recommended "rules" of the process: (1) at first, ideas should be generated, without any criticism or self-censorship; (2) the more ideas that can be generated, the better, including seemingly "wild" or implausible ones; (3) once as many ideas as possible have been generated,

229 See generally ROGER Fisher \& WILLIAM URY, GETTING to YES (1992); Carrie Menkel-Meadow, Toward Another View of Legal Negotiation: The Structure of Problem-Solving, 31 UCLA L. REV. 754 (1984). But see Robert J. Condlin, Bargaining With a Hugger: The Weaknesses and Limits of a Communitarian Conception of Legal Dispute Bargaining, 9 CARDOZO J. CONFLICT RESOL. 1 (2008).

230 See, e.g., BEER WITH STIEF, supra note 179; BENNETT \& HUGHES, supra note 178 (each devoting one or two pages to distributive bargaining and multiple pages to interest-based bargaining, eliciting interests and brainstorming). Similarly, a training session on mediating attorney-client fee disputes that one of us recently attended taught principles of brainstorming to the exclusion of all other processes a mediator might use to orchestrate the parties' bargaining.

231 See, e.g., Gerald Wetlaufer, The Limits of Integrative Bargaining, 85 GEO. L. J. 369 (1996).

232 See, e.g., FRENKEL \& STARK, supra note 5, at 256-57.

233 See generally Alex OSBORN, APPLIED IMAGNATION (1957). 
they can be evaluated; (4) ideas can then be combined, synthesized and improved upon, to produce the best possible outcomes.

Since the publication of Osborn's Applied Imagination, group brainstorming has been the subject of a great deal of social science experimentation. Studies generally proceed along the following lines: a group of undergraduate or graduate students, who may or may not know each other, are divided into small groups of four or five to try to brainstorm possible solutions to a given problem - say, how to attract European tourists to visit the U.S. in larger numbers, ${ }^{234}$ or what activities to arrange for visiting high school students who are have been admitted to the university. 235 Half the students are placed in so-called "nominal groups," working alone to generate ideas and then meeting to pool their ideas; the remaining students work in face-to-face, interactive groups, generating ideas collectively. Typically, subjects are provided some basic instruction on principles of brainstorming; sometimes, a control group, receiving no training in brainstorming, is added. 236

The results of such experiments are consistent and clear: "individuals who work alone and whose non-overlapping ideas are pooled... produce more and better ideas than [the same number] of individuals who work in an interactive group... Almost fifty years of brainstorming research has consistently shown that, when it comes to productivity, idea generation might best be left to individuals instead of groups." 237 Several meta-analyses have strongly confirmed this finding, ${ }^{238}$ one concluding that, compared to nominal groups, the "productivity loss of [interactive] brainstorming groups is highly significant and of strong magnitude."239

234 This is the so-called "tourists problem," which has been replicated in many different studies. See Corinne Faure, Beyond Brainstorming: Effects of Different Group Procedures on Selection of Ideas and Satisfaction with the Process, 38 J. CREATIVE BEHAV. 13, 24 (2004).

${ }^{235}$ Michael Kramer et al., The Impact of Brainstorming on Subsequent Group Processes: Beyond Generating Ideas, 28 SMALL GRouP RES. $218-42$ (1997).

${ }^{236}$ Id. at 218-42.

${ }^{237}$ Bernard A. Nijstad et al., The lllusion of Group Productivity: A Reduction of Failures Explanation, 36 EUR. J. SOC. PSYCHOL. 31 (2006).

238 See generally Michael Diehl \& Wolfgang Stroebe, Productivity Loss in Brainstorming Groups: Toward the Solution of a Riddle, 53 J. PERSONALITY \& SOC. PSYCHOL. 497 (1987) (showing this effect in 18 of 22 studies); Brian Mullen et al., Productivity Loss in Brainstorming Groups: A Meta-analytic Integration, 12 BASIC \& APPLIED SOC. PSYCHOL. 2 (1991); Michael Diehl \& Wolfgang Stroebe, Productivity Loss in Idea-Generating Groups: Tracking Down the Blocking Effect, 61 J. PERSONALITY \& SOC. PSYCHOL. 392 (1991).

${ }^{239}$ Mullen et al., supra note 238 , at 18 . There is some evidence that these 
While most of the attention of researchers has been focused on the comparative quantity of ideas generated by nominal and interactive groups, some researchers have also attempted to investigate the quality of ideas generated in different brainstorming formats. Idea "quality" has been defined differently in different studies, to include creativity, effectiveness, and/or practicability. ${ }^{240}$ However defined and operationalized, most studies have shown that nominal groups produce better ideas than interactive ones. ${ }^{241}$

As significant as these findings are, they are subject to a number of qualifications: First, until recently, brainstorming researchers have focused their studies almost exclusively on the idea-generation stage of the process, largely ignoring how groups actually sort through ideas and make decisions. An assumption of the research seems to have been that the larger number of ideas produced, the more likely that participants will be able to combine and build on each other's ideas, and the greater the probability of achieving an effective solution. ${ }^{242}$ But in practice, groups may find it difficult to process a large number of ideas effectively or make good decisions. ${ }^{243}$ Indeed, one of the only studies of group decision-making concluded that groups untrained in

discrepancies are reduced as groups become smaller, and that there is no statistically significant difference in idea generation between nominal and interactive brainstorming dyads. See Nijstad et al., supra note 237 , at 31.

240 Faure, supra note 234 , at 15.

${ }^{241} \mathrm{Id}$. at $15-16$ (citatioins omitted). The reasons for this production loss have also been subject to experimental study, and may include factors such as "evaluation apprehension" (people are fearful of expressing themselves freely in groups and therefore censor themselves); "social loafing" (some group members will work less hard when they see others carrying the load) and "production-blocking" (group members cannot state their ideas freely and without interruption, but must take turns). See, e.g., Nicole L. Oxley et al., The Effects of Facilitators on the Performance of Brainstorming Groups, 11 J. SoC. BEHAV. \& PERSONALITY 633, 634-35 (1996), citing sources. Evaluation apprehension may affect different people differently. Empirical research demonstrates that individuals who are self-confident and reasonably assertive do better in group brainstorming activities than people who are not. See Thomas J. Bouchard, Training, Motivation, and Personality as Determinants of the Effectiveness of Brainstorming Groups and Individuals, 56 J. APPLIED PSYCHOL. 324, 330-31 (1972); L. Mabel Camacho \& Paul B. Paulus, The Role of Social Anxiousness in Group Brainstorming, 68 J. PERSONALITY \& SOC. PSYCHOL. 1071, 1078-79 (1995).

${ }^{242}$ Kramer et al., supra note 235, at 219. But see Nicholas W. Kohn et al., Building on the Ideas of Others: An Examination of the Idea Combination Process, $47 \mathrm{~J}$. EXPERIMENTAL SOC. PSYCHOL. 554, 560 (2011) (recent study finding that brainstorming groups generally benefit for combining their own and others' ideas, whether generated individually or in groups, and calling for more study in this area).

243 Paul B. Paulus, Groups, Teams, and Creativity: The Creative Potential of Idea-Generating Groups, 49 APPLIED PsyCHOL.: AN INT'L. REV. 237, 261-62 (2000). 
the basics of brainstorming made decisions that are just as good as those made by nominal or interactive brainstorming groups with such training. 244

Second, most brainstorming research does not involve the use of trained facilitators to lead and orchestrate the brainstorming process. Does the presence of a facilitator reduce production losses associated with interactive brainstorming? The evidence is limited and mixed. One study 245 concluded yes, but only when the facilitators were "highly trained" (one-hour training, followed by role play, followed by an additional two-hour training with opportunities to listen to a recording of the role play and study a written transcript of it). When facilitators who had received only an hour of basic training led face-to-face brainstorming groups, these groups trailed nominal groups not assisted by a facilitator in generating ideas, by a wide margin. ${ }^{246}$

Third, almost all of the brainstorming studies have examined idea generation in groups of four or five people. There is some evidence that the idea generation advantage enjoyed by nominal over face-to-face brainstorming groups is reduced as the latter groups become smaller. One meta-analytic study concludes that there is no statistically significant difference in idea generation between nominal and interactive brainstorming groups of two. 247

Fourth, the cohesiveness or lack of cohesiveness of the group appears to have a substantial effect on productivity in the brainstorming process. In one early study, a researcher found that cohesive brainstorming groups (defined as groups in which people were permitted to choose their own partners, based on perceptions of their potential brainstorming ability) produced a significantly greater number of ideas and more unique ideas than either nominal groups or non-cohesive groups, at least when dealing with projects they cared about. ${ }^{248}$ Subsequent research has shown that interpersonal and task conflicts within a group interfere substantially with cognitive flexibility

244 Id. at 263-64.

245 Oxley et al., supra note 241 , at 644.

${ }^{246}$ Id. at 644-45. Compare Anne K. Offner et al., The Effects of Facilitation, Recording, and Pauses on Group Brainstorming, 27 SMALL GROUP RES. 283, 294 (1996) (finding that facilitated brainstorming groups did about as well as nominal groups in idea production), with Gerald P. Fleming, The Effects of Brainstorming on Subsequent Problem Solving 96-97 (2000) (unpublished dissertation, St. Louis University) (finding that facilitated brainstorming groups generated fewer ideas than either nominal groups or un-facilitated brainstorming groups), on file with authors.

247 See Nijstad et al., supra note 237, at 31 .

248 David Cohen, et al., Effect of Group Cohesiveness and Training Upon Creative Thinking, 44 J. APPLIED PSYCHOL. 319, 321-22 (1960). 
and creative thinking, especially as the conflicts become more severe. ${ }^{249}$

Fifth, and perhaps most important for our purposes, despite the fact that group brainstorming may seem less effective as a method of generating ideas than one would expect, studies suggest that most people enjoy the process, believe it to be effective, and are more satisfied with their own performance than when working as individuals. ${ }^{250}$ These findings may help explain why brainstorming remains popular: most people apparently believe that the process has positive consequences, beyond merely generating ideas, in building group cohesion and increasing commitment to decisions that are made. 251

Unfortunately, the impact of brainstorming in building group cohesion has received much less focused attention by researchers than the study of idea generation. It may therefore be useful to look at the broader empirical literature on cooperation and competition for indirect clues as to whether and how face-to-face brainstorming can reduce conflict and generate attitude change.

\section{B. Empirical Studies of Induced Cooperation}

A useful starting point is the "Robbers Cave" experiment, a rigorously designed field study of induced competition and cooperation, and their effects on intergroup relations, that has become a classic in its field. ${ }^{252}$ In this study, twenty-four eleven-year-old boys from the same city-from similar religious and middle-class socioeconomic backgrounds, but strangers to one another-were sent to a sleep-away camp in Oklahoma. They were

249 Carsten K.W. De Dreu \& Laurie R. Weingart, Task Versus Relationship Conflict, Team Performance, and Team Member Satisfaction: A Meta-Analysis, 88 J. APPLIED PSYCHOL. 741, 746 (2003) (meta-analytic findings challenging commonly held view that task conflict is generally helpful in group process, but relational conflict is not).

250 See, e.g., Nijstad et al., supra note 237, at 45-47; Paul B. Paulus et al., Perception of Performance in Group Brainstorming: The Illusion of Group Productivity, 19 Personality \& Soc. Psychol. Bull. 78, 79, 86-87 (1993 ); Fleming, supra note 246, at 90-92.

251 Faure, supra note 234, at 13. See also, Kramer et al., supra note 235; Paul Paulus, et al., Performance and Perceptions of Brainstormers in an Organizational Setting, 17 BASIC \& APPLIED SOC. PSYCHOL. 249 (1995). One study suggests, however, that both task and relational conflict (but especially relational conflict) interfere with participant satisfaction with brainstorming processes. De Dreu \& Weingart, supra note 249 , at $744-45$.

252 MuZafer Sherif et Al., INTERgroup CONFlict AND CoOperation: The ROBBERS CAVE EXPERIMENT (University of Oklahoma, 1961). 
divided into two sub-groups, and the study consisted of three stages. In Stage One, over a period of 5-6 days, the sub-groups were each allowed to form their own identities, relationships and hierarchies, without knowledge of the existence of the second sub-group. 253

In Stage Two, conducted over a period of the next 4-6 days, the sub-groups were engaged in a series of closely contested competitive games and activities (baseball and touch football games, tug of war and tent-pitching contest, culminating in a treasure hunt), with trophies and attractive prizes awarded only to the winning team. These were designed to produce, and did produce, considerable intergroup friction and heightened in-group solidarity and out-group stereotyping, consistent with one of the hypotheses of the study designers. 254

Stage Three followed immediately after the Stage Two competition and consisted of two separate sub-parts. In the first part, campers were allowed to have neutral contact with one another, engaging in activities like eating meals, seeing a movie or going to the beach together. As hypothesized, mere contact alone was not sufficient to reduce observed intergroup segregation, tensions, and stereotyping. Instead, it led to further acts of hostility and invective. ${ }^{255}$

In the second part of Stage Three, the boys were given a series of activities involving mutually interdependent or "superordinate" goals-goals of high value to both groups, but not achievable by either acting alone. These activities-which included working to resolve a (manufactured) water shortage, figuring out how to share expenses to rent a movie ("Treasure Island") that neither group could afford alone, and working together to jump start a "stalled" truck-all required intergroup cooperation and coordination of effort. Consistent with the authors' hypothesis, the induced cooperation during Stage Three succeeded in reducing "in group vs. out group" behaviors - although the authors are careful to describe how this happened very gradually, not immediately, resulting from a series of planned, mutually interdependent activities. 256

Over the years, the findings of the Robbers Cave study on the effects of

253 Id. at $74-95$.

254 Id. at $96-150$.

255 Id. at $158-59$.

$256 \mathrm{Id}$. at 210 . In designing the study, the authors note that they rejected the use of messages designed to correct group stereotypes because of the "large body of research showing that discrete information, unrelated to the central concerns of the group, is relatively ineffective in changing attitudes. Stereotypes crystalized during the eventful course of competition and conflict... are usually more real in the experience of group members than bits of information handed down to them." Id. at 202. 
competition and cooperation on attitudes and behaviors have been replicated and extended in scores of other experiments, involving both homogeneous and heterogeneous groups, with some directly involving the negotiation process. ${ }^{257}$ In general, when compared to a state of competition, cooperation has been shown by experimental studies to be associated with such effects as: (a) more effective communication in groups (more ideas verbalized, participants more attentive to and accepting of other people's views); (b) more friendliness and greater satisfaction with group processes; (c) better coordination of effort and orientation to task achievement; (d) reduced polarity (less focus on differences, greater focus on similarities and commonalities of viewpoints); (e) increased ability to engage in flexible thinking and to find creative solutions; and (f) reduced egocentrism and increased ability to take the perspective of others. ${ }^{258}$

As useful as these findings may be, much of the evidence for the benefits of cooperation in the context of negotiation has been provided by research utilizing prisoner's dilemma or other similar two-person laboratory games, ${ }^{259}$ in which payout matrices are designed to produce competitive or cooperative behavior. In an early experiment, for example, Morton Deutsch divided M.I.T. undergraduates into problem-solving groups in which students were either graded competitively ("the student producing the best ideas gets an A, the second best student gets a B") or cooperatively ("the group producing the best ideas gets an A, the group producing the second best ideas gets a B"). ${ }^{260}$ While later studies experiment with more complex and varied reward or

257 Morton Deutsch, Cooperation and Conflict Resolution: Implications for Consulting Psychology, 53 Consulting Psychol. J. PraC. \& RES. 76, 77 (Spring 2001) (defining cooperation as involving "positive interdependence"-a state in which people's goals are positively linked with each other in such a way that they "sink or swim together.") By contrast, competition is a state of "negative interdependence," in which one person's gain is another person's loss: if one swims, the other sinks, and vice versa.

258 Id. at 78; see also MoRton Deutsch, THE Resolution OF CONFLiCT 25-31 (1973) (collecting early studies); DAVID W. JOHNSON \& ROGER T. JOHNSON, COOPERATION AND COMPETITION: THEORY AND RESEARCH, 100-101 (1989) (collecting later studies); Charles M. Judd, Cognitive Effects of Attitude Conflict Resolution, $22 \mathrm{~J}$. CONFLICT RESOL. 483, 495 (1978) (competition, cooperation and perceptions of similarity ); Peter J. Carnevale and Tahira M. Probst, Social Values and Social Conflict in Creative Problem Solving and Categorization, 74 J. PERSONALITY \& SOC. PSYCHOL. 1300, 1301-02 (1998) (effects of expectation of conflict on categorization and perceptions of similarity); Susan M. Worley \& Andrew I. Schwebel, The Effect of Cooperation on Egocentrism in Divorce Mediation: A Simulation Study, 8 J. DIVORCE $151,161(1985)$.

259 DEUTSCH supra note 258 , at 314-47.

$260 \mathrm{Id}$. at 25-26. 
payout matrices, ${ }^{261}$ all suffer from a degree of artificiality.

\section{Targeted Race Relation Studies and Other Studies of Individual Prejudice}

Researchers have also extensively examined the role of intergroup contact and cooperation in reducing race, ethnic, and other forms of prejudice between heterogeneous groups. Results of early studies were mixed, with reductions of prejudice found in many studies, ${ }^{262}$ but exacerbation of intergroup tensions found in some others. ${ }^{263}$

Such studies may seem far afield from the world of disputing over legal claims or tangible harms. But as one scholar has noted, "[a]rguably the attitudes and behavior most difficult to change through rational argument are those having to do with ethnic and racial prejudice, because there is a strong emotional component to [them]." 264 If induced cooperation can work to reduce racial, ethnic and other forms of bias, might it have a similar effect in lowering animosities between angry, emotional parties in garden variety disputes?

In his classic work, The Nature of Prejudice, G.W. Allport proposed the contact hypothesis-the idea that social contact between majority and minority group members would lead to a reduction of bias when the contact situation afforded participants equal status and the opportunity to work on mutually interdependent goals. ${ }^{265}$ Social psychologists have been testing and refining this hypothesis ever since. Conceptualizations vary, but researchers have generally hypothesized that intergroup contact may not, by itself, be sufficient to produce changes in negative stereotypes. Rather, to reduce bias, the contact should be structured so that participants have equal status, share

261 See generally ROBERT AXELROD, THE EVOLUTION OF COOPERATION (1984); ROBERT AXELROD, THE COMPLEXITY OF COOPERATION (1997).

262 See, e.g., DANIEl M. WiLner, ET AL., HuMAN RELATIONS IN INTERRACIAL HousING: A STUdY OF THE CONTACT HYPOTHESIS 147 (1955); Morton Deutsch \& Mary Evans Collins, Interracial Housing: Influence of Integrated, Segregated Housing on Racial Attitudes Measured, 7 J. HousING 127, 134 (1950); Henry A. Singer, The Veteran and Race Relations, 21 J. EDU. Soc. 397, 404-05 (1948).

263 Yehuda Amir, The Role of Intergroup Contact in Change of Prejudice and Race Relations, in TOWARDS THE ELIMINATION OF RACISM 245-308 (Phyllis A. Katz ed., 1976).

264 Aronson, supra note 22, at 879.

265 Donna M. Desforges, et al., Effects of Structured Cooperative Contact on Changing Negative Attitudes Toward Stigmatized Social Groups, 60 J. PERSONALITY \& Soc. Psychol. 531, 531 (1991). See also, John Dovidio, et al., Intergroup Contact: The Past, Present and the Future, 6 GROUP PROCESSES \& INTERGROUP REL. 5, 5 (2003). 
mutual goals, and have the opportunity actively to cooperate with one another. Ideally, interactions should also afford participants the opportunity to get to know one another, with information exchanged of a type to disconfirm negative stereotypes. 266

A vivid example of this theory in action involves "jigsaw learning." The author of several early field studies later described the impact of this cooperative learning process on student attitudes in the Austin public school system in 1971, soon after it was desegregated. Believing that classroom competition might be exacerbating longstanding racial and ethnic tensions, the authors placed students in small, culturally diverse, interdependent learning groups. Illustrative was a lesson in which students had to teach each other about portions of a biography of Eleanor Roosevelt in order to do well on a scheduled exam. One Mexican-American student in one of these groups ("Carlos") had been derided by his classmates as stupid, and had learned over the years to keep quiet in order to avoid being ridiculed. The authors describe the effects of reinforcing cooperative learning behavior as follows:

When thrown on their own resources, the children eventually learned to teach and to listen to one another ... The word "eventually" is crucial. Cooperative behavior doesn't happen all at once ... After a few days... it began to dawn on the students in Carlos's group that the only way they could learn Carlos's paragraph was by paying attention to what he had to say. Moreover, they began to develop into pretty good interviewers . . . Carlos began to respond to this treatment by becoming more relaxed . . . The other children started to see things in him they had never seen before. They concluded that Carlos was a lot smarter than they had previously thought. For his part, Carlos began to enjoy school more and began to see the Anglo students in his group not as tormentors but as helpful and responsible people ... [A]s he began to feel increasingly comfortable in class and started to gain more confidence in himself, his academic performance improved. The vicious cycle had been reversed . . 267

Allport's contact theory has generated extensive study over the past fifty years, with scholars more recently looking beyond race and ethnicity relations to examine the effects of intergroup contact and cooperation on attitudes toward other stigmatized groups. In general, they have found that structured, cooperative contact produced generalizable improvements in attitudes of members of "in-groups" toward members of "out-groups."268

266 Desforges, et al., supra note 265, at 531-32.

267 Aronson, supra note 22, at 879-81 (citations omitted).

268 See, e.g., Donna M. Desforges, et al., supra note 254, at 540-42 (persons with 
Not all studies have produced such positive results, however. In real world settings involving groups with some history of conflict, creating conditions of mutual interdependence has not always led to friendlier and less biased attitudes. ${ }^{269}$ Efforts to reduce or eradicate status differences among such groups or individuals have not always been successful. ${ }^{270}$ When a cooperating group fails to accomplish a joint task, their cooperative efforts can nevertheless increase intergroup attraction but only when the groups have a history of cooperation. 271 When groups have competed in the past, failure in a joint endeavor has been shown to result in decreased attraction between the groups. ${ }^{272}$

One recent meta-analytic review, analyzing 515 previous studies involving more than 250,000 subjects, concludes that all other things being equal, mere exposure between different groups does promote greater intergroup liking and prejudice reduction, whether or not Allport's optimal conditions are met. 273 There is an inverse association between intergroup contact and prejudice, for all studies. ${ }^{274}$ However, taken together, it was found that Allport's structured conditions produce significantly greater reduction of prejudice than mere exposure alone. ${ }^{275}$

mental illness); David W. Johnson \& Roger T. Johnson, The Effects of Intergroup Cooperation and Intergroup Competition on Ingroup and Outgroup Cross-Handicap Relationships, 124 J. SOC. PSYCHOL. 85, 92-93 (1984) (learning disabled and emotionally disturbed children); Christiana Vonofakou, et al., Contact With Outgroup Friends as a Predictor of Meta-Attitudinal Strength and Accessibility of Attitudes Toward Gay Men, 92 J. PERSONALITY \& SOC. PSYCHOL. 804, 816 (2007).

269 Jean-Claude Deschamps and Rupert Brown, Superordinate Goals and Intergroup Conflict, 22 BRIT. J. SOC. PSYCHOL. 189, 194 (1983) (citing several studies of labor-management relations).

270 See Elizabeth G. Cohen \& Susan S. Roper, Modification of Interracial Interaction Disability: An Application of Status Characteristic Theory, 37 AM. SociologiCAl Rev. 643, 654 (1972); Irwin Katz, et al., Behavior and Productivity in Biracial Work Groups, 11 HUM. REL. 123, 137 (1958).

271 Stephen Worchell, et al., Intergroup Cooperation and Intergroup Attraction: The Effect of Previous Interaction and Outcome of Combined Effort, 13 J. EXPERIMENTAL SOC. PSYCHOL. 131, 138-39 (1977).

272 Id. at 139.

273 Thomas F. Pettigrew \& Linda R. Tropp, A Meta-Analytic Test of Intergroup Contact Theory, 90 J. PERSONALITY \& SOC. PSYCHOL. 751, 765-66 (2006).

${ }^{274} \mathrm{Id}$. at 766 . The authors report that the effect size is "small to medium," but because of the very large sample size, the results are highly statistically significant. The more rigorous the individual study, the greater the effect measured.

$275 \mathrm{Id}$. (citations omitted). Interestingly, the authors were unable to isolate any specific condition as being most important in enhancing prejudice reduction; none were 


\section{Psychological Processes Explaining the Benefits of Induced Cooperation}

What are the processes by which cooperative, equal-status intergroup contact improves communication, reduces prejudice and produces other beneficial effects? In a world with scarce resources, it has been suggested, people tend to view their relations with other groups as inherently competitive. Perceptually, when people are placed into groups, actual differences between members of their own in-group tend to be minimized and differences with out-groups tend to become exaggerated and over-generalized. For most people, this is anxiety-producing. Cooperative, mutually interdependent activities promote a sense of each participating person as an individual, rather than as a member of a group. They inculcate a feeling of "we-ness" rather than "us versus them-ness," resulting in reduced intergroup anxiety and an increased ability to engage in mutual perspective-taking. ${ }^{276}$

Cognitive dissonance may also play a role. Writing many years later about his early studies demonstrating the positive effects of integrated housing on racial attitudes, for example, Morton Deutsch noted:

[The] findings suggested that behavior change preceded attitudinal change: The white women in the integrated projects often behaved in an unprejudiced manner toward their Negro neighbors before they felt this way. Had we been clever enough to realize the general implications of this finding we might have anticipated the major idea underlying Festinger's theory of cognitive dissonance. . . . Namely, people tend to make their beliefs and attitudes accord with their actions. ${ }^{277}$

found to play a special role.

276 See generally John Dovidio, et al., Cooperation, Common Identity, and Intergroup Contact, in COOPERATION: THE POLITICAL Psychology OF EFFECTIVE Human InTERaction 143 (Brandon A. Sullivan, et al., eds., 2008); Thomas F. Pettigrew \& Linda R. Tropp, How Does Intergroup Contact Reduce Prejudice? Meta-analytic Tests of Three Mediators, 38 EUR. J. SOC. PSYCHOL. 922, 929 (2008) (meta-analysis of 515 studies). Reduced anxiety also may be linked to more positive moods, which themselves have been shown to increase people's ability to think creatively and inclusively. See, e.g., Alice M. Isen \& Kimberly A Daubman, The Influence of Affect on Categorization, $47 \mathrm{~J}$. PERSONALITY \& SOC. PSYCHOL. 1206, 1217 (1984); Alice M. Isen, et al., Positive Affect Facilitates Creative Problem Solving, 52 J. Personality \& SOC. PSYCHOL. 1122, 1129 (1987).

277 Morton Deutsch, Socially Relevant Science: Reflections on Some Studies of 
Whatever the precise psychological mechanisms at work, however, induced cooperation works (like role reversal) as a form of self-persuasion:

$[\mathrm{N}] \mathrm{o}$ direct attempt is made to convince anyone of anything. Rather, individuals find themselves in a circumstance where it becomes efficacious to convince themselves that a particular thing is the case: for example, that a particular group they have joined is attractive ... that members of a minority group are not inferior, and so on ... [T] hey become motivated to engage in self-persuasion . . . a more powerful form of persuasion . . . than more traditional persuasion . . . because in direct persuasion, the audience is constantly aware of the fact that they have been persuaded by another. Where self-persuasion occurs, people are convinced that the motivation for change has come from within. ${ }^{278}$

\section{E. Mediation Applications and Questions}

What conclusions can we draw about group brainstorming as a mode of persuasion in mediation from these diverse strands of scholarship, with their gaps and inconsistencies? The process seems to hold great promise in some cases but is also risky, and certainly is not appropriate for every dispute.

First, with regard to idea generation, the research evidence is equivocal as to whether face-to-face brainstorming produces more ideas-in the mediation context, more options for resolution - than other available formats. Many variables will affect this calculus in a mediation, including the number of people at the table, the depth of training of the neutral in brainstorming facilitation techniques, the self-confidence of the parties, and their ability to articulate ideas in a quasi-public forum. In the real world of mediation, the number of brainstorming ideas generated may be limited by the reluctance or unwillingness of negotiators to articulate any alternative outcomes to the ones they strongly prefer. And of course, some negotiated disputes are truly zero-sum matters or cases involving structural barriers that severely limit the options that can be considered.

Second, even if conducting a mediation brainstorming process does produce more options for resolution, there appears to be limited research evidence that having more options to consider necessarily leads to more, or better, agreements. This is not to say that expanding resolution options doesn't aid in resolving disputes, only that this has been mostly presumed, and needs more empirical investigation.

Can a process of face-to-face brainstorming build a sense of group

Interpersonal Conflict, 24 AM. PSYCHOLOGIST 1076, 1080 (1969).

278 Aronson, supra note 22, at 882. 
identity in a difficult mediation, causing participants to set aside (even temporarily) their individual interests and analyze a problem more as a "team"? We have observed this happen in practice and believe it to be true. Nonetheless, it is clearly a substantial leap from creative brainstorming in corporate departmental meetings or cooperative elementary school jigsaw learning teams, to the highly strategic, often emotional world of competitive negotiation. The parties in a mediated dispute are in a state of mutual, cooperative interdependence only to the extent that they prefer some (but not necessarily the same) negotiated agreement over their current options. Neutrals often have very limited time in which to try to build an atmosphere of cooperation through brainstorming efforts. Status, power, or ability differences between the parties may be difficult to eradicate, notwithstanding any general team-building effects of a brainstorming process. And if brainstorming is attempted in mediation and fails, it may exacerbate inter-party tensions, not reduce them.

On the other hand, orchestrating a face-to-face brainstorming process may offer hope of reducing the demonization and rigid thinking that often accompanies high conflict disputes. ${ }^{279}$ Research involving identity-based bias or prejudice, which are factors in only a small fraction of all mediated cases, may seem to have little general relevance for the mediation process. But rigid, categorical thinking and hostile attributions are a common phenomenon in even the most routine mediations (e.g., in a landlord-tenant dispute over a $\$ 500$ security deposit, "what else would you expect from a slum lord like him?'). The research on bias reduction suggests that inducing the parties to cooperate through face-to-face brainstorming may help the parties see each other more as individuals and less as "types." And because of the self-persuading nature of successful brainstorming, a resolution reached through such a process is likely to be a durable one.

If a neutral decides to try to orchestrate a brainstorming process, when during the process should she do so, to enhance its chances of success? One of the abiding lessons of studies on induced cooperation and other forms of self-persuasion is that they take time and lead to gradual change. This suggests that if brainstorming is going to be attempted at all, it should be initiated relatively early in the process, at a point when there is considerable time remaining. As we have noted elsewhere, however, mediators are well-advised not to try to resolve the issues facing them prematurely, before the information base of the dispute has been fully developed, the disputants have had a chance to say fully what is on their minds, and have experienced

279 See, e.g., Louis Kriesberg, Social Conflicts 69-72 (Neil Smelser 2d. ed., 1982). 
some emotional "letting go" of the conflict. ${ }^{280}$ This suggests that brainstorming, like any negotiating process, should be postponed until the later stages of the mediation. This is especially the case in competitive negotiations-perhaps particularly those involving lawyers-in which the process must allow sufficient time for the bargaining to traverse its various strategic stages and ritualized "dance" of gradual concessions. ${ }^{281}$ In our experience, many hard boiled negotiators will not even consider agreeing to a process like brainstorming unless their competitive strategies have clearly led to impasse, and only then late in the game (if at all).

Can a late stage, impasse-breaking brainstorming process be effective in producing greater group cohesion and attitude change? Can hard-nosed competitors "turn on a dime"? The story of Carlos and his classmates is perhaps instructive in demonstrating how the approach of deadlines can help turn a competitive enterprise into a more cooperative one in short order. At the end of a hotly contested mediation, with a deadline looming, the mediator may be able to impress on the parties the mutual risks and costs of not "getting the job done."

But much of this, of course, is conjecture. Most neutrals intuitively understand the value of cooperation and try to inculcate it in their mediations, for example by developing a mutual set of ground rules for the process or, later, a jointly created agenda of topics to be explored and issues to be negotiated. As we have seen, a good deal of empirical work has been done demonstrating the value of induced cooperation in improving intergroup relations generally and the negotiation process in particular. But we have no direct empirical evidence measuring the impact of brainstorming in mediation in inducing inter-party cooperation. This would seem to be a fertile area for future study.

\section{Producing Movement: The Power of Sequential Requests}

Assume that your brainstorming efforts in the Halverson case were unsuccessful. The defendants were willing to consider the possibility of part-time, contractual work for the complainant at some time in the (unspecified) future but not the kind of immediate full-time work that she

${ }^{280}$ FRENKEL \& STARK, supra note 5, at 126-27. On the emotional stages that disputants frequently must traverse before they are ready to resolve a conflict, see, e.g., Louis Kriesberg, Timing and the Initiation of De-Escalation Moves, in J. WILLIAM Breslin \& JefFrey Z. Rubin, eds., Negotiation Theory and Practice 223-24 (J. WIlliam Breslin \& Jeffery Z. Rubin eds., 1991); Gerald Williams, Negotiation as a Healing Process, 1996 J. DisPUTE RESOL. 1, 42-56 (1996).

${ }^{281}$ FRENKEL \& STARK, supra note 5, at 127. 
was demanding. Negotiating the language of a positive job reference was not enough to bridge the gaps between the parties. You have now spent more than five hours in mediation and it is clear that both sides are running out of patience.

The company has put an offer of $\$ 27,500$ on the table; that offer was quickly rejected by plaintiff's counsel. Given their voluntary presence at the table and their acknowledgment of certain risks they face, however, you are certain that the employer is prepared to go higher, although how high is unclear, given the fairly early stage of the dispute and the risks that the plaintiff also faces.

After another caucus, the plaintiff has stated that, if necessary, she will accept a figure of $\$ 42,500$ to end the matter today-but not a penny less. Based on your extended conversations, you believe her. You calculate that enough time remains for two quick rounds of caucuses. In thinking about how you might persuade the company's representatives to consider offering $\$ 42,500$, three possible strategies come to mind:

(A) Ask for a smaller amount that you are reasonably sure they would move to, say $\$ 35,000$, and, once they say yes, ask them to tell you, in confidence, whether-if necessary-they would go to $\$ 42,500$ if that would end the matter;

(B) Ask for a higher figure- one that you are reasonably sure they would reject-say $\$ 55,000$, and then ask for the $\$ 42,500$;

(C) Ask for $\$ 42,500$.

You wonder: Which of these is likely to be the most effective?282

Experimental research suggests that as between approaches A and B, it may not matter. Either of those approaches is more likely to produce the target result than the direct approach, C.

Sequential - as compared to straightforward-requests to gain agreement to a target goal have been the subject of study for more than four decades. The two best-known approaches have been termed "foot-in-the-door" and "door-in-the-face." The foot-in-the-door strategy involves starting with a small, very likely-to-be-accepted request, followed (once accepted) by a larger (target) one. Door-in-the-face approaches use a mirror opposite technique: starting with a large, very likely-to-be-refused request, followed

282 Needless to say, at any given point a wide variety of psychological and strategic factors might influence the defense's response to settlement figures suggested by the mediator. These might include their reactions to the plaintiff's pattern of concessions, the degree of trust they have in the mediator, the impact of time scarcity on their willingness to make a next move that could settle the case today, and their calculation of the chances of settling the case favorably later, after they allow the mediation to end in an (apparent) impasse. 
by a more moderate (target) one. In experimental settings, both approaches have been shown to be dependably more effective than direct requests in inducing compliance with the target.

For many students of negotiation, this conclusion may seem unremarkable, resonating with their experience, intuition and much else that has been written about effective bargaining. ${ }^{283}$ But empirical research into these two phenomena tells us more. The conditions under which these approaches work best and the cognitive and affective explanations for their success may offer helpful insights into how persuasive efforts in mediation might best be carried out. Let us take these sequential compliance-seeking tactics one at a time.

\section{A. Foot-in-the-Door (FITD)}

The name given to this compliance technique conjures up images of a traveling salesman trying to gain entry into someone's home in order to have a chance to make a sale. In fact, the conditions under which this strategy has been shown to work are typified by early experiments which involved entering subjects' homes. Experimental research demonstrates that getting someone to agree to a small initial request increases the likelihood that he or she will comply with a second, larger one.

In one early representative study, researchers first phoned Palo Alto housewives and asked (and got) them to take a few minutes to answer a few questions about soaps they used. Three days later, the researchers called the women again to ask whether they would allow a team of five or six men access to their homes' kitchen and other storage areas for a two-hour survey of their household products. These women agreed to the two-hour request at over twice the rate of another (control) group of women who had only been

${ }^{283}$ For example, the foot-in-the-door approach would appear to involve the commitment and consistency principle, which states that people, having made a commitment to act in one way, generally wish to be seen as acting consistently. CIALDINI, supra note 16, at 57-67. The tactic is also consistent with standard competitive bargaining behavior: By getting to the target in steps rather than all at once, a party avoids the risk of overpaying by making two moves without a reciprocal response from the opposing side. The efficacy of the door-in-the face approach might be seen as reflecting the power of anchoring: The second, smaller request always appears more reasonable when compared to the size of the first. NEALE \& BAZERMAN, supra note 35, at 48-49. Door-in-the-face also can be seen as demonstrating the reciprocity norm in action, with the second, smaller request by the requester seen as a "concession" from the first, larger one, warranting a corresponding concession by the subject. CIALDINI, supra note 16 , at $17-21$. 
asked for the two-hour home inspection. ${ }^{284}$

In another study, the same researchers first asked one group of California housewives to either display a small window sign or to sign a petition in support of either safe driving or keeping California beautiful. Two weeks later, these subjects - and a control group of whom no prior requests had been made-were asked (by a different requester) to agree to a larger ("target") undertaking: allowing a large, unattractive "Drive Carefully" billboard to be installed on their front lawn for a week. The group that had earlier agreed to post the window sign or sign the petition complied with the second request at more than twice the rate $(55 \%)$ of the control group members $(20 \%){ }^{285}$

The effectiveness of foot-in-the-door in increasing compliance with the larger "target" request (as compared to straightforward target requests only) has been explained on the basis of changed self-perception: as a result of having agreed to the initial request, the subject sees herself as one who is cooperative, helps good causes and strangers. That inference, in turn, propels the subject to act consistently, agreeing to the second, larger request. Where the first request is made in the presence of a reward, threat, or other external justification, agreeing to that request is less likely to be attributed by the subject to his or her own internal motivations; as a result, the sequential strategy is less likely to work in such situations. 286 Given this explanation, ${ }^{287}$ it should not be surprising that the success of FITD strategy increases with the size of the agreed-to initial request ${ }^{288}$ (the more significant the first act of volunteerism, the greater the sense of being

284 Jonathan L. Freedman \& Scott C. Fraser, Compliance Without Pressure: The Foot-in-the-Door Technique, 4 J. PERSONALITY \& SOC. PSYCHOL. 195, 198-200 (1966).

285 Id. at 200.

286 Jerry M. Burger, The Foot-in-the-Door Compliance Procedure: A Multiple-Process Analysis and Review, 3 Personality \& SOC. PsYCHOL. ReV. 303 (1999); James P. Dillard, et al., Sequential-Request Persuasive Strategies: Meta-Analysis of Foot-in-the Door and Door-in-the-Face, 10 HuM. COMM. RES. 461, 471 (1984) (Earlier meta-analysis suggesting that evidence on this is mixed).

287 Some researchers and commentators have expressed doubts about this explanation, noting skepticism as to whether a change in self-perception could be triggered by complying with small requests of the kind used in FITD experiments. They assert that a more plausible account is that compliance with an initial request activates powerful attitudes (e.g. commitment to the subject matter of the request, a desire to appear compassionate) that already exist in the subject. See Donald R. Gorassini and James M. Olson, Does Self-Perception Change Explain the Foot-in-the Door Effect? 69 J. PERSONAlity \& SOC. PSYCHOL. 91, 102 (1995).

288 Edward F. Fern et al., Effectiveness of Multiple Request Strategies: A Synthesis of Research Results, 23 J. MARKETING RES. 144, 149 (1986). 
helpful) or that its effect is strongest when the requests are "prosocial" in nature (altruistic, benefitting communities or non-profit enterprises, doing a favor for a stranger, etc.). ${ }^{289}$

\section{B. Door-in-the-Face (DITF)}

Inviting rejection also seems to pay off. An early and often cited experiment is representative of much of the research in this area: when stopped on a university campus and asked whether they would chaperone juvenile delinquents on a two-hour trip from their detention center to the local zoo, $16.7 \%$ of subjects said yes. But when similar subjects had first been asked (and had refused) to volunteer two years of time to serve as counselors to such youth, a follow-up request for the two hours of chaperoning resulted in a $50 \%$ compliance rate. ${ }^{290}$ Although most studies of this phenomenon yield results of less dramatic magnitude (including some showing no or even negative impact), meta-analyses of many studies over three decades bear out the enhanced compliance produced by first asking for more than you hope to attain. 291

Further research in the intervening decades has refined these conclusions in more and less predictable ways: while DITF can work in many settings (including requests on behalf of arguably harmful organizations), ${ }^{292}$ its effects are larger where the request is for a socially useful purpose. ${ }^{293}$ DITF also seems to work better when both requests are made by the same person, face-to-face, will have the same beneficiary, and where the second request follows the first without delay (defined as within 5 minutes). ${ }^{294}$ But

${ }^{289}$ Dillard, et al., supra note 286 , at 477.

290 Robert B. Cialdini, et al., Reciprocal Concessions Procedure for Inducing Compliance: The Door-in-the-Face Technique, 31 J. PERSONALITY \& SOC. PSYCHOL. 206, 209 (1975).

291 See Daniel J. O'Keefe \& Scott L. Hale, The Door-in-the-Face Influence Strategy: A Random Effects Meta-Analytic Review, 21 COMM. YEARBOOK 1, 16 (1998) [hereinafter, O'Keefe \& Hale I].

292 See James Price Dillard \& Jerold L. Hale, Prosocialness and Sequential Request Compliance Techniques: Limits to the Foot-in-the-Door and the Door-in-the-Face?, 43 Comm. STUD. 220, 228 (1992). But see O'Keefe \& Hale I, supra note 291, at 24 (no measurable DITF effect where requests are not prosocial).

293 Dillard \& Hale, supra note 292; O'Keefe \& Hale I, supra note 291, at 24.

294 O'Keefe \& Hale I, supra note 291, at 17. See also Daniel J. O'Keefe \& Scott L. Hale, An Odds-Ratio-Based Meta-Analysis of Research on the Door-in-the-Face Influence Strategy, 14 COMM. REP. 31, 37 (2001) [hereinafter, "O'Keefe \& Hale II"]. By contrast, FITD seems to work even when there is substantial time delay between the 
interestingly, the size of the reduction between the initial, larger request and the second, more moderate one does not seem to impact the DITF effect dependably. 295

How and why DITF works are potentially even more significant to those seeking to persuade. The phenomenon was initially explained as an example of the social norm of reciprocity: subjects complied with the second (smaller) request in exchange for (i.e., to reciprocate for) the requester's "concession" from the first request, almost as if they were bargaining in a negotiation. ${ }^{296}$ However, more recent and comprehensive examination of DITF studies have cast doubt on this explanation. The reciprocity rationale seems at odds with the findings that (1) DITF effects are not influenced by the size of the second request's "concession"; and (2), that its effects are smaller when made on behalf of different beneficiaries or where the interval between requests exceeds a few minutes. The reciprocity explanation also does not account for the increased effectiveness of DITF in prosocial request situations. ${ }^{297}$

More recent studies, based on surveys of the feelings experienced by DITF subjects, have yielded a different explanation-one that is based on guilt. The idea is that most people feel guilty when they (metaphorically) slam the door in the face of someone who makes a request-particularly (although not exclusively) one who is perceived as selfless or altruistic. This causes them to want to assuage that feeling by complying with a second request from the same person. Agreeing to the second request may be motivated by the anticipation that it will produce a reduction of the guilt from having turned down the initial request. 298 Although no one explanation has been settled on, the guilt rationale has emerged as the most plausible. ${ }^{299}$

\section{Mediation Applications and Questions}

initial and the target request and the two requests are made by different people. See Burger, supra note 286.

295 O'Keefe \& Hale I, supra note 291, at 18; O'Keefe \& Hale II, supra note 294 , at 36 .

296 See Cialdini et al., supra note 290, at 213-14.

297 See O'Keefe \& Hale I, supra note 291 , at 24 . Another early hypothesis was that the "perceptual contrast" from comparing the sizes of the larger first and smaller second request makes the latter appear to be less onerous (and thus easier to accept) than if it stood alone. But this (anchoring-like) explanation also seems incompatible with DITF findings that assign significance to whether the same person makes both requests or whether the request is altruistic in nature. $I d$.

298 Daniel J. O'Keefe \& Marianne Figge, Guilt and Expected Guilt in the Door-in-the-Face Technique, 66 COMM. MONOGRAPHS 312, 319-23 (1999).

299 O'Keefe and Hale I, supra note 291, at 25. 
The conditions under which this research has been conducted are far removed from the world of disputing. What might one extrapolate from such experiments when working with people in conflict?

\section{Framing Offers and Concessions}

A consistent theme running through this research is the impact of the "prosocial-ness" of the requests on the rate of compliance produced. While either form of sequential request (FITD or DITF) produces enhanced compliance regardless of the nature of the request, both strategies are most effective at reaching a target goal when subjects are asked to perform acts that are seen as altruistic in nature.

Might this have implications for the mediation process? Can mediators describe positional concessions and other demonstrations of flexibility by the parties in mediation as altruistic acts? Might early procedural agreementsfor that matter, even the initial agreement to take part in mediation-be framed as instances of the parties' better nature, so as to encourage FITD-type changes in self-perception?

What of agreements that involve a softening of position: the warring neighbor who is asked to be the first to wave the olive branch, despite no guarantee that the gesture will be reciprocated; the company executive who, instead of continuing to press a strong defense to a claim of product liability instead decides to act in a socially responsible manner and change the product design? Each of these concessions might be framed by the mediator in either self-serving or altruistic terms. ${ }^{300}$ Do some neutrals miss an opportunity to achieve resolutions by only emphasizing how making concessions will advance the parties' own self-interests? Should mediators (paradoxically) underscore the giving-and not just the getting-in mediation? 301 This would be a fertile area to test by research based in actual mediation

300 The distinction between selfish and selfless is a fine one. It can be argued that even the most altruistic of acts serves to satisfy a person's own needs, albeit the need to benefit others. And concessions in mediation can always be seen as being given in return for getting something - at a minimum, the enhanced likelihood of the end of conflict.

301 Expressing demonstrable gratitude (social approval) for a party's initial helpfulness and cooperation may pay dividends. FITD research has shown that subjects who receive extended appreciation for agreeing to perform a small favor comply with a subsequent larger request more generously than those who had simply been "thanked" for the initial favor. Donald R. Gorassini \& James M. Olson, supra note 288 , at 95 . In the same vein, the research suggests that concessions potentially viewed by offerors as "submissive" acts would better be re-framed by mediators as "helpful" gestures. Id. 
settings.

\section{Orchestrating the Bargaining}

As experienced neutrals know, many mediated disputes are exercises in zero-sum, adversarial bargaining from start to end. Even the most cooperative, interest-based negotiations often involve issues that are bargained over competitively. ${ }^{302}$ Such settlement discussions, usually seeking a compromise through incremental convergence of party positions, are often conducted through caucused shuttle diplomacy. This research may point to new ways of thinking about such caucuses.

First, many neutrals who find themselves orchestrating a competitive bargaining process through private meetings routinely choose simply to carry offers from party to party, verbatim, perhaps adding a note or signal of their own impression of the likelihood of future movement. ${ }^{303}$ The lessons of this research could be seen as pointing to a different approach —one in which the mediator displaces the parties as the focus of the bargaining. ${ }^{304}$ With the mediator operating as the (party-authorized) source of all proposals, he or she can make throwaway (small or large) first requests and frame and time follow-up requests geared to yielding subsequent agreement to a settlement target within the range defined by the parties' confidential instructions. ${ }^{305}$

Second, this empirical literature may be instructive for more conventional orchestration of bargaining by the parties themselves or for process management by the neutral. The lessons of DITF may provide support for the neutral's encouraging some parties to be less, rather than more, reasonable with their initial offers or demands-in order to harness the

302 See James J. White, The Pros and Cons of "Getting to Yes", 34 J. LEGAL ED. $115,116(1984)$.

303 See Dwight Golann, How to Borrow a Mediator's Powers, 30 Litigation 41, 44 (Spring 2004) (contending that some lawyers view this as the mediator's role).

304 This is hardly a radical notion and may already be typical of late stages of caucused bargaining. For example, mediators who launch their own "trial balloons" to avoid party reactive devaluation of offers-are-in essence, doing this.

305 Such a lesson might offend critics on a normative level. With all of the bargaining information reposing in the neutral, notions of party control and self-determination may be compromised and impartiality sacrificed to the overarching desire to find a deal. Moreover a neutral's consciously seeking to create (and then exploit) a sense of obligation or guilt might seem highly problematic. But, so long as the parties cede such control willingly, might not such mediator interventions serve as a needed antidote to the strategic, psychological, and cognitive barriers that can otherwise deprive the parties of the resolution they came to mediation to achieve? 
power of a sequence that starts with a rejection. Or FITD may suggest the wisdom of seeking compliance with benign, process-oriented requests (e.g. as to ground rules, agenda setting, or staying at the table despite doubts or anger) in order to induce changes in self-perception that might pay dividends in cooperation when problem-solving and bargaining begin.

Of course the research we are discussing may not lend a theoretical foundation for any such conclusions. Would these same experimental results have been obtained if subjects were emotionally (or strategically) in conflict with the person making requests of them? Would sequential request strategies that have been demonstrated to be effective in two (experimental) rounds work if -as in many tough mediations-more (sometimes many more) than two rounds of offers and concessions are involved? Or would other cognitive or affective processes take over? And even as to two-round sequences, how many times can they be used with one subject in one sitting? If FITD works to achieve early stage procedural agreements (e.g. to proceed with the process and then to honor a set of ground rules), will it be effective again in seeking positional movement toward settlement from the same party? Experiments conducted under mediation conditions might shed light on such questions.

\section{CONCLUSION}

In this article, we have surveyed social science research findings bearing on both direct and indirect modes of persuasion, and have raised questions about whether and how this empirical research might apply to the work of mediators. We have also identified several gaps in the research that seem worthy of further study. At the risk of oversimplifying, the research seems to show that: counter-attitudinal advocacy, or role reversal, works as a mode of influence, potentially producing lasting changes in attitudes. However, where subjects have deeply held beliefs about the topic being addressed, those changes are likely to be slow and incremental.

Receiving a full and apparently sincere apology has strong and significant effects on the attitudes of apology recipients, including, in the settlement context, their (but not their lawyers') willingness to accept settlement offers. Researchers have devoted virtually no attention to the potential persuasive effects of making amends on apologizers themselves.

Claims that group brainstorming produces a) more or better ideas, b) better decisions, or c) greater group cohesion are not directly borne out by social science research. Indeed, the research demonstrates that individuals produce more and better ideas when working alone than when working in groups. With respect to decisionmaking, little empirical attention has been 
paid to how groups choose from ideas that have been generated. Prisoner's dilemma experiments and studies having to do with race relations and other relations between "in-groups" and "out-groups" strongly suggest positive and lasting effects of induced cooperation in reducing conflict.

When it comes to direct modes of persuasion, the research suggests that asking questions-at least highly suggestive rhetorical questions-can be less persuasive than making corresponding direct statements. When making direct statements, explicit, two-sided, "refutational" statements-providing specific, detailed, substantively-grounded reasons why one argument or course of action is superior to another-are the most persuasive message form.

Both fear appeals and guilt appeals can be highly persuasive, although these two modes of influence work in different ways. Persuasive messages that induce fear work most effectively when they convey both serious danger and strong, feasible ways of coping with it. Such threat-based messages seem to trigger thoughtful appraisal instead of mere emotion, which can neutralize defensive avoidance mechanisms that may otherwise interfere with the rational weighing of alternatives. Unlike fear appeals, guilt appeals are most persuasive when carried out in moderation. Strong, explicit guilt messages may produce reactance and anger on the part of the subject and therefore may be counterproductive.

Finally, research suggests that those who seek to extract a specific concession from a subject would do better to use a sequence of requests (starting with less or more than is sought) than to ask for the target outright. Moreover, a pattern of gradual concessions is likely to be fostered where the subject feels that his movement is a helpful, prosocial act.

Of necessity, almost all of this research views each form of persuasion under study in isolation. By contrast, mediators in challenging matters rarely have only one persuasive intervention to choose from at any given juncture. Rather, they can choose from a menu of options and must often employ multiple persuasion approaches, under time pressure, to produce progress. Helpful as what we have reported may be, data on the comparative and sequential effectiveness of two or more persuasion options would be even more useful.

Some of what succeeds in persuading in a laboratory setting-for example role reversal and receiving apologies - seems unsurprising and easy to square with mainstream mediation thinking. Other social science findings - about, e.g., idea generation in group brainstorming or asking questions rather than making statements in order to encourage re-examination-seem to call into question, at least at first blush, conventional mediation wisdom and practice. How certain persuasion modes 
seem to work-for example, rhetorical questions serving to distract and feeling pressuring, concessions flowing out of cooperative self-perceptions and altruistic motives - may shed new light on both skills and normative debates among mediators. Indeed, some of this research, e.g., showing that appeals to fear can enhance logical thinking or that explicit, detailed messages persuade best, may have considerable significance for such longstanding debates as the relative merits of facilitative versus evaluative mediation and the importance of a mediator's having substantive (as well as process) expertise.

Does the world of mediation resemble the laboratory? Superficially, of course not. Static, one-shot, questionnaire-based surveys of college student or working mother subjects seem a far cry from competitive and emotional interactions among mediators and disputants. But on closer examination, the difference may not be so great: at least some of the data reported is based on the responses of addicted smokers, students self-interested in avoiding an onerous examination, people of strong religious conviction or racial prejudice - in short, people harboring entrenched attitudes and desires that may be comparable to the mind set of the most intransigent of legal disputants. Nevertheless, the field of mediation would greatly benefit from empirical research on persuasion specifically in the mediation context. Throughout this article, we have tried to identify fertile areas for such further study.

Even with its limitations, we believe that the social science findings reported in this article, taken as a whole, may have broad significance for mediation trainers and practitioners, as well as for the administration of civil justice. It is now likely that the number of civil legal matters submitted to and resolved through mediation greatly exceeds the dwindling number of cases resolved by trial each year. Despite the exponential growth in the use of mediation in the past quarter century, the field still operates to a substantial degree on untested claims and ideologies. If mediation is to become fully professionalized, it needs to overcome its squeamishness about the topic of persuasion. It needs to base its best practices and ethical norms on more than folklore, opinion or the official imprimatur of dispute resolution organizations. It needs reliable, evidence-based knowledge about what kinds of mediator interventions work in producing settlements, and how they are experienced by people in disputes. 